\title{
'CRITICAL INGREDIENTS OF SUCCESS'
}

\section{EXERCISE FOR MEN: EXPLORING THE PREFERENCES AND EXPERIENCES OF MEN WHO HAVE HAD A DIAGNOSIS OF CANCER}

By

Colleen Kendrick

A thesis submitted to the Victoria University of Wellington in partial fulfilment of the requirements for the degree of Master of Arts (Applied) in Nursing

Victoria University of Wellington 2012 


\section{Abstract}

Evidence demonstrates the benefits of exercise for those with a cancer diagnosis and there is an increasing recognition of the need to tailor exercise opportunities for specific patient groups. However, little is known about the preferences and experiences of exercise in men who have had a diagnosis of cancer. In May 2011, the Waikato/Bay of Plenty division of the Cancer Society of New Zealand introduced a supervised, circuit-based group exercise programme specifically for men. Given this was the first known such programme in New Zealand, this study involved a process evaluation of the programme's development and implementation. The aims of the study were to explore the experiences of the men who participated, to investigate their preferences for exercise, and identify factors essential to the ongoing design and delivery of acceptable, accessible and appropriate exercise programmes for men. The 10 male participants and the physiotherapist who delivered the programme were interviewed about their experiences of the 6 week programme. The men were aged $62-$ 80 years with a median age of 69 , had diverse professional and personal backgrounds, varied types and stages of cancer and a wide range of physical fitness. The interview data were analysed using an inductive, thematic approach. The programme met the men's needs and each felt invigorated for attending. The men all wanted the programme to continue. Four major themes emerged: 1) the importance of a safe, inclusive programme, 2) camaraderie and the impact of competition and humour, 3) acceptability of the programme and its purpose, and 4) the overall value of the programme. This research builds on existing knowledge and contributes to a deeper understanding of the utility and feasibility of a group-based exercise programme for men, and the factors that need to be considered in designing further programmes. Practicalities, possibilities and implications for practice and future research are discussed. These include the use of simple transferable resources and the ease in which this flexible programme could be further developed and expanded, the value of a multidisciplinary approach, and the potential multiple benefits for men's health care.

Key words: Cancer, Men, Exercise, Preferences, Programmes, Evaluation 


\section{Acknowledgements}

There are many I wish to acknowledge who have helped me on this academic journey.

First and foremost I want to acknowledge the men in my life and their unswerving support. My "main" man Roy, my life partner and husband of 32 years, thank you for understanding how important this has been to me. Matt and Josh, you are our most important accomplishments, friends and sons. I am so proud of you as young New Zealand males, who fit so well in this place of your belonging, our wonderful bicultural land of Aotearoa. Matt; wordsmith, athlete and truck driver, you have always been at the same time my harshest critic and my greatest encourager. I envy your innate ability as wordsmith and admire your natural athletic talent. Josh, thank you so much for your practical and willing help with all my IT challenges and your enveloping bear hugs when during this oh so challenging year, it felt as though it was all too much. You men have helped me understand so much about what makes the Kiwi male who he is. I know firsthand the part sport, hard work, physical activity and physical strength play in making you the men you are. Dad, you showed me much about the pioneering spirit, breaking in a small farm, with innovation, perseverance and hard work. I will treasure forever, our caring for mother together. Though you called yourself a "rough old farmer" you were the best and most gentle carer. And to the youngest Kendrick males, Bradlee and Sam; you have brought love and lightness and fun into the intensity of this year. Your hugs and visits to Grammy's house have brought welcome respite from books and articles and the COMPUTER! Philippa and Tayla thank you for not just being my son's partners, but my friends. As fellow students you have understood firsthand the challenges of wearing many hats and juggling work and study.

Without Dr Katherine Nelson this project would have not been possible. Kathy thank you for taking me on even before you met me. I am indebted. Thank you for the numerous emails, and phone calls and invaluable advice. I couldn't have even considered this journey without your initial help to get started and your ongoing academic support and guidance. Thank you too for the kindness, understanding and empathy throughout; first as my beloved sister became so unwell and then as I took time away from this project to care for her. The flexibility I was allowed by all at VUW enabled us as a family to care for Liz in her final days so very well. 
Dr Gillian Corbett, best friend and mentor over these last 10 years, thank you for teaching me so much and helping me believe I could do this. Dr Ray Harvey you helped in so many practical ways. Fiona Hewerdine, we shared some of this academic journey. You made me walk on glass at great heights. Thank you so much. Academic minds; Dr Kieren Faull and Dr Margi Martin you inspired me at the beginning of my postgraduate study. Margi you will never know how much it meant that you sent articles of interest even when I wasn't studying and told me "You are writing at this level."

Cynthia Wensley, you re-ignited my interest and belief in completing a thesis. You encouraged me to 'focus' and introduced me to Dr Katherine Nelson for which I will always be so very grateful. Debbie Penlington I am so glad we met. Your moral support strengthened me. Graham Harbutt, thank you for your support; for smoothing the way and enabling me to trial the programme.

One of the greatest delights in this journey has been the contact with leading New Zealand researchers in this area including Dr Rose Richards and Dr Justin Keogh and contact with international colleagues such as Dr Rob Rutledge, who kindly linked me with others working in this area. Responses to tentative emails to world leader and expert, Dr Kerry Courneya, were unexpected.

Finally I want to say a huge thank you to the physiotherapist and the 10 men who participated in this study. It has been a delight to work with you on this joint venture.

This thesis would not have been possible without generous funding from Movember and the Cancer Society of New Zealand. A special thanks to Dr Jan Pearson. I also acknowledge the Waikato/Bay of Plenty Cancer Society for their support of the exercise programme and for granting me unpaid leave to undertake the study. A special thanks too, to Victoria University of Wellington and the assistance from those at the disability services who wrote my words when I could not.

THANK YOU ALL. 


\section{Dedication}

This thesis is dedicated to the 10 amazing men who participated in this study and others who I have had the privilege of accompanying on their journey. Bronte and Stan, what I learnt from you about courage and resilience in my first years in oncology, will remain embedded in my practice forever. Ralph you responded to my request 6 years ago to start a men's group at our local office. I witnessed your skilled leadership as you supported others with manliness, understanding and unparalleled sensitivity. Evan and Mike you took the mantle and continue. While unable to participate in this study you were the forerunners. You have taught me much about men supporting other men well. 


\section{Preface: A Composite}

He had struggled with his treatment, overwhelming cancer related fatigue, reflux and chest pain. His abdomen was still swollen from the effects of the steroids. He had come to the office for his final massage, the only service apart from my infrequent visits, he had found met his needs. We had often talked about the value of meeting other men who might be facing similar challenges as they underwent an aggressive chemotherapeutic regime and he had skirted around the topic. He was a shadow of the man he had been a year ago and though he had been given the all clear for now, he was vulnerable and unsure about his future. We stood on the step as he left and he asked if there was anything he should be doing to stop the cancer coming back and what should he eat and do to help him rebuild his strength quickly. His confidence and identity to some degree had been shattered. A man in his forties, he was a stoic kiwi bloke who had been brought to his knees; a man who stated that before this diagnosis, he had always believed himself to be 'bullet proof'. He was not a talker, more comfortable to be doing and active, something he had found difficult amidst the fatigue and fear that accompanied his diagnosis and treatment.

I outlined the benefits of exercise and walking and thought as we spoke, of similar conversations I had had with other men in this same position, isolated from other men who could really understand what they had just encountered. I thought too of other men who had shared with me the sense that they were no longer men. Some of these men's lives having been changed forever by the emasculating effects of hormone therapy or chemical castration and the changes of 'man boobs', hot flushes and emotional mood swings. Some had even articulated the feeling of no longer feeling human. They felt 'less than' in the sight of others and most significantly in their own eyes; their senses of being different making them feel even more alone. The very essence of what made them a man seemingly stripped away by the multiple losses and role reversal, loss of control, loss of physical strength, loss of ability to provide, and loss and change in bodily functions.

Even those less affected, referred to the frustration and lack of motivation that often accompanied the overwhelming fatigue and physical weakness. Depression was not uncommon though they often did not wish to acknowledge that. 
I handed the young man the leaflet about reducing his risk of recurrence, feeling that there must be something more to offer, to support men in a way that they would find more acceptable, to help them build their inner and physical strength and confidence as they negotiated the road to recovery. 


\section{Table of Contents}

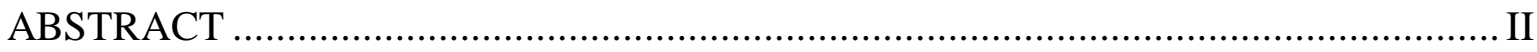

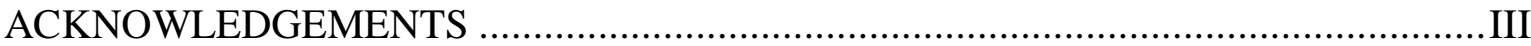

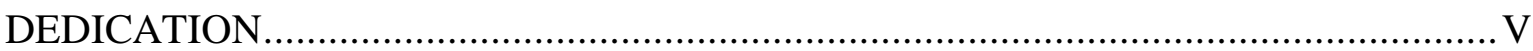

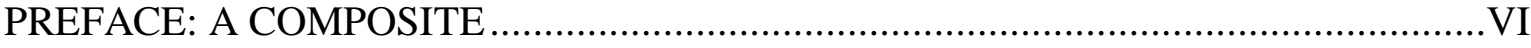

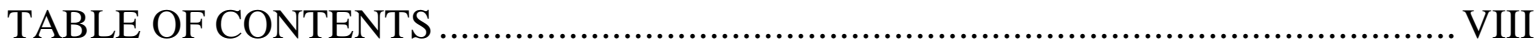

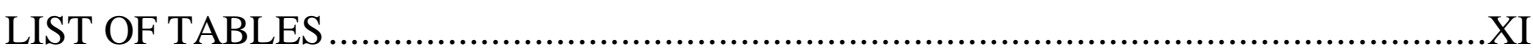

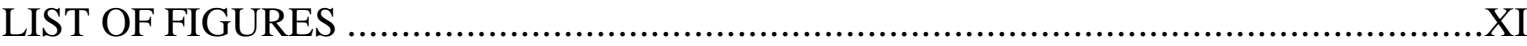

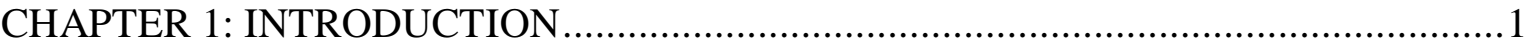

1.1 THE RESEARCH QUESTION AND AIMS...........................................................

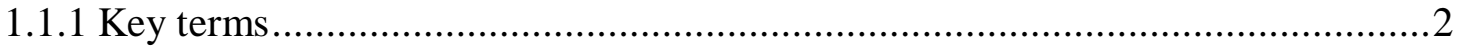

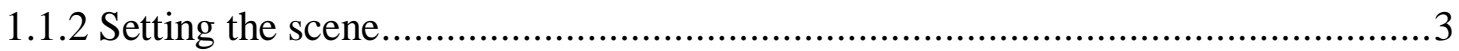

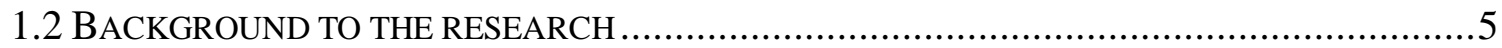

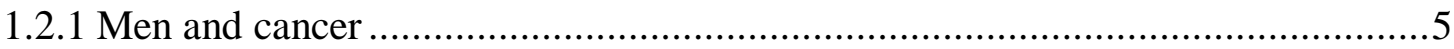

1.2.2 Cancer Society of New Zealand ............................................................... 7

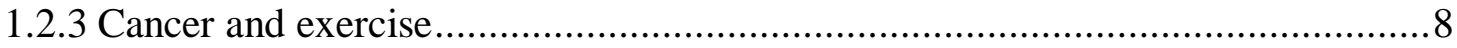

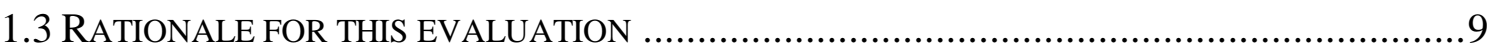

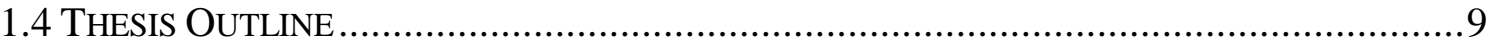

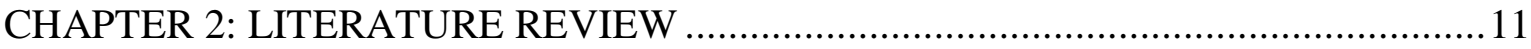

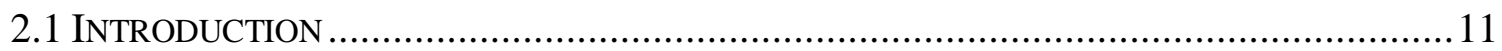

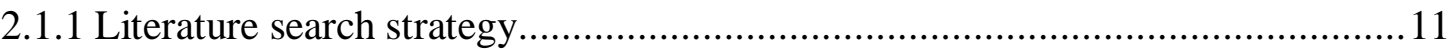

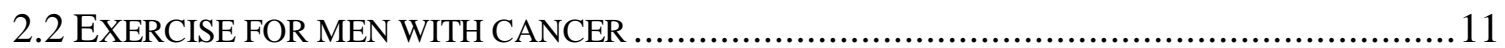

2.3 EXERCISE PROGRAMMES FOR MEN WITH CANCER ................................................. 14

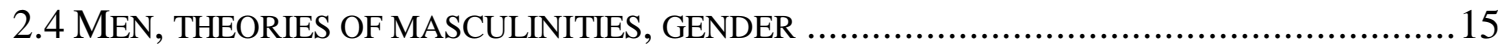

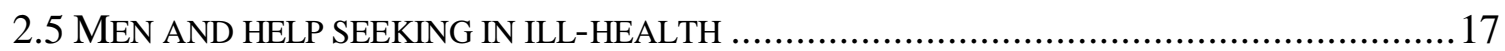

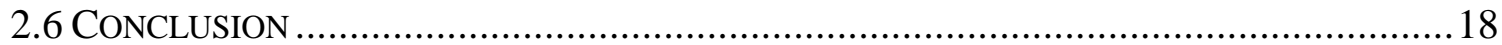

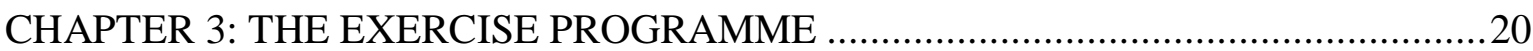

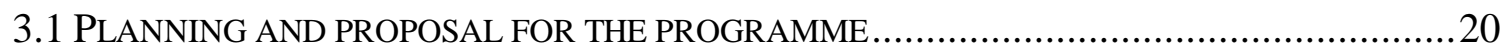

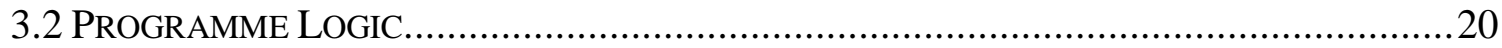

3.2.1 The Evidence: Guidelines and guiding principles .....................................22

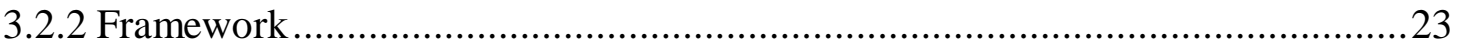

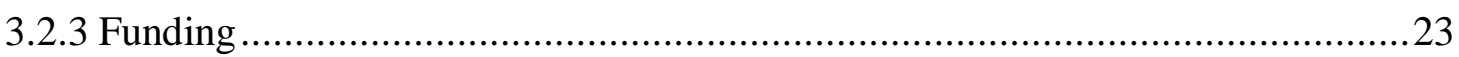

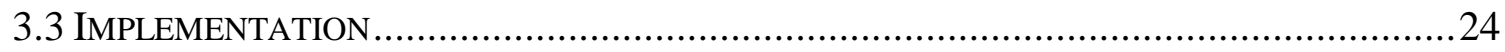

3.3.1 Recruitment and promotion of the programme..........................................25

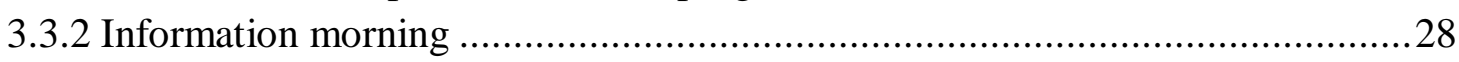

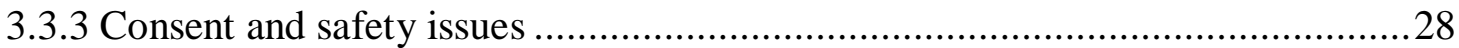

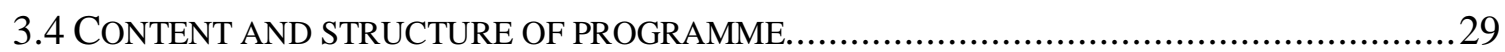

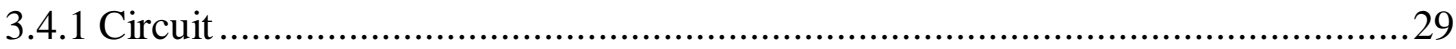




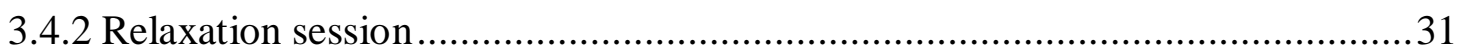

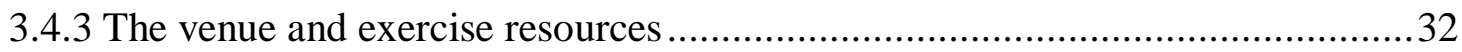

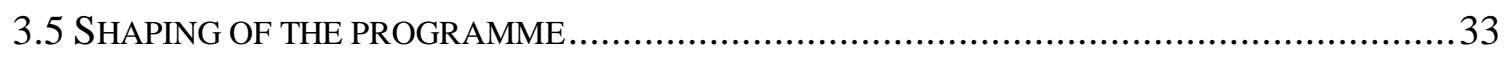

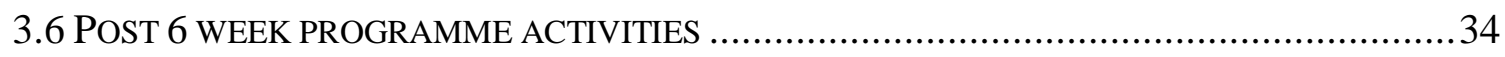

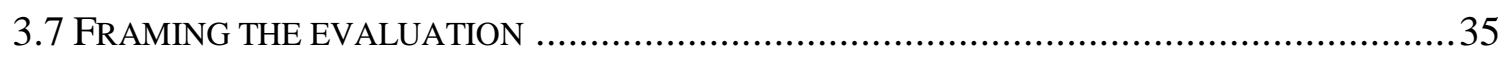

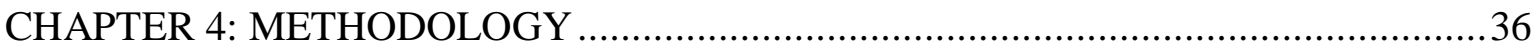

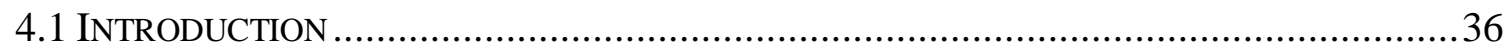

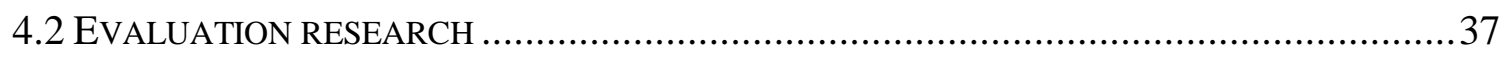

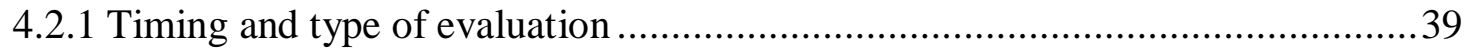

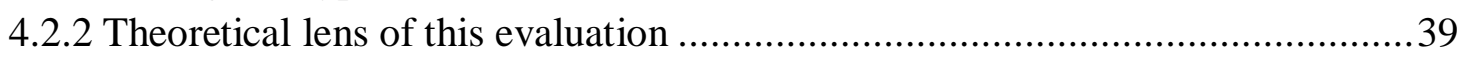

4.2.3 Formative process evaluation approach ....................................................40

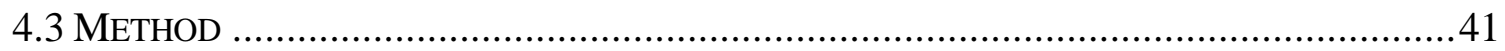

4.3.1 Potential strengths and weaknesses of the methodology and design ................42

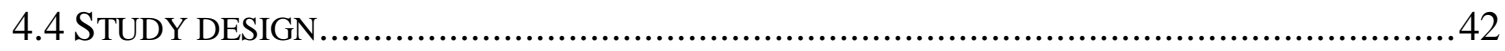

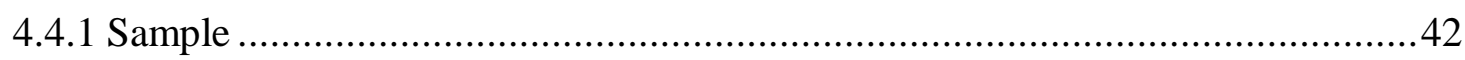

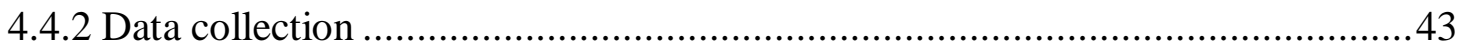

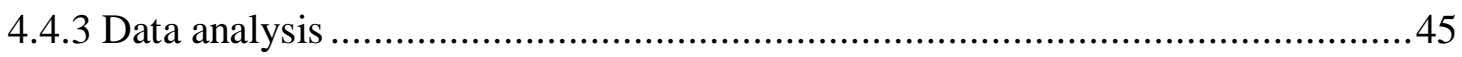

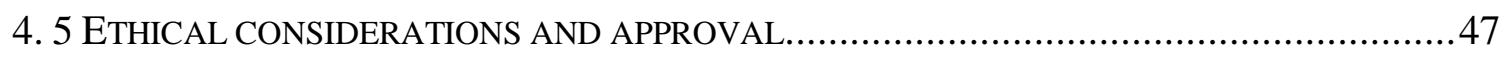

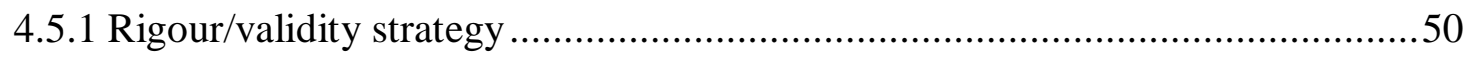

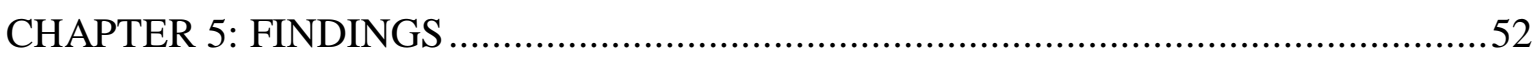

5.1 INTRODUCTION

5.2 INTRODUCING THE PHYSIOTHERAPIST AND HER SKILL SET ….................................52

5.3 INTRODUCING THE MEN AND THEIR BACKGROUND AND WHO THEY WERE...................53

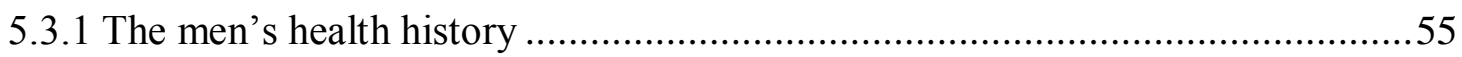

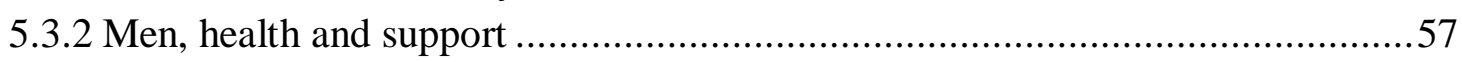

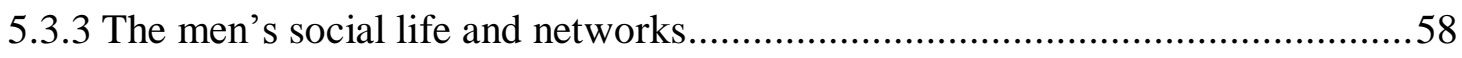

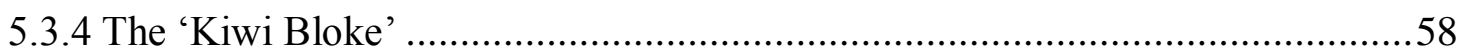

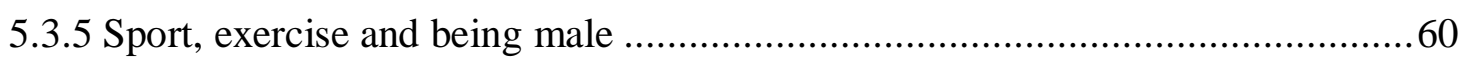

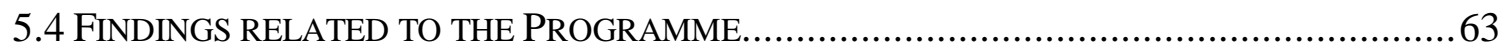

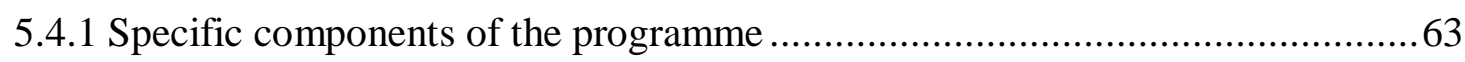

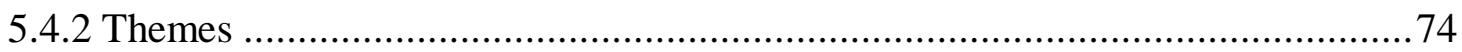

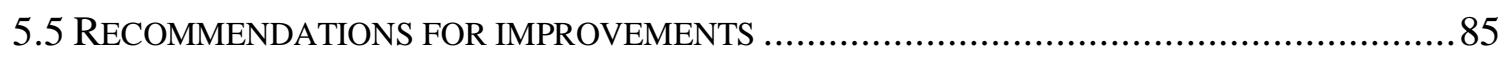

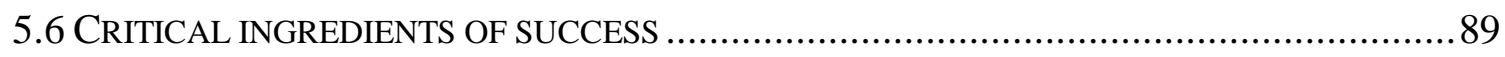

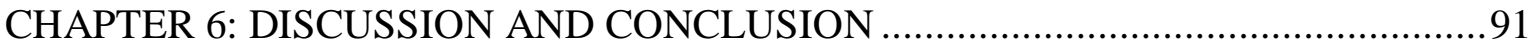

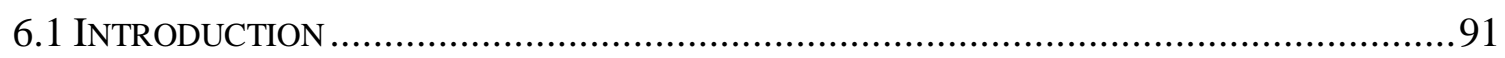

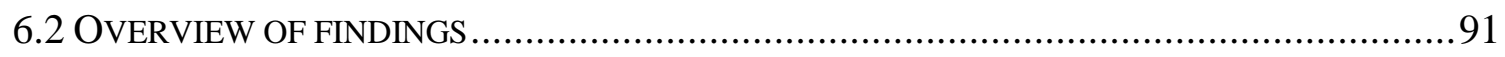

6.3 SAFE, INCLUSIVE PROGRAMME: PHYSICAL AND EMOTIONAL SAFETY ........................92

6.4 CAMARADERIE: HuMOUR- COMPETITION- CONVERSATION ........................................96

6.5 ACCEPTABILITY OF THE PROGRAMME AND ITS PURPOSE ........................................ 97

6.6 VALUE OF THE PROGRAMME: ACHIEVEMENT- CONTROL- CARED FOR.........................99

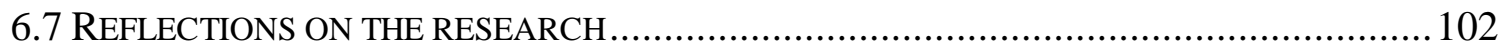

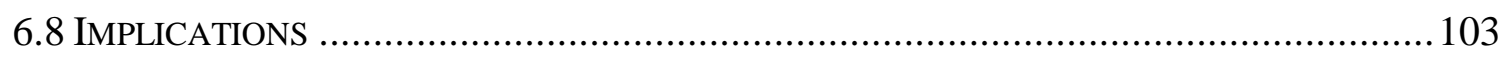

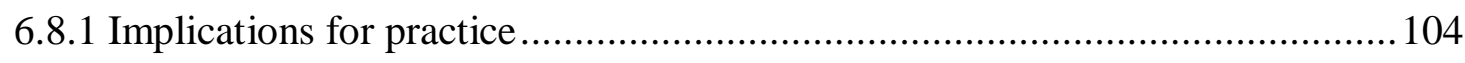

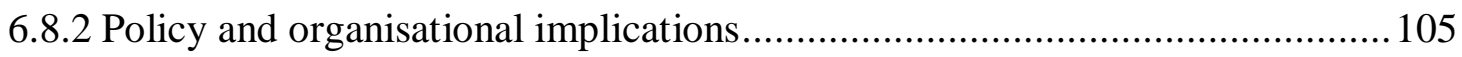




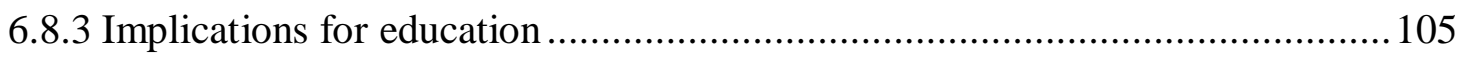

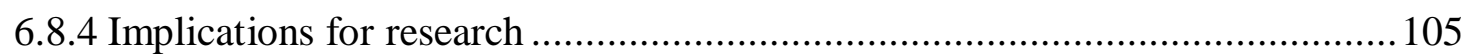

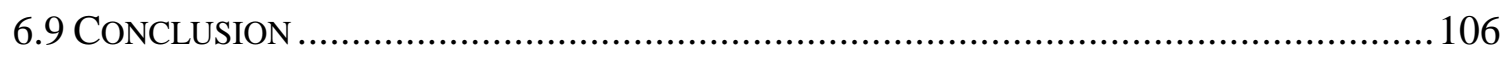

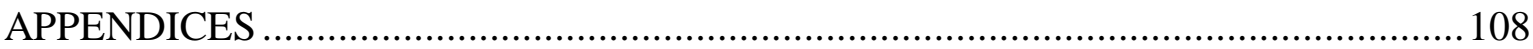

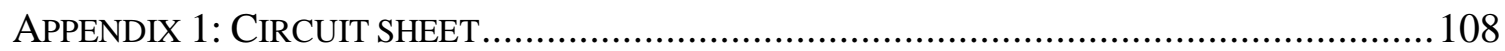

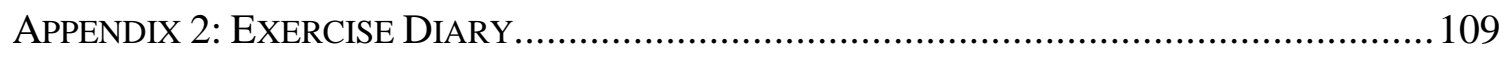

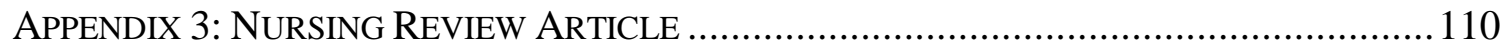

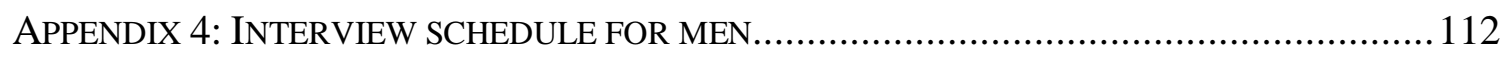

APPENDIX 5: INTERVIEW SCHEDULE FOR PHYSIOTHERAPIST .................................... 114

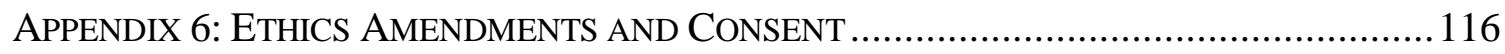

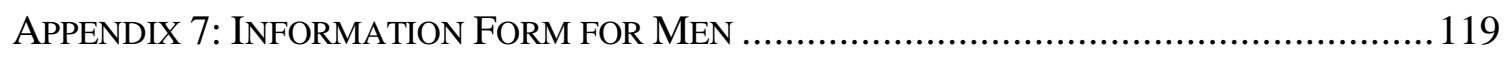

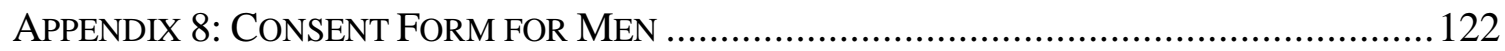

APPENDIX 9: INFORMATION FORM FOR PHYSIOTHERAPIST ........................................ 124

APPENDIX 10: CONSENT FORM FOR PHYSIOTHERAPIST ............................................. 127

APPENDIX 11: CONFIDENTIALITY AGREEMENT FOR TRANSCRIBERS .............................. 129

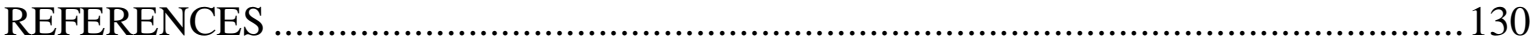




\section{List of Tables}

Table 1: Summary of planning, implementation and ongoing evaluation of the exercise for Men Programme ........................................................... 24

Table 2: Demographics, ethnicity and employment history .....................................54

Table 3: The participants' diagnoses and treatment type ........................................56

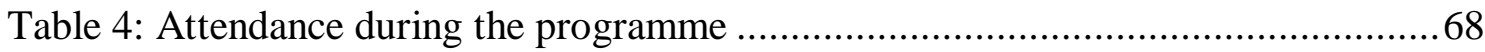

\section{List of Figures}

Figure 1: Programme logic of men's exercise programme ..................................21

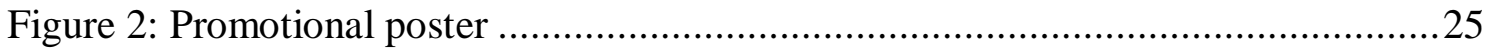

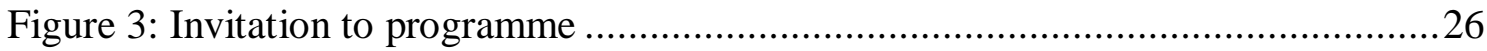

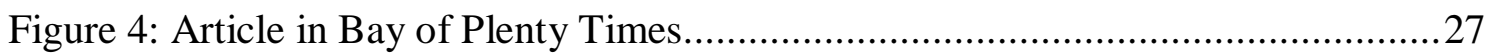

Figure 5: Entry to programme and recruitment to research...................................29

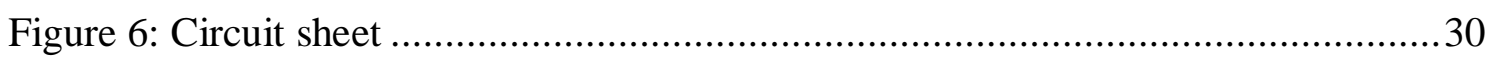

Figure 7: Photograph of floor area for exercise programme ................................... 32

Figure 8: Photograph of mats and some of the exercise equipment.............................32

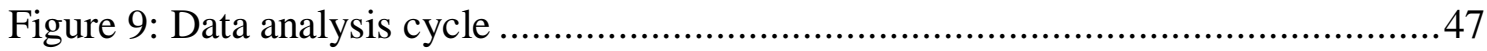

Figure 10: Core components of the Cancer Exercise Programme for Men...................64 


\section{Chapter 1: Introduction}

Men and women are both affected by a cancer diagnosis and in New Zealand (NZ) more men are diagnosed and die from cancer than women (Ministry of Health $[\mathrm{MOH}]$, 2012). The Cancer Society of New Zealand (CSNZ) is interested in increasing men's health promotion and support services for men and is committed to reducing health inequalities. Evidence demonstrates that exercise is beneficial for those with a diagnosis of cancer, pre, post and during treatment. Enquiries nationally in February 2011 revealed that while exercise programmes designed to meet the specific needs of women with cancer such as the Encore and Pink Pilates programme were offered, there were no parallel programmes in NZ designed specifically for men.

This thesis reports on the findings of a process evaluation of a supervised exercise programme specifically for men who have had a diagnosis of cancer. The programme was introduced in April 2011 at the Tauranga Office of the Waikato/Bay of Plenty (BOP) division of the CSNZ. Little is known about the preferences and experiences of exercise in men who have had a diagnosis of cancer. This study was designed to address this void in knowledge by exploring the experiences and preferences of the men who participated in this new programme. The insights gained from these men's perspectives should assist the ongoing design and delivery of acceptable and accessible exercise programmes for men regardless of cancer type.

This chapter outlines the research, defines key terms, introduces the researcher and provides and outlines the background and rationale for establishing an exercise programme for men who have had a diagnosis of cancer. It also provides an overview of the evaluation carried out.

\subsection{The Research Question and Aims}

The evaluation was designed to explore: What were the experiences and perspectives of key stakeholders (men and the physiotherapist) involved in the newly introduced exercise programme developed for men with a diagnosis of cancer? The general aims of the project were to i) contribute to knowledge related to the provision of effective and appropriate exercise programmes that will attract men and cater for their needs, and ii) investigate what men considered would enable and deter their participation in a structured exercise programme designed to cater for them. 
The specific aims were:

I. To describe the implementation and delivery of the exercise programme

II. To establish how well the exercise programme met the needs of the men who attended it

III. To identify what stakeholders considered worked well and what could be improved in the delivery of the exercise programme

IV. To identify factors that could influence men's uptake of a supervised exercise programme

V. To inform ongoing development of similar programmes and provide feedback to other Cancer Society divisions about what worked and what they may find useful in setting up such a programme.

While the primary aim was to evaluate whether this new programme met men's exercise needs, it was envisaged that the CSNZ would also be interested to know whether exercise programmes are something that men would engage in, and the feasibility and safety of such programmes for a variety of men.

\subsubsection{Key terms}

Four key terms used in this thesis are: Cancer related fatigue (CRF), Exercise programme, Men who have had a diagnosis of cancer and Program(me) evaluation. These are described below in the following paragraphs.

\section{Cancer related fatigue}

Cancer-related fatigue is defined as:

A distressing persistent subjective sense of physical, emotional and/or cognitive tiredness or exhaustion related to cancer or cancer treatment that is not proportional to recent activity and interferes with usual functioning. (National Comprehensive Cancer Network (NCCN) Practice Guidelines in Oncology, 2012, p. 1)

It is not relieved by rest or sleep (Kangas, Bovberg, \& Montgomery, 2008). Its aetiology is unclear and there are many medical and psychological contributing factors; fatigue is often linked in symptom clusters with pain and depression among cancer patients (Kuchinski, Reading, \& Lash, 2009). 
CRF is often caused by the cancer itself, with up to $40 \%$ of newly diagnosed patients presenting with symptoms of fatigue at diagnosis (Hofman, Ryan, Figueroa-Mosele, Jean-Pierre, \& Morrow, 2007). It is also present for many when having treatment; 70$80 \%$ of those undergoing chemotherapy, $60-90 \%$ of those being treated with radiotherapy, and $100 \%$ of those receiving combined treatment, experience cancer related fatigue often for periods in excess of six months post treatment. CRF is universal for those who are palliative (Hofman et al.; Kuchinski et al., 2009).

\section{Exercise programme}

In the context of this thesis an exercise programme refers to a structured exercise intervention designed to increase physical activity.

\section{Men who have had a diagnosis of cancer}

Much thought was given to this term. While in the past the term 'male cancer survivors' would have been used, there is an increasing ambivalence and negative perception to the use of the term 'survivor', amongst those who have previously been referred to as such (McGrath, 2011). The term "Men who have had a diagnosis of cancer" was chosen as an alternative, in part for its clear description and the overarching inclusive nature which includes any man who has had cancer.

\section{Programme evaluation}

The use of social research methods to systematically investigate the effective use of social intervention programs in ways that are adapted to their political and organisational environments and are designed to inform social action in ways that improve social conditions (Rossi, Lipsey, \& Freeman, 2004, p. 431).

\subsubsection{Setting the scene}

As a Cancer Society Liaison Nurse (CSLN) for the Waikato/Bay of Plenty (BOP) division of the CSNZ my role is to support adult cancer patients with any cancer diagnosis and their family/whanau at most points of the cancer continuum: at diagnosis, while they undergo treatment, through survivorship and often again at recurrence and progression of disease. The CSLN role is multidimensional. In my role, I facilitate support groups and the Living Well education programme, a programme for patients and their family/whanau. 
Working in the community, I had become increasingly aware of unmet supportive needs of men with cancer and the inequitable provision of supportive programmes for women. For example, the Look Good Feel Better programme, a makeup morning designed to promote self esteem, was available for women with cancer, but there was no equivalent programme that was specially designed for men to increase their self esteem and help ameliorate the loss of physical strength during their cancer journey. Simultaneously, awareness of the overwhelming evidence regarding the benefits of exercise for my client group had grown (Cramp \& Daniel, 2009; Schmitz et al., 2010).

Thus, three factors prompted my interest in providing the exercise programme for men who had had a diagnosis of cancer that is the subject of this thesis. The first was the seeming lack of targeted support outside of family and personal supports that was available for men overall. The second was my search for evidence into how to effectively manage CRF which led me to discover the critical role of exercise in managing cancer related fatigue and in ameliorating other effects of cancer and treatment. The third was the request from male patients wanting to know what they could do to rebuild their strength. Many struggled with altered body image and function, loss of strength, and de-conditioning. When advised about the benefits of exercise, the majority were dismissive about the value of simply walking. Some attempted to join or rejoin a gym, wanting to be amidst the culture of strength, sweat and a good 'work out' in an effort to reclaim their masculinity but found that unrealistic. A Danish study that explored the effect of a combined psycho-education and physical activity programme designed specifically for men, piqued my interest (Adamsen, Rassmussen, \& Pedersen, 2001). I realised that providing an exercise programme that was attractive to men could be beneficial on multiple levels.

Following conversations with, and enlisting the support of, major stakeholders including the local Clinical Director of Oncology, Haematologists, Physiotherapists, my Support Services Manager and colleagues, I submitted a proposal to the Waikato / BOP division of the CSNZ to implement a 6 week exercise programme for men who had had a cancer diagnosis at the Tauranga office of the Cancer Society. This programme was to be available to men regardless of cancer type and is the subject of this research. 


\subsection{Background to the research}

\subsubsection{Men and cancer}

Within New Zealand [NZ], latest statistics show that of the 20,317 cancer registrations in 2008, 10,482 were males and 9835 females (MOH, 2008). In terms of breaking down the numbers of men diagnosed with specific cancers; internationally, the leading cancer site in males is lung followed by prostate (Jemal et al., 2011). In NZ the three most common sites for men are prostate, colorectal and lung; annually approximately 2,500 men are diagnosed with prostate cancer, 1,300 with colorectal cancer, 1,000 with lung cancer, and 900 with melanoma. With respect to sex related cancers, while testicular cancer is rare it occurs most often in younger men 18-39 years. Of note, gender is no safeguard against breast cancer; $1 \%(n=20)$ of all breast cancers diagnosed annually in NZ are in men (www.cancer.org.nz). Lung cancer is the leading cause of death from cancer in NZ men, with colorectal and prostate cancer close behind. In 2008, 889 men died of lung cancer, 693 from bowel cancer and 670 of prostate cancer. Most recent published statistics show that 4005 females and 4561 men died of cancer in 2008 (MOH, 2008).

These statistics are sobering. Nevertheless the upward trend of the numbers of those diagnosed with cancer annually is tempered by the increasing numbers of those who live with cancer. With the advent of increasingly sophisticated and effective methods of detection and treatment of cancers long term survival rates are increasing (World Health Organisation [WHO], 2012). Globally it is estimated that more than $60 \%$ of those diagnosed will go on to survive for 5 years or longer (Globocan, 2008).

In March 2012 it was estimated that there were approximately 101,923 men on the NZ Cancer Register alive, post a diagnosis of cancer. While impossible to tell who of these men would be living with the disease and who would be in remission (personal communication, Robert Hipkiss, March 21, 2012, Ministry of Health) it is fair to say that a large percentage of those men would be living with the effects of cancer and its treatment. While projections estimate that cancer rates are set to reduce over the next 5-10 years the burden of cancer will increase in $\mathrm{NZ}$ as the population increases and people live to an increasingly older age (http://www.health.govt.nz/publication/cancerprojections-incidence-2004-08-2014-18). While many types of cancer diagnoses are 
now viewed as chronic conditions, and increasing numbers are living with cancer as opposed to dying of it, living with a diagnosis of cancer brings many challenges.

The largest numbers of men living with cancer are those with prostate and bowel cancer. The effects of treatment for these cancers cannot be underestimated. A large percentage of those who have had prostate cancer are left with erectile dysfunction, loss of libido, impotence, late effects scarring from radiotherapy and resulting bladder and bowel dysfunction, urgency, irregularity and incontinence. Testosterone deprivation the mainstay of treatment for advanced prostate cancer, while effective, leaves men with gynaecomastia, loss of muscle and bone density, mood swings and hot flushes. Loss of strength is a real feature of this and other treatments (Hagen, Grant-Kalischuk, \& Sanders, 2007; Oliffe, 2005, 2006).

Treatment for colorectal cancers also carries a burden, particularly for those diagnosed with locally advanced and metastatic disease. While there is a high cure rate from surgery alone when diagnosed early, those diagnosed with more advanced disease require aggressive treatment; chemotherapy and surgery for those with colon cancer or combination chemo-radiation and surgery for those with rectal cancers. A percentage of these patients require a stoma at surgery, which is sometimes irreversible. Additionally, some of those with rectal cancer are left with a decreased rectal reservoir and experience bowel urgency and incontinence. External beam radiation has an additional effect on both the bladder and bowel. Peripheral neuropathy, a common side effect of current chemotherapeutic agents for colorectal cancers is often ongoing. Statistics show that lung cancer brings a poorer prognosis than other cancers and is frequently diagnosed at a late stage with accompanying symptoms, shortness of breath, pain, haemoptysis, weakness, and cachexia (Gift, Stommel, Jablonski, \& Given, 2003; Globocan 2008; MOH, 2012; Schag, Ganz, Wing, Sim, \& Lee, 1994).

Whether young or old and regardless of the cancer type, inevitably a diagnosis of cancer leaves with a legacy of change for these men. It is part of my role to enable and facilitate access to appropriate support for these men as they attempt to find their new normal. While the CSNZ is set up to support and provide services for both men and women, overall men's uptake of supportive programmes and services is lower than that of women. It has not been possible to access national statistics. However, Hazel Neser (personal communication, May 22, 2012) national coordinator of the Living 
Well Programme which is offered to both men and women supports my experience that this programme and others delivered by the CSNZ are largely subscribed by women. She suggests that the reason may be that "delivery of supportive cancer services may be perceived as less male-friendly, suggesting male weakness/neediness" and that 'the term 'supportive care' would put some men off, especially services that involve discussion in small groups as this would be seen as too 'touchy feely' for the average NZ male. This would be even more so for men of Polynesian descent."

\subsubsection{Cancer Society of New Zealand}

The CSNZ is a not for profit, non-government organisation (NGO) with the Mission of "Improving community well-being by reducing the incidence and impact of cancer. The Cancer Society is committed to working with communities by providing leadership and advocacy in cancer control with core services in: Health Promotion, Supportive Care, Information and Resources and Research" (CSNZ website). As an NGO the CSNZ receives no direct government funding and is therefore exempt from political pressure so is in an ideal position to advocate and offer evidence based practice. Along with this comes the responsibility to ensure publicly donated funds are used wisely. Thus its focus and purpose is not to offer all or duplicate services that are already offered, rather the CSNZ is "a pro-active advocate for cancer patients in New Zealand, providing a voice on all kinds of issues affecting prevention, screening, detection and treatment" (CSNZ, www.cancer.org.nz).

To this end CSNZ often works in partnership with and support of other cancer charities. One of their most recent partnerships is with Movember who since 2008 have been working in partnership with CSNZ "towards the shared goal of reducing the impact of prostate cancer on New Zealand men and their loved ones" (Movember, http://nz.movember.com). While this statement has a focus of men with prostate cancer, the CSNZ are committed to advocating for the provision of appropriate support for all men who have had a cancer diagnosis regardless of cancer type.

My role as CSLN sits within the provision of support services. The CSNZ goal most closely linked with the introduction of any new service within Supportive Services are: "Goal 4: Improving the quality of life for those with cancer, their family and whanau through support, rehabilitation and palliative care" (CSNZ, www.cancer.org.nz). The CSNZ is committed to reducing health inequalities and to that end is interested in 
improving its services for Maori and Pacific People and men. With the increasing numbers of those living after successful cancer treatment, CSNZ advocates for and facilitates access to cancer rehabilitation.

\subsubsection{Cancer and exercise}

An ever increasing body of knowledge demonstrates the benefit of exercise for cancer patients both during and post treatment (Adamsen, Quist, \& Andersen, 2009; Cramp \& Daniel, 2009; Schmitz et al., 2010). There is also evidence in a recent literature review Physical Activity Among Cancer Survivors, undertaken for the CSNZ that physical activity plummets during and post treatment (Szymlek-Gay, Richards, \& Egan, 2011). While many people who have had a diagnosis indicate they would be interested in exercise programmes designed specifically for them, research shows that in reality, most turn down such a programme (Szymlek-Gay et al.). These authors suggest this may be because patient preferences are not taken into account. They highlight the need for further research to develop tailored exercise programmes which consider the preferences and needs of specific patient populations.

One such patient population is that of men with cancer. Enquiries at the beginning of this project indicated that of the few exercise programmes specifically for cancer patients in NZ, none were specifically designed to attract men or support their needs. A telephone survey of CSNZ Supportive care managers and staff $(n=18)$ carried out to describe current approaches in promotion and support of physical activity among cancer survivors, confirmed that men as a group were not catered for (Robertson, Richards, Egan, \& Swymlek-Gay, 2012). This report highlighted the complexity around the provision of supportive programmes and resources for patients with varying needs. It referred to a lack of interest and numbers for exercise programmes offered at the CSNZ and reinforced the need to first identify facilitators and barriers to exercise for target populations.

Research suggests that while women are often attracted to groups, which provide an intimate and confidential forum for discussing and sharing their concerns, actionorientated activities such as an exercise programme may appeal more to male cancer patients (Adamsen et al., 2001). Offering an exercise programme for men who have had a diagnosis might be an ideal method of delivering a more holistic care for men; enhancing physical well being and promoting self esteem, and providing them with a 
much needed wider psycho-social support. It would combine the goals of both Support Services and Health Promotion; ensuring the best cancer care within support services and promoting healthy practices.

\subsection{Rationale for this evaluation}

In order for the CSNZ to promote and deliver exercise programmes that attract and encourage males to exercise, it needed to first understand what men wanted, what they considered to be effective, and what enabled and deterred men's participation in such programmes. With little known about what is the best way to provide exercise for males with cancer, the literature pointed to the worth of an evaluation which explored whether men found that an exercise programme tailored for them was individualised to their needs and what deterred or facilitated their participation in the programme. It also pointed to the need to examine whether there were particular components in a programme (e.g., comradeship, group-based activity, or individualised instructions) that were important.

The information gained from this evaluation provides insight into what works and what can be improved in the delivery of such programmes. It adds to knowledge about how best to assist men who have had a cancer diagnosis to exercise in a way that is effective and that suits them. It contributes to a deeper understanding of the utility and feasibility of a group based exercise programme for men, the factors that need to be considered in designing further programmes and provides a platform for further research. Findings will be fed back to the National office of the CSNZ for dissemination so that those wishing to set up similar programmes can benefit from this study.

\subsection{Thesis Outline}

The thesis is divided into six chapters. This first chapter introduced the aim of the research and the reasons it was undertaken. Chapter 2 reviews the most current literature regarding exercise for men with cancer, along with the literature that adds to knowledge about masculinities, men's health and men's help seeking behaviours and preferences in the presence of cancer and other diseases. Chapter 3 outlines the programme logic underpinning the exercise programme, and describes its design and implementation. Chapter 4 outlines the methodology and design used to undertake the evaluation including the rationale for its use, recruitment, data collection and analysis. 
Chapter 5 introduces the participants and presents the findings from each category, identifying key themes and the men's preferences, using their voices. Chapter 6 discusses these findings and reflects on the limitations and strengths of the research. It outlines the implications for practice, policy, education and research, and offers recommendations. 


\section{Chapter 2: Literature Review}

\subsection{Introduction}

A literature review was carried out to investigate current knowledge about the preferences and experiences of men who have had a cancer diagnosis in relation to exercise and exercise programmes. It was also important to investigate the specifics of men's help seeking behaviour in the presence of illness and in particular a cancer diagnosis. The literature helped position and inform the evaluation.

The major focus of this chapter is on the literature related to men's experiences and engagement with exercise programmes. Given that the evaluation discussed in this research is about a programme targeted at men there is also a brief overview of masculinity related research. While the initial search helped inform the programme, the literature used to design the actual exercise programme is presented in the next chapter.

\subsubsection{Literature search strategy}

Using databases CINAHL, Proquest, and Pubmed, searches using the keywords Cancer, Men, Exercise, Preferences, Programmes, and Evaluation were carried out. The search was further refined and limited to years 2000-2011 and English language as this would capture most relevant and up to date knowledge. A total of 456 articles were retrieved. Following a review of the abstracts for relevance, the full texts of 30 articles were read. Reference lists were searched and a further seven articles and documents were identified. A further search done prior to completion of this thesis to obtain recent literature identified 15 more articles to integrate into the literature review. The findings are presented in four parts; 1) exercise for men with cancer, 2) exercise programmes for men with cancer, 3) masculinities, and 4) men and help seeking in ill health.

\subsection{Exercise for men with cancer}

Research to date shows the overwhelming benefits of exercise for cancer patients both during and post treatment. Single randomised controlled trials (RCT) studies (Adamsen et al., 2009), a recent NZ literature review (Szymlek-Gay et al., 2011) and international systematic reviews (Cramp \& Daniel, 2009; Kangas et al., 2009) all point 
to multiple benefits and safety of exercise even for patients who are palliative if the exercises are tailored appropriately (Kuchinski et al., 2009).

Research has also demonstrated the interest of those with a cancer diagnosis for exercise counselling and assistance with exercise (Szymlek-Gay et al., 2011). This interest extends to those receiving palliative care, (Lowe, Watanabe, Baracos, \& Courneya 2010; Oeschle et al., 2011; Oldervoll et al, 2005) with two thirds of those in the study conducted by Oeschle et al. (2005) expressing an interest in participating in an exercise programme. However, literature that would inform how to tailor exercise programmes for men is scarce and most studies that have investigated exercise for men with cancer, have focussed specifically on men with prostate cancer and the effects of exercise.

These majority of these studies have looked at the effects of aerobic, resistance or a combination of aerobic/resistance exercise on men with prostate cancer on androgen therapy and / or undergoing radiotherapy (Segal, Reid, Courneya, et al., 2009; Thorsen, Courneya, Stevinson, \& Fossa, 2008). Studies have looked at differing length of programmes, ranging from 1-12 weeks and longer. Home based and group based programmes and home based programmes with intermittent group booster sessions have also been examined (Culos-Reed et al., 2007; Culos-Reed et al., 2010; Galvao Taaffe, Spry, Joseph, \& Newton, 2012; Gjerset, Fosså, Dahl, Loge, \& Ensby, 2011).

Keogh and McLeod's (2012) systematic review of the benefits of exercise for prostate cancer patients showed that overall exercise interventions in this group are effective in reducing cancer related fatigue, with resistance exercise particularly having an impact on improving muscle mass, body composition, physical fitness, functional performance, and quality of life. While recruitment to the trials and adherence to the exercise programmes varied, group based programmes demonstrated significantly better physical fitness, functional performance and quality of life outcomes than home based programmes. Keogh and colleagues (Keogh \& Jones 2011; Keogh \& McLeod, 2012) encourage Cancer clinicians and Palliative care specialists to lobby for and refer their patients to evidence based exercise programmes. In an earlier study, which identified exercise decline following a diagnosis of prostate cancer, especially in those who were older, Keogh et al. (2010) recommended that physical activity interventions aimed at prostate cancer patients should take into account both the men's attitudes and 
the factors which enable or deter them from participating in such activities. To do this one must first explore the preferences and experiences of men and design programmes that will attract them.

Courneya and colleagues have conducted many studies using questionnaires and surveys with large samples to investigate the exercise preferences of different cancer specific patient populations (Gjerset et al., 2010; Jones \& Courneya, 2002; Karvinen et al., 2006; Karvinen, Courneya, Venner, \& North, 2007; Vallance, Courneya, Jones, \& Reiman, 2006). The most common cited preferences for exercise include walking as the most preferred exercise and morning as the most preferred time to exercise. Many of their findings regarding patient preferences for exercise are transferable to both sexes, but if we rely on these findings alone, disproportionate representation of the sexes may skew our understanding of what men actually want.

I was unable to find research that looked specifically at male preferences for exercise. Courneya (personal communication, February 10, 2011), confirmed that none of his research had focussed specifically on gender preferences in exercise stating that they generally "have not examined the preferences of male cancer survivors as a group. However, if we are examining a mixed sex cancer (e.g., colon, non-Hodgkin's lymphoma, bladder, kidney) we usually test for differences in preferences between men and women (and usually find some)."

In a recent study by Courneya and colleagues into the exercise preferences of Norwegian cancer survivors, Gjerset et al. (2011) found that men were more likely to want exercise counselling if they had co-morbidities and had undergone chemotherapy. Younger men were once again found to be more likely to exercise regularly than older men. However, although the majority of the 1284 respondents to the questionnaires indicated they wanted to commence exercise immediately after treatment preferably in a group and at moderate intensity, there was no mention in the research of what would attract men to a group intervention programme.

Another recent study (Belanger et al., 2012) of younger cancer survivors, once again found walking again to be a preferred activity. However, it seems that hypothetical preferences do not always translate to practice in reality. Though walking is repeatedly over many studies shown to be the most preferred physical activity, the uptake of a 
walking group offered by the Wellington Division of the CSNZ attracted only three men and twenty women (Hazel Neser, personal communication, May 22, 2012).

\subsection{Exercise programmes for men with cancer}

In NZ, at the outset of this project there were no programmes specifically for men with any cancer type. Steel Pilates a male version of the Pink Pilates exercise programme for women with cancer, was introduced in November 2011. I have found no formal evaluation of this, or any other exercise programme designed exclusively for men with any cancer type.

The closest study to look specifically at the experience and preferences of men regardless of cancer type, for programmes which incorporate physical activity is a small descriptive, exploratory study conducted in Denmark by Adamsen, Rassmussen and Pedersen (2001). These researchers looked at a combined physical activity and psycho-education programme designed specifically for men. The programme was established in response to an unpublished needs analysis conducted by Ree for the Danish Cancer Society in 1999 which highlighted the gaps in support for men with cancer. The 17 men, aged from 21-71 recruited to this 16 week programme were from diverse backgrounds and had varied diagnoses and stages of cancer. The programme was facilitated by a female specialist nurse and a male and a female physiotherapist. Two focus group interviews were carried out, one at 12 weeks and then another two weeks after the programme had finished. Participant observation was spread over three sessions and provided a metaposition. The study found that the men were attracted by the physical aspect of the programme and the safety of both the venue (a well known hospital facility) and the professional facilitation. An average of eight men attended each session. The 10 men who were interviewed reported increased well-being and a sense of solidarity and comradeship with others in the group and continued in a patient led format following the conclusion of the programme.

Adamsen and various colleagues widely publish ongoing studies into the benefit of multi-modal exercise programmes consisting of exercise, massage and relaxation, during and post treatment and in a variety of disease and age specific cancer populations (Adamsen, Quist, Andersen, et al., 2009a; Adamsen, Andersen, Midtgaard et al., 2009b) but appear to be no further ahead in designing and developing effective exercise programmes for men. Adamsen et al. (2009a) recognise the ongoing gap for 
men and made recommendations for the provision of innovative programmes to attract and cater for men. They pointed out that $73 \%$ of the self selected participants in their RCT were female.

Likewise a more recent meta-analysis of Quality of Life Outcomes from Exercise Interventions for Cancer Survivors, while demonstrating the efficacy of exercise interventions for female cancer survivors, highlighted the lack of existing interventions for males (Ferrer, Huedo-Medina, Johnson, Ryan, \& Pescatello, 2011). Ferrer et al. also emphasise the need for effective exercise interventions for men who have had a cancer diagnosis.

\subsection{Men, theories of masculinities, gender}

It was not the intention, or focus, of this study to make an in depth search into theories of masculinities. However, as the evaluation was about a programme for men as a population group whose needs for physical activity programmes and resources are not met, I needed to explore gender differences and needs to understand more about what men, and more specifically NZ men, would consider important in an approach to cater for their specific needs. While this is in no way a comprehensive review of masculinities literature it does give some insights. Initial enquiries led to review of seminal masculinities literature (Connell, 1996, 2005; Sabo \& Gordon, 1995) and literature by Phillips (1996) and Law, Campbell and Dolan (1999) about the NZ male.

Much is made of hegemonic masculinity and men's lack of emotional expression, their quest for power and success and the importance of body function and strength (Connell, 2005; Courtenay, 2000; Sabo \& Gordon, 1995). With respect to the NZ view of masculinity, Phillips (1996) and Law et al. (1999) discuss and outline some of the factors that played a critical part in forming the NZ male and the accompanying stereotype of the rugby, racing and beer drinking New Zealand male; the 'Man's Man", a 'hard man', 'the hard worker' who 'worked and played hard'. This literature highlighted amongst other factors the importance of physical strength and independence for the pioneering NZ male. With the focus on Pakeha (NZ European) as opposed to Maori (indigenous) men, this was clearly only part of the picture. While independence was and still is highly valued in NZ European culture, interdependence and community is a large part of the Maori ways of being (Durie, 1998). 
Physical strength, is however, of great value in both cultures and one of the things that became apparent in the NZ literature, was the importance of physical strength and the role of sport, in particular rugby, in Aotearoa. This sport was seen to provide common ground for all New Zealand men; Maori and Pakeha, and farmers and soldiers alike (Law et al., 1999). Phillips (1996) outlines the many societal changes in NZ over the period 1960-1995. He refers to the "bloke under siege" and discusses some of the myths of and threats to the stereotypical 'Kiwi bloke' (a reference to a NZ male). Over these decades roles have changed and it would seem men are often caught between the ideal of the strong masculine protector and the sensitive new age man. In my search to find what was important to the NZ male today, I made contact with Celia Lashlie author of He'll Be Ok: Growing Gorgeous Boys Into Good Men. Lashlie responded:

One of the major concerns I have about men and boys in New Zealand is the lack of good research and debate about what makes them who they are. What is the essence of manhood in New Zealand, what does it look like and how free are our men and boys to be who they really are as opposed to how others think they should be?" (Personal communication, 6 April 2011)

Although not research in the true sense, Lashlie conducted the Good Man project in 2002 and had many discussions with adolescent boys in an effort to find out more about their world; what that world looked like to them and why they made the decisions they did. The boys identified trust, loyalty and humour as the top three characteristics of a good man (Lashlie, 2005). In her opinion "men need and want to belong to something bigger than themselves, to see themselves as part of a whole" (p. 213). Lashlie points out men's commitment when belonging to, or being part of something, and the importance for men of attending and participating. She highlights the differences between men and women; that while "as a gender women love talking" a man enjoys action and "physicality." She emphasises the importance of humour for men.

Through reading the literature it became clear that regardless of whether men are 'hard wired' or 'socially constructed' to behave in a particular way, in reality many of the behaviours that are seen to typify the essence of masculinity can affect their ability to cope with cancer both negatively and positively. Over the last 25 years, masculine behaviours have been labelled as unhealthy (Courtenay, 2000; Moore, 2008). 
However, while some traditional masculine characteristics such as independence, self sufficiency, risk taking, strength, stoicism, toughness, make it difficult for men to seek health related help for themselves (Courtenay), others such as being assertive and decisive, have been found to be helpful in men's cancer experience (Gordon, 1995). Macdonald (2006) suggests that instead of blaming men for not accessing health care and adopting health behaviours, health care professionals should adopt a more helpful pragmatic approach that accommodates their preferred ways of being.

\subsection{Men and help seeking in ill-health}

While not looking specifically at men's help seeking or acceptance of support within the cancer setting, Gibbs and Reidpath (2005) identified that within the context of chronic illness men were more accepting of support that was information and action orientated. Klemm, Hurst, Dearholt and Trone (1999) found that "men were twice as likely to seek and give information and women more than twice as likely to seek and give encouragement and support" (p. 65). This male preference for information seeking is further demonstrated in a study of online cancer group discussion forum (Seale, 2005) and succinctly summarised by the phrase "Women communicating and men searching” (Jackson, Ervin, Gardner, \& Schmitt, 2001, p.363).

Seale (2002) highlighted the media's influence on the public perception of what is appropriate and acceptable and identified the unequal representation of female versus male cancers in the media. Furthermore Seale et al. (2006) refer to societal expectations about what is appropriate gendered behaviour influencing the differing 'culture' of men and women's cancer experiences (p. 2578). Seale (2005) highlights the media's portrayal of the male cancer experience as more isolated than that of females and "simply involving the encouragement of resilience and a 'fighting' attitude that leaves men essentially unchanged" (p. 521).

Furthermore O'Brien, Hunt and Hart (2005) point out that it is considered masculine "to ( be seen to) endure pain and to be strong and silent about 'trivial' symptoms, and especially about mental health or emotional problems" (p. 507). O’Brien et al. (2007) highlight the taboo nature of disclosing depression for many men. O'Brien et al. (2005) found three factors enabled help seeking: if the men has endured symptoms to some acceptable threshold; if they had "physical and visible symptoms" and if others (particularly spouses) had prompted help seeking. They identified that: 
for many men help-seeking is only contemplated following pain, endurance, stoicism and visible injury [and is more acceptable when] perceived as a means to preserve or restore another, more valued, enactment of masculinity. (p. 514)

Work was also often seen to hinder men's help seeking, particularly in relation to attending supportive programmes. Gibbs (2005) found that the ability to continue working was viewed by many men to indicate they were still whole. She highlighted the strong link between work, achievement and men's identity. Seymour-Smith (2008) found that for those men who did attend support groups it was more acceptable to talk about belonging in the "legitimately masculine" role of supporter rather than as the supported. This may not just reflect the men's own view of their masculinity. Wenger (2011) pointed out "in any given situation a man...acts knowing that others are evaluating whether his act is appropriate for a man" (p. 489).

It is no surprise then that Cecil, McCaughan and Parahoo (2010) advise those providing services for men to focus on cultivating men's positive ways of coping rather than increasing the threat to their sense of masculinity. In their interviews of 8 men with varying cancers they found that interventions that focus on talking and sharing of experiences were not the best way to help these men who were already feeling a threat to their masculinity. They identified instead the worth of practical support to help men adjust to the role and body changes that threaten the view of their masculinity. This sentiment is supported by Oliffe and Thorne (2007) who make reference to the common view amongst men that those who express their emotions openly are weak, and effeminate. They cite literature which reveals that men express their support and closeness with other men in a more action oriented ways: by helping each other, humour and joking with each other, shared activity, and solving problems together (Lips, 1997; Pease, 2002; Seidler, 1997 cited in Oliffe \& Thorne). Oliffe et al. (2009) too identified men's use of humour when discussing emotional or embarrassing issues. Accommodating these preferences would be paramount in our project.

\subsection{Conclusion}

This literature review though not exhaustive confirmed previous literature regarding the value of exercise for men with cancer, not only in reducing cancer related fatigue but in improving physical form and quality of life. At the same time it highlighted the 
paucity of literature about the specific preferences of men with cancer for exercise with the majority of studies focussing on outcomes of exercise for men with prostate cancer. This review also revealed the call from experts in the cancer and exercise realm for innovative programmes for men with cancer and reinforced the need for research into what will attract and enable men to exercise. It pointed to the seeming advantage of group based exercise and the major drop off in exercise in older men with cancer. It identified the interest even those receiving palliative care had in exercising.

With respect to men's search and acceptance of appropriate support the literature reviewed pointed to the need to pitch this to men's preferences for practical and tangible support which upholds as much as possible men's sense of masculinity and control at the same time as connecting them with other men. The following chapter goes even further and outlines the literature and guidelines related to the setting up the exercise programme. It describes the exercise programme and its underpinning logic. 


\section{Chapter 3: The Exercise Programme}

The exercise programme for men who have had a diagnosis of cancer was implemented in April 2011. As outlined in Chapter 1, this initiative was prompted by current evidence and international guidelines, and patient enquiries. The primary aim was to deliver a structured, supervised, safe and effective exercise programme that attracted and met the individual needs of men who have had a diagnosis of cancer. This chapter outlines the evidence that underpins the programme and the subsequent planning, implementation and shaping of the programme.

\subsection{Planning and proposal for the programme}

The Promoting Action on Research Implementation in Health Services (PARIHS) framework which is based on the relationship of three key elements: evidence, context and facilitation guided the programme's development. The frameworks works on the premise that for successful transfer of evidence to practice; a) the evidence must be strong, robust and match patients need and health professional consensus, b) the context or practice environment, must be open to change with strong leadership and a quality evaluation process, and c) have skilled and appropriate facilitation from internal and external facilitators (Rycroft-Malone, 2004). Using this framework as a guide, a proposal to pilot an exercise programme at the local Tauranga office of CSNZ was submitted by the researcher (in her role as CSLN) in 2010 to Support Services Manager at the Waikato Bay of Plenty Division of the CSNZ. The proposal was the culmination of a critical analysis of the evidence into the role of exercise in the management of cancer related fatigue and the recognition that men's supportive needs were often not being met.

The evidence regarding the benefits of exercise was strong and irrefutable, the local Medical Director of Oncology gave his written support and the Support Services manager was keen to see a programme develop. Local colleagues also gave their full support. A programme was subsequently designed that targeted men and was clinically safe and effective.

\subsection{Programme Logic}

Figure 1 illustrates the guiding and underpinning premise the programme was based on. 
Name: Exercise programme for men who have had a diagnosis of cancer who are wanting to increase strength and fitness

Programme Goal: Provide a sustainable, feasible, accessible and acceptable exercise programme which is tailored to men's preferences and meets the needs of men who have had a diagnosis of cancer for exercise and physical activity

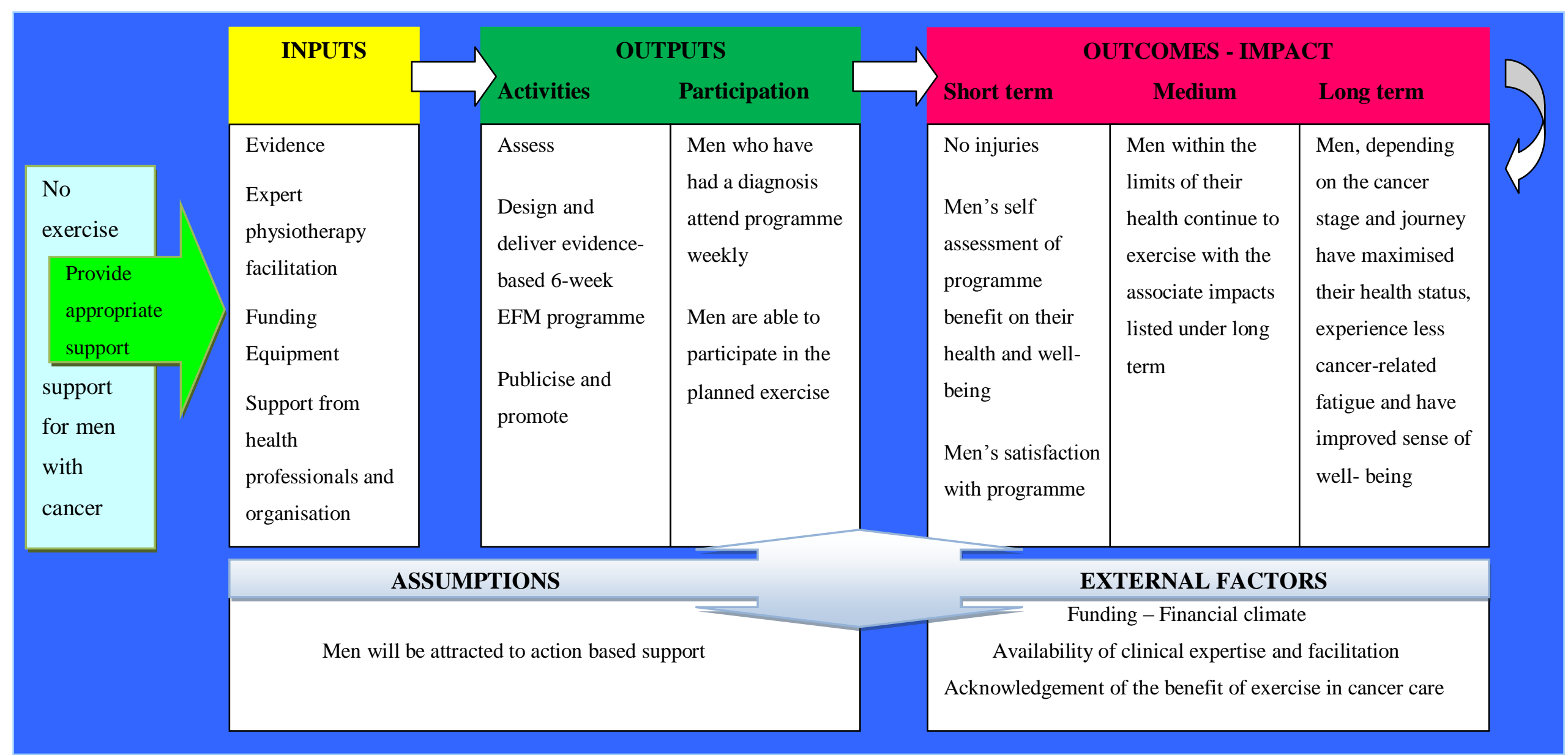

Figure 1: Programme logic of men's exercise programme*

*Adapted from University of Wisconsin program logic model (www.uwex.edu/ces/.../evallogicmodelworksheets.html) 


\subsubsection{The Evidence: Guidelines and guiding principles}

Research found that patients are more likely to initiate and maintain an exercise programme if there is a structured intervention (Szymlek-Gay et al., 2010). Exercise needs to hold patient's interest, be enjoyable and build confidence (Hayes, Spence, Galvao \& Newton, 2009). While general community exercise programmes are available, many cancer patients have associated body image concerns, loss of energy and physical strength and are reluctant or unable to attend. Group based programmes with support from fellow patients increase motivation (Kuchinski et al., 2009). Furthermore, it has been established that programmes that are group based, individually tailored, supervised and gradually progressed facilitate exercise (Blaney et al., 2010). The Australian position stand (Hayes et al., 2009) recommended individualised exercises of low to moderate intensity exercise for five days per week, gradually increasing to 30 minutes or more with five minute warm up and five minute cool down.

With no literature to refer to that had specifically explored men's preference of supervised exercise programmes, advice was sought from two experienced physiotherapists. The first, the team leader of the Physiotherapy Department at the local public hospital, worked with men with a diagnosis of cancer who had continence and pelvic floor issues. The second worked in private practice and had previous experience in acute, rehabilitative and palliative oncology in the United Kingdom. They each considered that a circuit based programme would have widest appeal to men, allow individualisation and cater best for a diverse group. An evaluation of a similar circuit programme for a mixed sex group recovering from cancer demonstrated its feasibility (Stevinson \& Fox, 2006).

Together the physiotherapists and I reviewed the NCCN guidelines (2010) noting the recommendations for both resistance and endurance exercise, and the need for caution for those with bony metastases, thrombocytopenia, anaemia, fever and neutropenia. The American College of Sports Medicine (ACSM) guidelines (Schmitz et al., 2010) gave clear criteria for length of time post surgery and advice regarding types of exercise for those with stomas. We reviewed the literature regarding the safety and efficacy even for palliative patients (Oldervoll et al., 2005; Oechsle et al., 2011). 
The proposed programme began to take shape. Existing research identified the benefit of gradually progressed, individualised, monitored, combination aerobic and resistance exercise programmes with goals for good and bad days, delivered in a group setting (Blaney et al., 2010; Hayes et al., 2009; NCCN, 2011; Schmitz et al, 2010). Flexibility would be key with varying exercises and goals. Review of the literature also highlighted the efficacy of relaxation in reducing pain and fatigue when the technique is mastered and practiced regularly After reviewing the Physical Activity after Cancer Treatment (PACT) trial: a multi-modal exercise programme consisting of exercise, relaxation and massage, which was shown to be safe and effective both during and post treatment (Adamsen et al., 2009) the physiotherapists agreed that a 15 minutes relaxation session following 30 - 45 minutes of circuit work could be incorporated into and enhance the cool down period. The second physiotherapist expressed her interest in facilitating and designing such a programme. Approval was given by management at the Waikato/Bay of Plenty CSNZ to pilot the programme.

\subsubsection{Framework}

The individualised, supervised, multi-modal weekly exercise group programme, comprising of a combination aerobic, resistance and stretching exercise circuit, followed by a 15 minute relaxation session would cater for 6-10 men and would be held each Friday for six weeks. Participants would be advised to exercise at home on alternate days and given an exercise log to fill in.

The programme would be tailored to the individual participant's fitness and ability. It would cater for any man who had had a diagnosis between the age of 18 - 80, at any stage of the cancer trajectory and needed to be flexible especially for those undergoing treatment or with more advanced disease. Resources would be simple, inexpensive and transferable so that men could continue with the exercises in their own homes without having to outlay great expense.

\subsubsection{Funding}

As outlined in Table 1, funding to plan, facilitate, implement, resource and evaluate this pilot programme was provided by a scholarship from the Movember funding to CSNZ in February 2011. The evaluation is the focus of this Masters thesis. 


\subsection{Implementation}

The programme was held in the Tauranga Office of the Cancer Society rooms and co-facilitated by the physiotherapist and the researcher in her employment as the Cancer Society Liaison Nurse. The programme was free to all who attended.

Table 1: Summary of Planning, implementation and ongoing evaluation of the Exercise for Men Programme

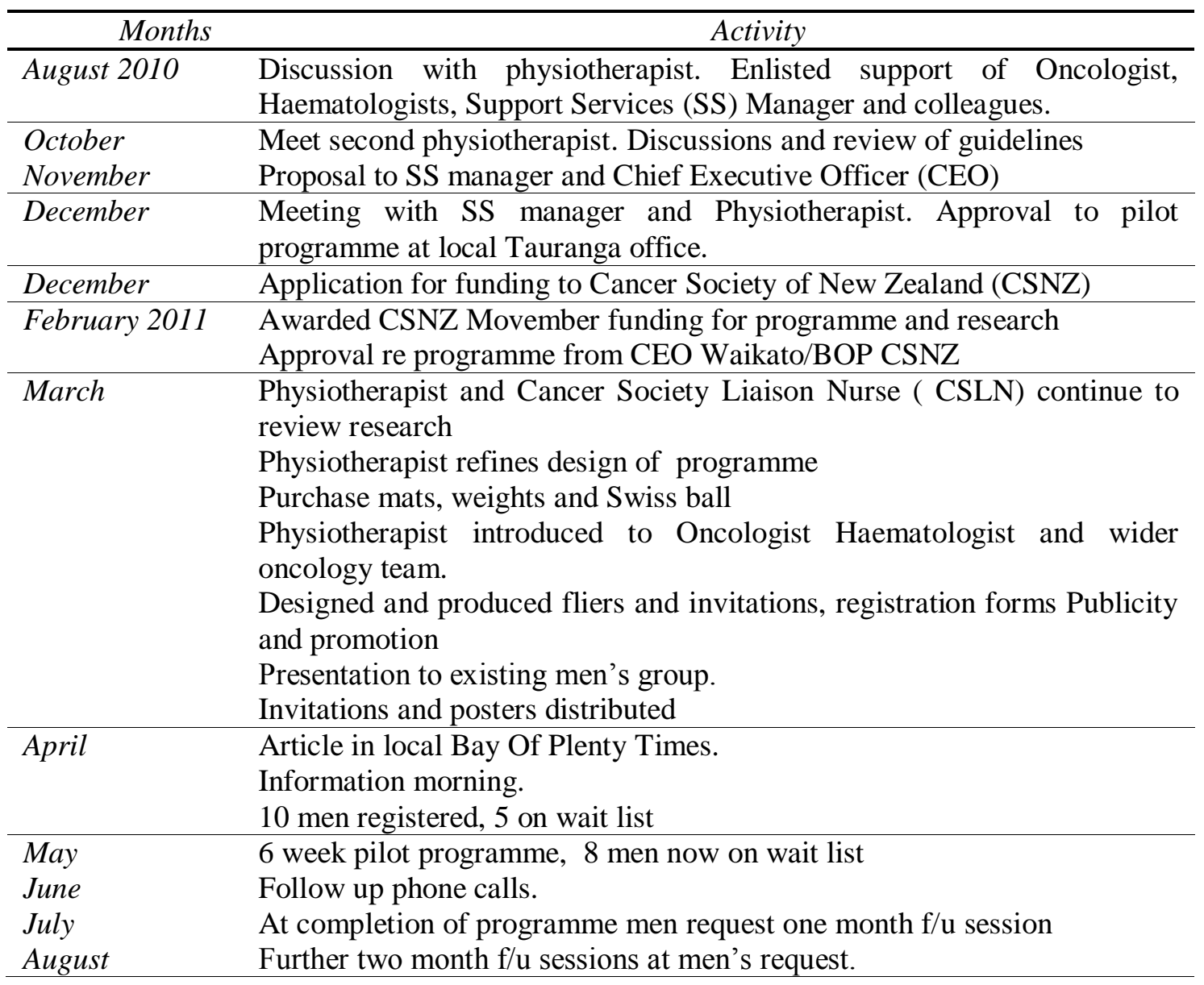

Meetings were held with the local Medical Director of Oncology and the Haematologist to introduce the physiotherapist and outline the programme. These provided an opportunity for them to raise any concerns and be assured of the physiotherapist's skills and expertise. In addition, the physiotherapist was introduced to other key oncology personnel, including the specialist nurse, the nurse manager, the chemotherapy nurses and the social workers and familiarised with the physical facilities of the Cancer Centre that many of the men would be familiar with. 


\subsubsection{Recruitment and promotion of the programme}

Recruitment for the programme was via posters and personal invitations to men who had recently received support at the Cancer Society in Tauranga. In an effort to design visual images that would attract men, relevant literature was searched to look at words and images that men might respond to. While a variety of phrases and slogans that might appeal to men were considered, literature identified that gender neutral words were found to be most effective in recruiting men with chronic disease to supportive programmes (Gibbs \& Reidpath, 2005).

Thus the programme advertising was pitched to inform succinctly, using simple clear words. The caption "Exercise for Men" was underscored with the subheading, "Have you had a diagnosis of cancer. Do you want to increase strength and fitness?" (Figure 2).

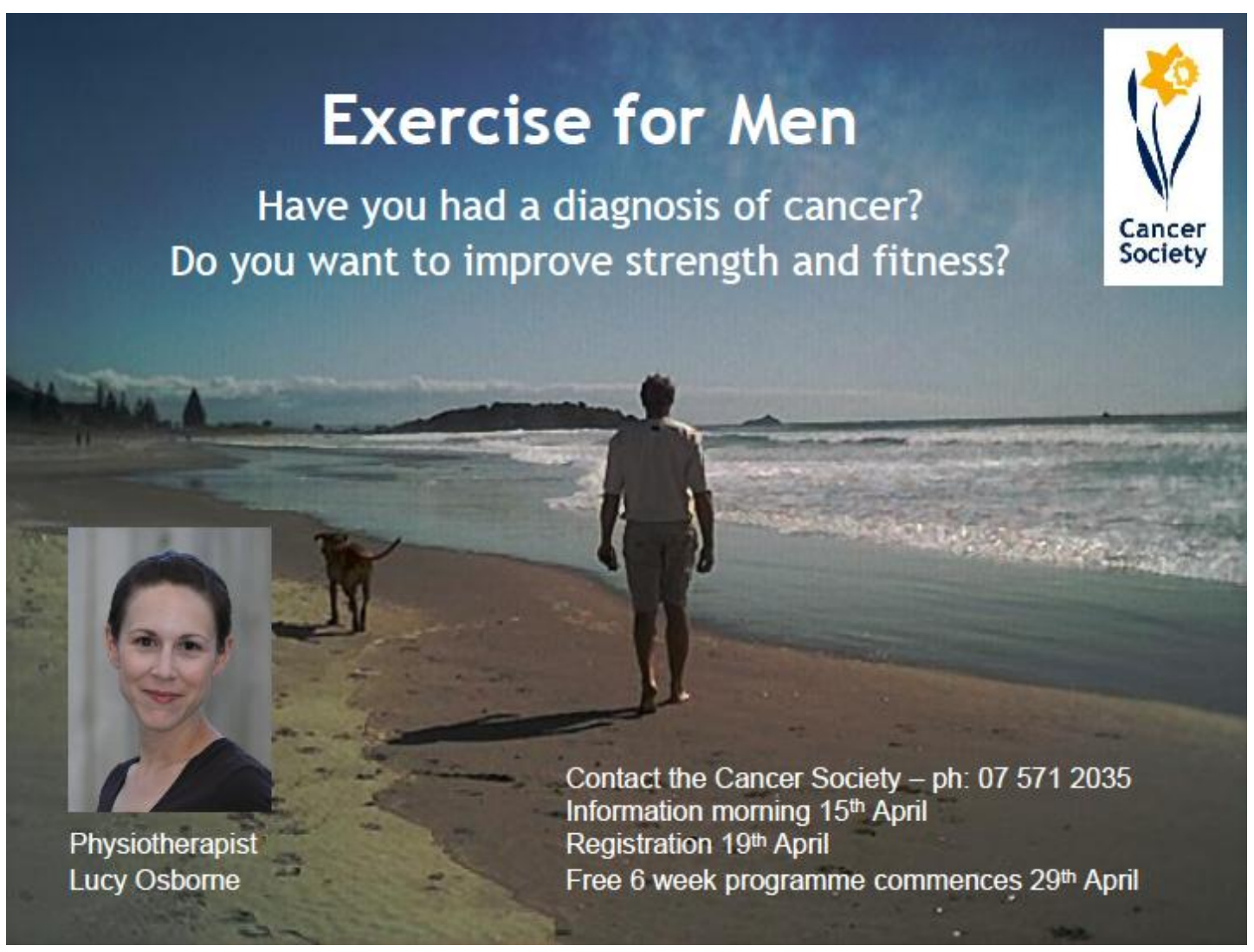

\section{Figure 2: Promotional poster}

*Photographs reproduced with permission

The visual image of a man of indeterminate age walking with a dog on the beach was chosen after searching much of the information geared towards men. The Cancer Society Logo and a photograph of the physiotherapist were inserted to further inform interested men, who was providing and facilitating the programme. The A3 and A4 
sized promotional posters were displayed at the Cancer Centre, Med labs, Radiology, Medical Centres, Pharmacies and various prominent places in community. Men who attended the men's support group at the Cancer Society were told about the upcoming programme. Invitations (Figure 3) were sent to male clients and given to the Oncology team to distribute as they considered appropriate.

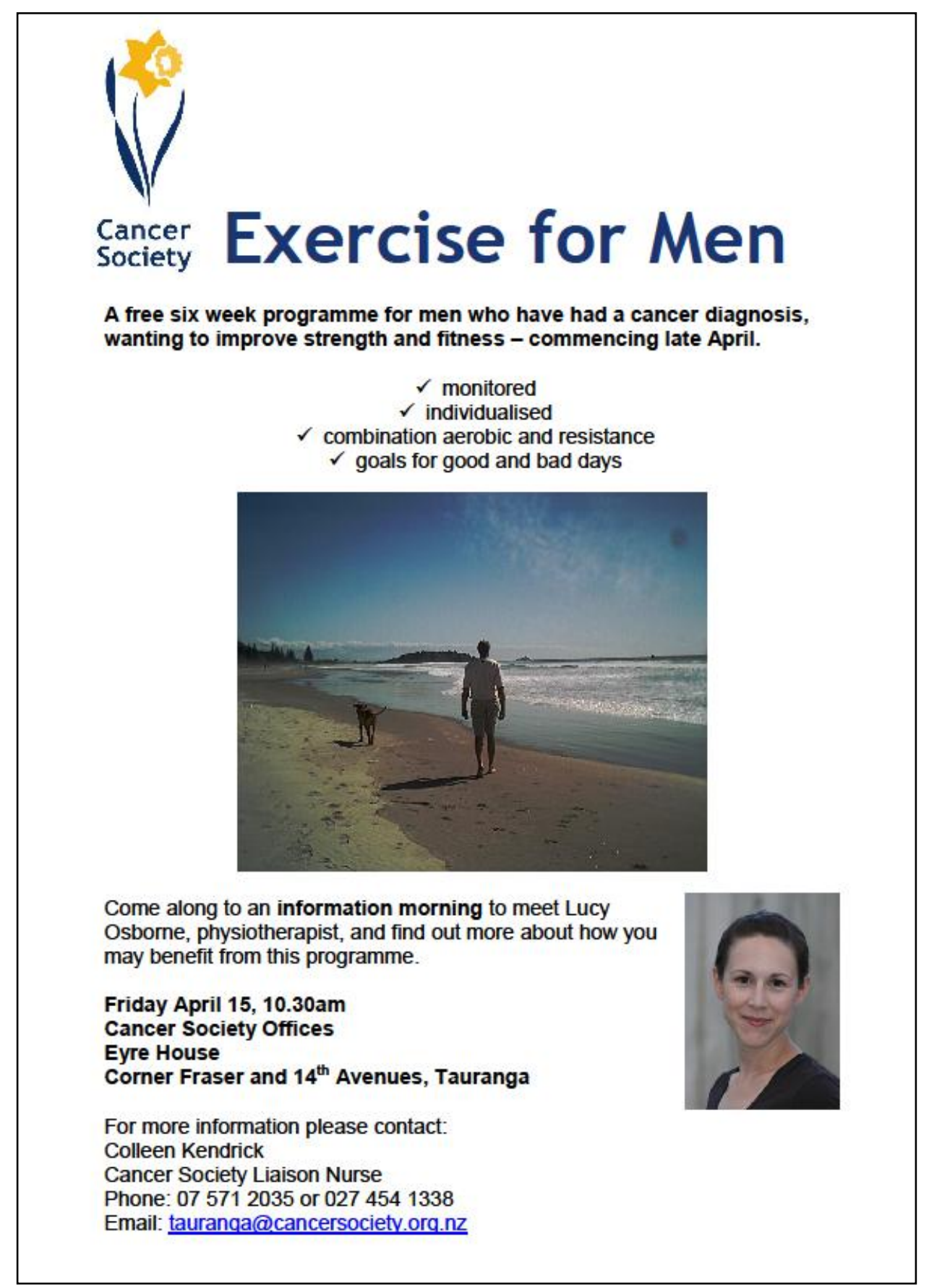

Figure 3: Invitation to programme*

*Photograph reproduced with permission 
Advertising in the local paper was not considered as previous experience had shown advertising other supportive programmes, to yield no responses. Given my previous recruitment success following an article on an initiative in the local paper, I approached the newspaper to elicit their support in writing an article on the proposed programme. A journalist and photographer interviewed the physiotherapist Lucy Osborne, and myself and an article about the upcoming programme was published in the Bay of Plenty (BOP) Times the night before the Information Morning was held (Figure 4). This article attracted wide attention and while six men from the Cancer Society client base and existing men's group had already expressed interest in the programme, the newspaper article attracted a number of men who had had no previous contact with the Cancer Society.

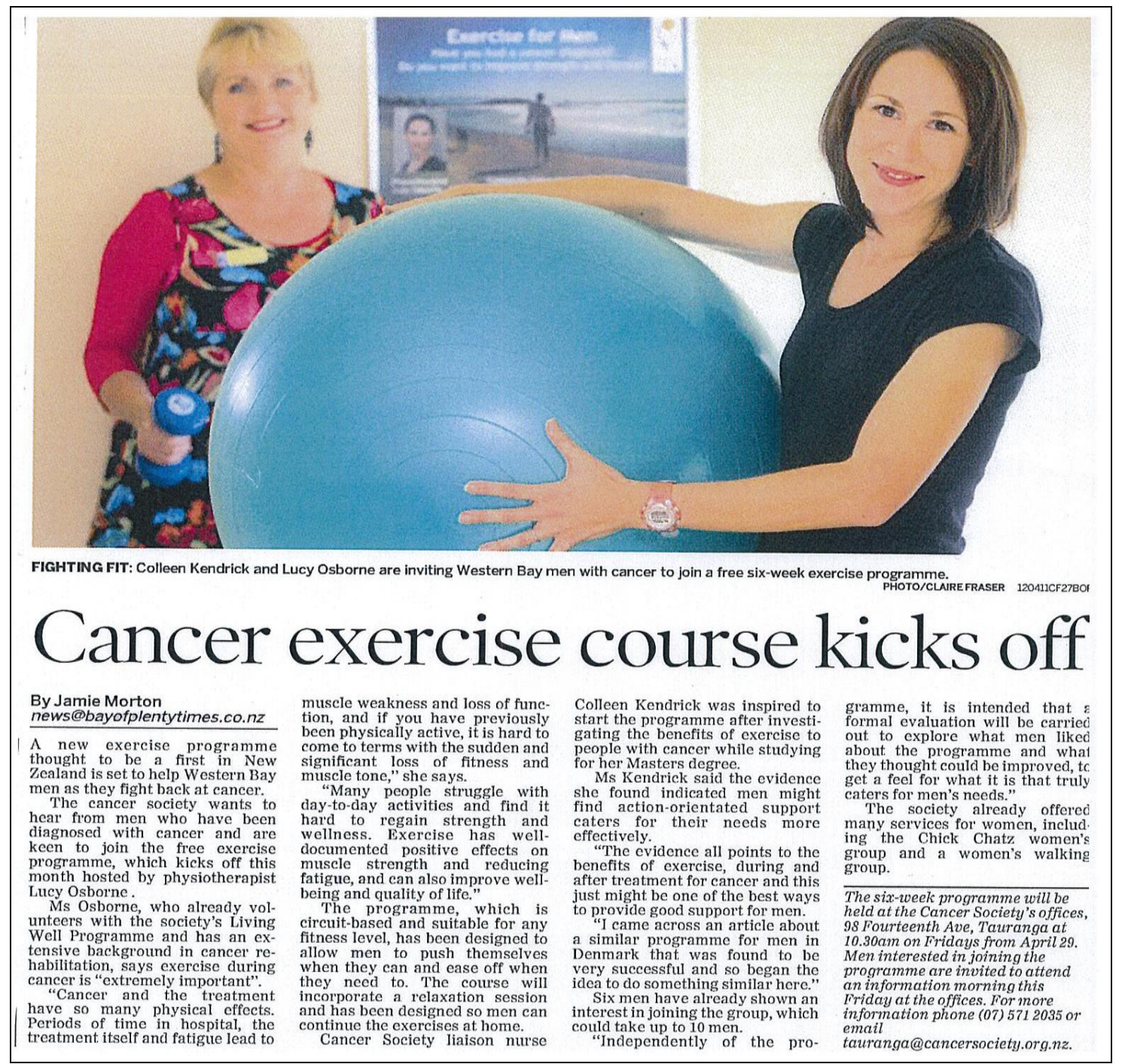

\section{Figure 4: Article in Bay of Plenty Times*}

*Reproduced with kind permission of the Bay of Plenty Times. Article published p. 3, April 14, 2011 


\subsubsection{Information morning}

An information morning was held two weeks prior to the commencement of the programme which enabled men to learn more about the programme and to ask any questions they had. It also gave an opportunity for the physiotherapist to informally assess the appropriateness of the proposed exercises for the men who were likely to come and for the men to meet with the physiotherapist to individualise their goals. The men were made aware from the outset that following the six week trial, the programme would be evaluated for patient uptake, satisfaction, the extent it met their needs, whether and in what way they perceived it benefited them and to examine the delivery and implementation of the programme.

\subsubsection{Consent and safety issues}

While research confirms the safety of individualised low to moderate intensity exercise even for those with advanced age and disease (Cramp \& Daniel, 2009; Kuchinski et al., 2009; Velthuis, Agasi-Idenburg, Aufdemkampe, \& Wittink, 2010), in order to ensure assessment and entry to the programme was robust, it was initially intended that the men would gain consent from their consultant or general practitioner (GP) to participate. Following discussion with the Support Services manager it was recognised that this could incur an extra expense to the men. As a result at the information morning the men were given the added option of the liaison nurse contacting the GP or Specialist on their behalf. The majority chose that option while some chose to write their own waiver of responsibility. One man gained written consent from his GP.

In all, 15 men expressed interest in registering for the programme. It was agreed that 10 was the maximum that could participate in each programme safely, in terms of space and safe supervision. Interest continued during the period of the programme, and at one time eight men were wait listed for any further programme. Six of the men attracted by the media advertising of the exercise programme, registered for the Living Well programme which was running concurrently. Recruitment is summarised in Figure 5. 


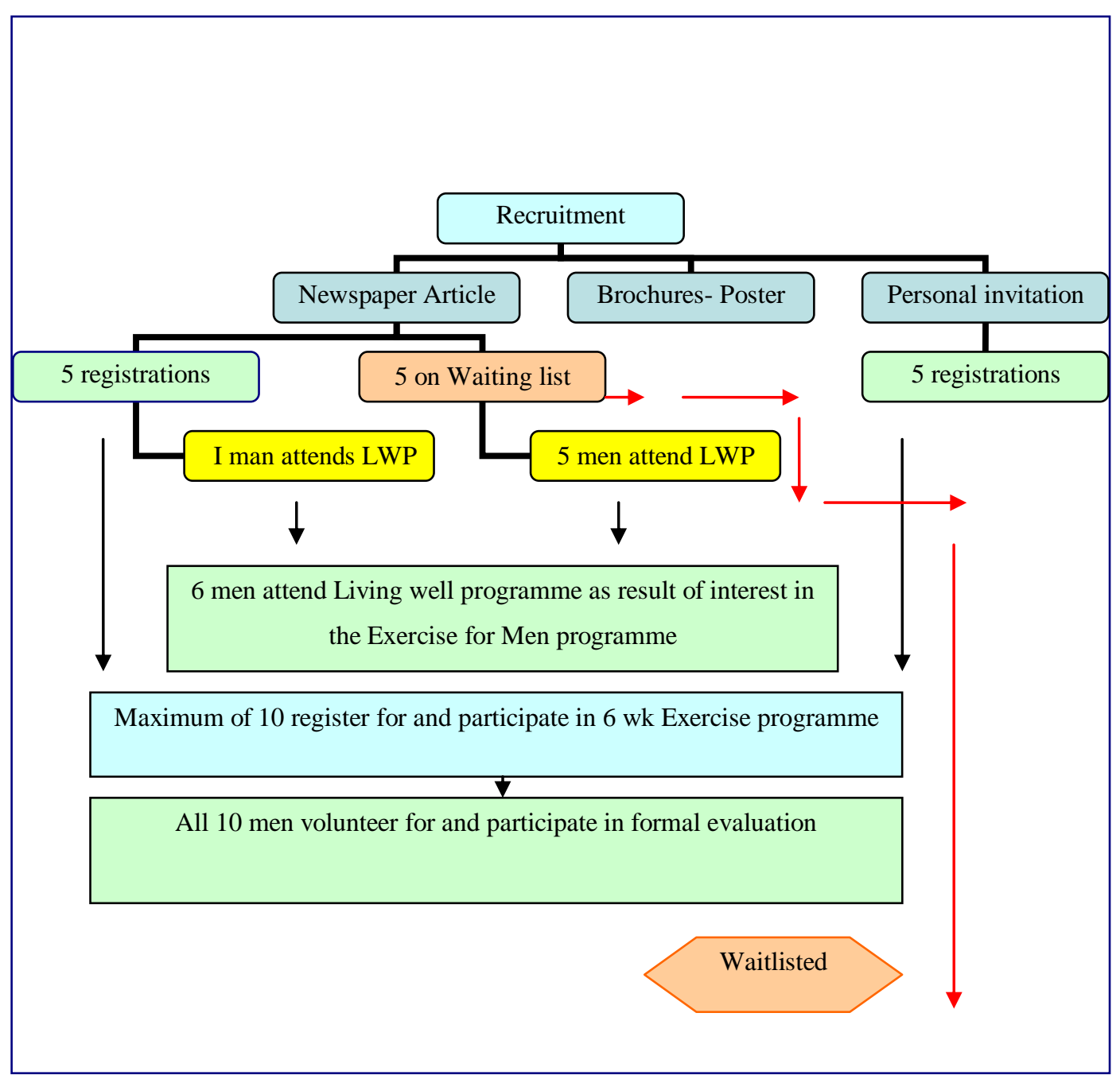

Figure 5: Entry to programme and recruitment to research

\subsection{Content and structure of programme}

The physiotherapist spent much time and gave considerable thought to the physical safety, efficacy and achievability of the exercises as she refined and designed specifics of the programme. The final circuit comprised of six stations consisting of a mixture of aerobic, resistance and stretching exercises. To cater for individual needs and allow gradual progression exercises, each station had three levels of difficulty. The men were each given a circuit sheet to fill in at each session to record their progress (Appendix 1).

\subsubsection{Circuit}

Figure 6 illustrates the final design of the circuit programme designed by the physiotherapist specifically for this group of men. 
Kaimai

CANCER SOCIETY CIRCUIT

PHYS I

(

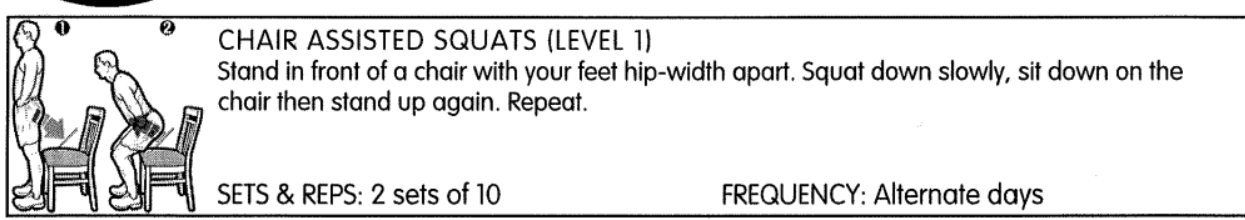

BODY-WEIGHT SQUATS (LEVEL 2)
With your feet a shoulder-width apart, squat down, ensuring your knees glide over your
second toes.

LUNGE
Rem a standing position, step forward bending your knees as far as you can go safely.
SETS \& REPS: 10
FREQUENCY: Alternate days

STEP-UPS
Do as many as you can in two minutes.

PLANK POSITION (LEVEL I)
With your hands and feet on the floor and arms straight, assume the plank position. Hold.
SETS \& REPS: 45S - Imin
FREQUENCY: Alternate days

PRONE BRIDGE (LEVEL 2)
With your forearms and feet on the floor and elbows directly under your shoulders, assume
the plank position.
SETS \& REPS: 45s - 1min
FREQUENCY: Alternate days

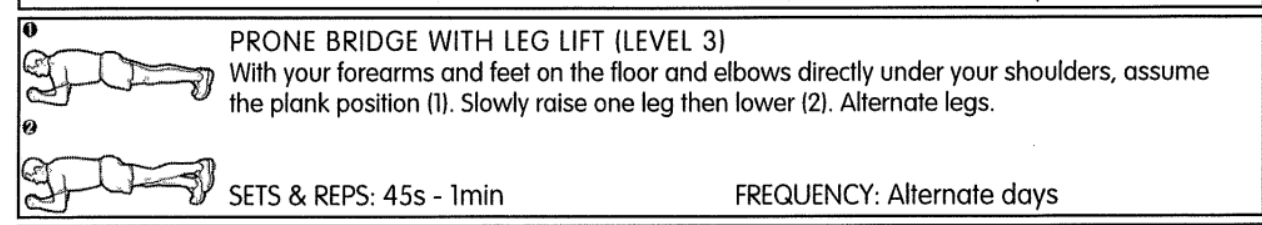

DOUBLE-LEG CALF RAISE (LEVEL 1)
Standing, slowly rise up onto your toes as far as you can (2). Slowly lower and repeat.
SETS \& REPS: $3 \times 10$
FREQUENCY: Alternate days




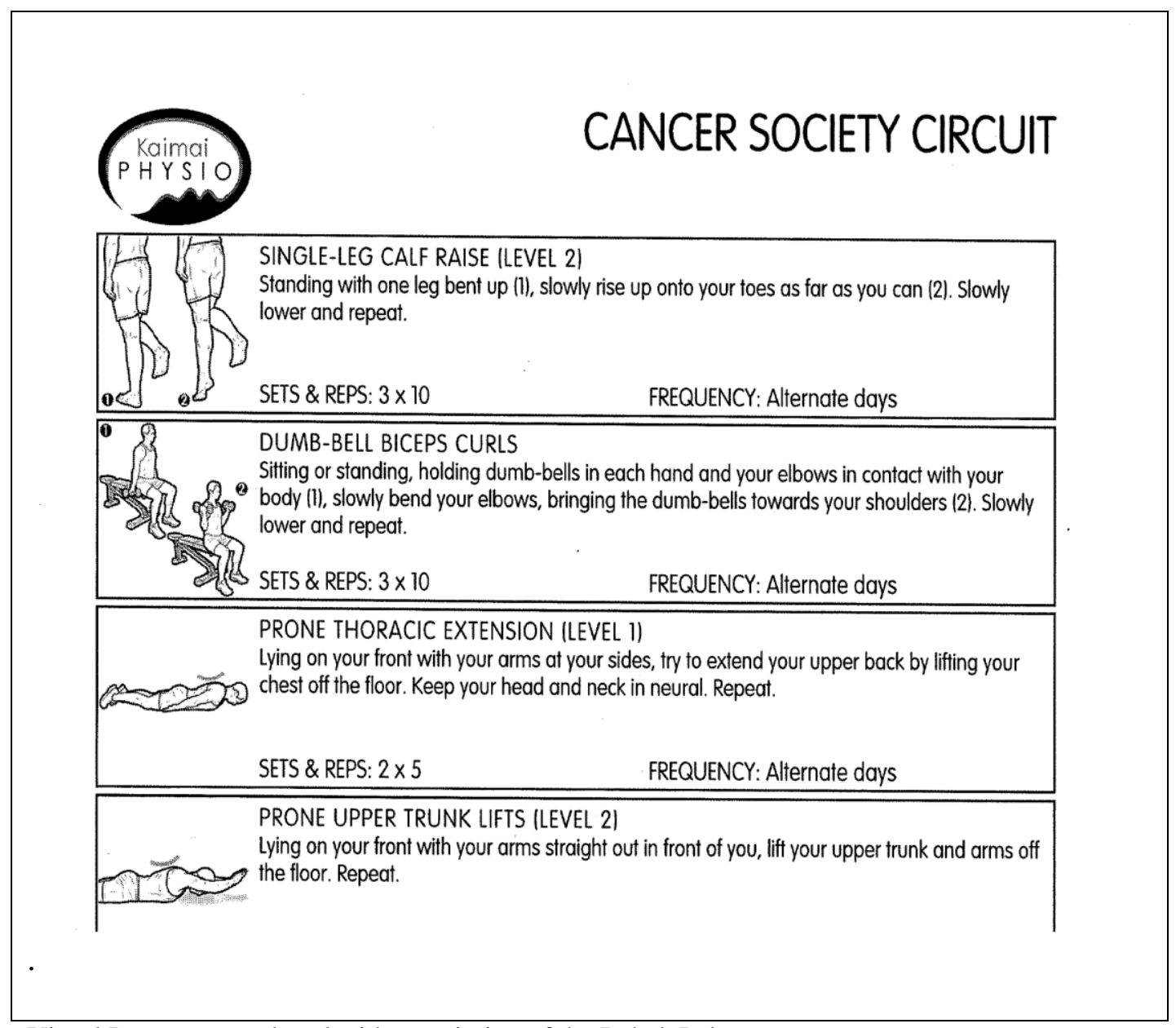

Visual Images reproduced with permission of the Rehab Lab

While it was initially envisaged that men would work alone at each station and gather as a group for the last 15 minutes for the relaxation stretching session, space dictated that the men work in pairs.

\subsubsection{Relaxation session}

Initially the relaxation session which followed the circuit was presented as stretching and relaxing on mats on the floor. The seated circle format was introduced at the third session and continued. The focus on the breathing aspect of the last relaxation session increased over the six weeks. The men were in no hurry to leave their seats at the end of the session and often had conversations that included the whole group. 


\subsubsection{The venue and exercise resources}

The only equipment necessary for this circuit was mats, two sets of hand weights, a

Swiss ball and a stepper. The simplicity of the venue and resources is demonstrated in the photographs below (Figures $7 \& 8$ ).

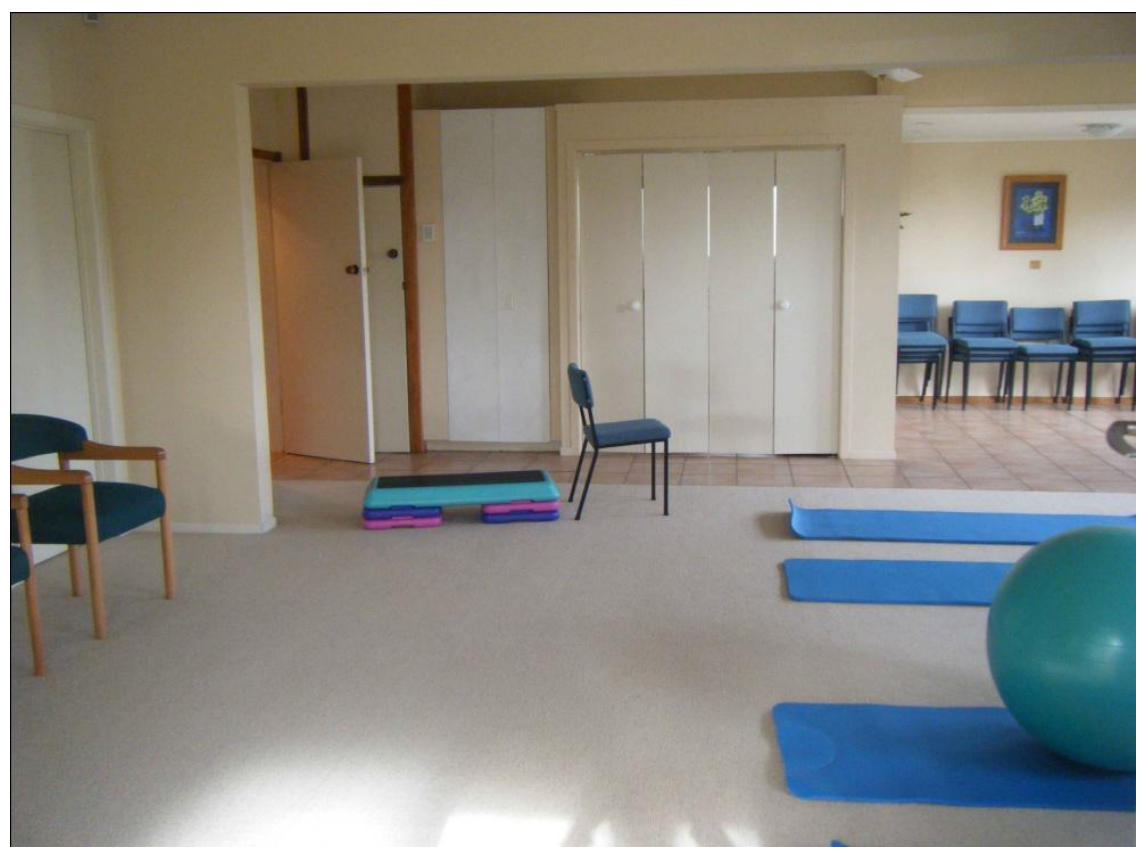

Figure 7: Photograph of floor area for exercise programme

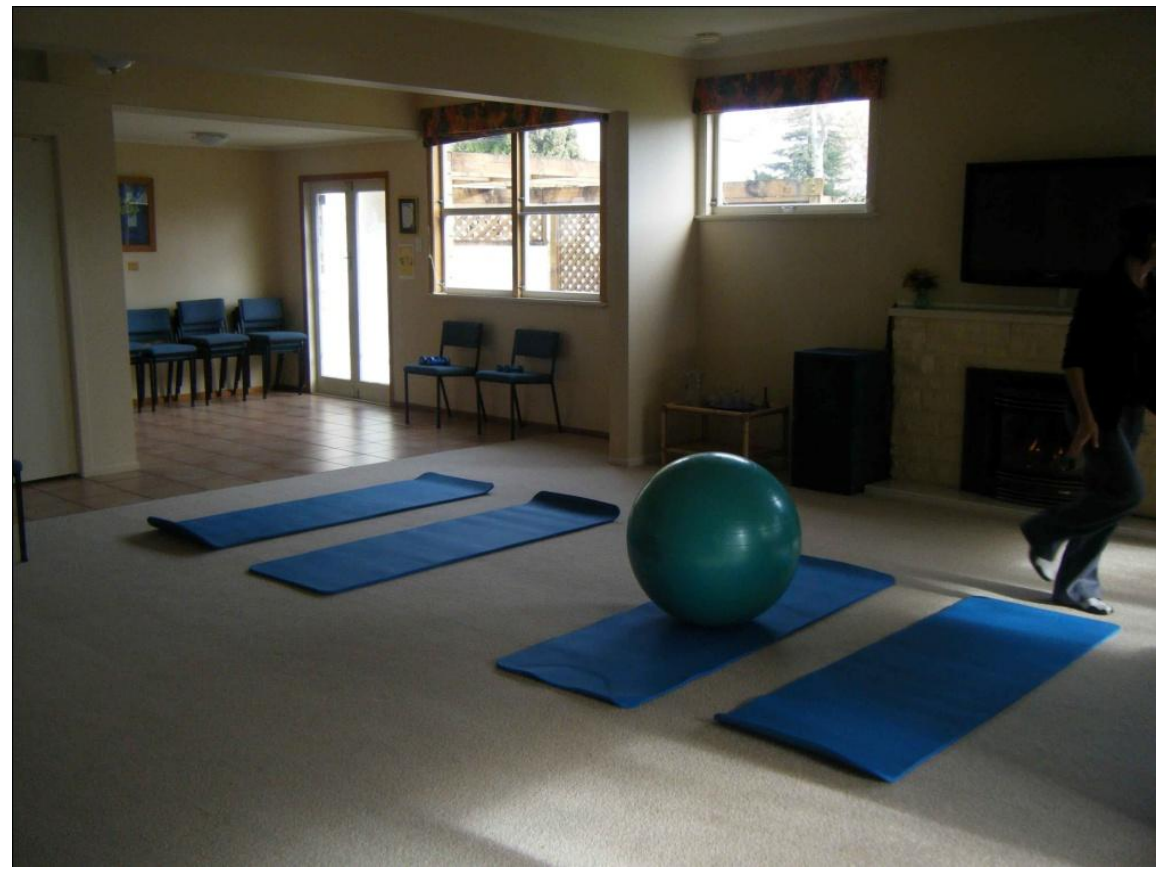

Figure 8: Photograph of mats and some of the exercise equipment 


\subsection{Shaping of the programme}

Throughout the six weeks the men were asked for their thoughts and views about what they would like to see as part of the programme. Although the programme was designed within a framework, space was allowed for ongoing changes that would allow for the participants preferences and meet their individual needs. The men's physical and emotional safety was paramount. Lucy and I debriefed following each session and discussed what we saw to be working and not working. Lucy gave the men her contact details so they could contact her if they had any concerns. I made follow up phone calls to all of the men following the first session and then in between sessions to men we felt may have potential concerns. We observed closely for any nuances or concerns.

The physiotherapist Lucy was careful to ensure the safety of all the participants and during the first session she ensured each man had time to learn the correct technique at each station. Most started at a lower level and the men completed only one circuit the first day. It became clear that during the first session that the men needed some way of knowing when the two minutes at a station was up. One of the men suggested a referee's whistle and in the following sessions the whistle became a feature. Lucy blew the whistle very loudly which was a topic of much fun and discussion. We fostered a light hearted yet real atmosphere where the men could mention whatever they wished.

In addition to my supportive role as nurse, I was responsible for refreshments and at the second session provided half time oranges between circuits. Oranges at half time were adopted as a group tradition. After the third session one of the men requested the opportunity to have a "cuppa" together following the sessions. Most of the men stayed for the light refreshment of a fruit loaf, rice crackers and hummus, and fresh fruit. It was noted that the men began to come earlier and leave later over the six weeks and enjoyed their conversations.

It was very clear at the outset that the programme would run for six weeks. The purpose of the programme was to motivate the men and teach them the techniques of the exercises which they could then continue at home. To that end an exercise diary (Appendix 2) was given to each of the men so they could monitor their progress as they integrated the exercises into their daily routines. 


\subsection{Post 6 week programme activities}

Several of the men expressed their wish to continue to meet, requesting ongoing monthly follow up sessions. Two follow up sessions, one at one month and another at two months were held, the first at the Cancer Society office and the second at one of the gym facility at one of the participant's gated village.

The men expressed their interest in seeing the programme continue and three accompanied me to give a presentation about the programme to a group of multidisciplinary health professionals at the Psychosocial Forum, Tauranga Hospital. The men also accepted my invitation to be filmed exercising in the background during my interview for the Movember website. With a big smile on his face one of the participants gave me a bag of oranges for half time. All expressed interest in attending further programmes.

The programme has attracted media publicity throughout the time of this study with an article in the Nursing Review (Appendix 3) and a further follow up article in both the BOP times and Katikati advertiser. A medical consultant who attended the Psychosocial Forum invited me talk to a group of senior house officers at one of their Continuing Medical Education meeting and has recommended entering this study at the upcoming innovation and research awards. The local Oncology team refer men to the programme.

Further 'Exercise for Men' programmes have now been held; two in Tauranga and one in Katikati. A poster presentation at PONZ November 2011 and a presentation of provisional findings at the CSNZ support services Hui in March 2012 received favourable feedback with interest expressed from other divisions and a request from the CSNZ National Manager of Supportive Care Services for a copy of the power point presentation to discuss further at a meeting with the 6 divisional SS managers to be held at National office. Discussions about further expansion of the programme to other offices are planned following submission of this thesis.

The programme continues to attract men not previously engaged with the CSNZ with 8 of the 12 men recruited in the last programme not having any prior contact with CSNZ support. The age range 40s to 80 with a wide variety of cancer types and includes a higher number of men currently undergoing treatment. As per provisional 
findings the programmes have been extended to 8 weeks with requests for the programme to continue indefinitely.

\subsection{Framing the evaluation}

Several theoretical frameworks were shown to shape the exercise programme. These were about masculinity and ill health, group versus individual need. In planning the evaluation, questions arose. Would it be best to use a masculinities framework with its focus on gender and power differentials? After all it was the specific exercise needs and preferences of men I was wishing to explore. Alternatively perhaps a health promotion framework with its focus on change to healthy behaviour would fit well. The theory of planned behaviour which proposes that "people will likely choose a behaviour they believe will be most beneficial to them, highly enjoyable and supported by others and that they have confidence in achieving" (Belanger et al., 2012, p. 49) is currently the most widely used psychological theory used in current research to explain exercise behaviour in cancer groups (Keogh \& Jones, 2011). Yet for the process evaluation that was planned this would have added too much complexity. After careful consideration a pragmatic programme logic underpinning was chosen as outlined in this chapter. This next chapter outlines in greater depth the methodology employed in the evaluation of this programme. 


\section{Chapter 4: Methodology}

\subsection{Introduction}

To begin to address the void in knowledge of how best to provide exercise for men who have had a diagnosis of cancer, the research objective of this study was to explore the experiences, preferences and perspectives of the key stakeholders (men and the physiotherapist) involved in a newly introduced supervised group exercise programme developed for men who had a diagnosis of cancer.

This chapter will outline the overarching methodology of formative process evaluation used in the study and the rationale for its use. The design and approaches used for data collection and analysis are described and discussed. Ethical implications associated with the research method and the special considerations for a researcher conducting research within the area of her nursing employment will also be presented along with the measures taken to ensure validity and rigour.

It was clear that the best way to find out whether the programme aligned with what men wanted and whether they had other preferences, would be to ask them. It was less clear in what way they should be asked. As outlined in Chapter 2 the majority of published research into exercise preferences of cancer patient populations has been conducted by Courneya and colleagues using questionnaires and surveys of large groups from these patient groups. While these methods give a wide representative overview of patient preferences through statistical and quantitative analysis, they do not allow for rich description of individual patient experience and preferences, and the nuances and subtleties of contextual influences (Parahoo, 2006).

The literature review pointed to the worth of an evaluation of an exercise programme for men which could explore the men's experience of that programme. Such an evaluation could establish whether the men considered it was individualised to their needs, what factors deterred or facilitated their participation in the programme, and whether there were specific components in the programme (e.g., comradeship, group-based activity, or the individualised instructions) that were particularly important. The introduction of the new supervised exercise programme outlined in the previous chapter created an ideal opportunity to put these questions to the men who enrolled in the programme and ask their views. While action based research or 
an outcome based pilot of the programme could also have yielded useful information (Wadsworth, 2011), a formative process evaluative methodology using semistructured interviews post programme was chosen as the most appropriate approach and design for this study.

\subsection{Evaluation research}

Wadsworth (2011, p. 184) states "Evaluation involves ascribing value, merit, worth or significance to something or some social process (called 'the evaluand')." It involves a systematic approach (Rossi, Lipsey, \& Freeman, 2004). While evaluation research is commonly used in social science research, it has until relatively recently been viewed within nursing research as being without strong theoretical underpinnings and as such, not often published (Walsh, Duke, Foureur, \& MacDonald, 2007). Research with a strong theoretical focus has been preferred and more highly regarded. However, with the heightened awareness of accountability within healthcare and increasing recognition of the political, fiscal and practical importance of evaluation in complex nursing contexts it has more recently emerged within nursing research as a recognised and valid form of research (Walsh et al.).

There are several approaches or forms of evaluations that can be used in complex nursing settings (Walsh et al., 2007). Before embarking on this evaluation it was important to select the appropriate approach by first examining the theoretical underpinning of the different types of evaluation. While evaluations which use a pre and post test design have been most widely used in health settings to determine the effectiveness of an intervention, Walsh et al. point to the growing appreciation within nursing research of the need to take into account the importance of the acceptability, feasibility and context of any programme. This requires obtaining the views of different stakeholders (Pawson \& Tilley, 1997). Rather than focusing on whether a programme works, realistic evaluation delves deeper to understand "causal mechanisms," why and how a programme works, for whom it works and in what circumstances it works (Pawson \& Tilley, 2004; Wilson \& McCormack, 2006).

In this research where the primary aim was to elicit the stakeholders' perspectives of this programme, and whether it met the participant's needs, it was critical to understand what made it work, for whom it would work and how it could be modified to work or work better. Thus the realistic evaluation framework was 
chosen. Initially, critical realism had been considered the most appropriate approach for this evaluation and some aspects of this lens 'fit' well.

Critical realism underpins a realistic evaluation approach and is increasingly recognised as an appropriate philosophical framework in evaluations undertaken by nurses (McEvoy \& Richards, 2003; Wilson \& McCormack, 2006). Key features include the role of context in shaping what works, and what does not work, in a programme. It positions participants in a programme as central to any evaluation. Furthermore, Wilson and McCormack identify the influence not only of all the players, and the venue on a programme but also factors such as the previous experience of stakeholders and the relationship between where the programme takes place and the rules or social norms of that place. McEvoy and Richards (2003, p. 417) state "the influence of contextual factors need to be properly understood if evidence based interventions are to be effectively translated into practice." Realistic evaluation takes into account not only the process of change but the context it occurs in. There is no doubting the implications the existing context plays in the success or failure of a programme. Context also heavily influences a programme's future development.

Furthermore, what works for one set of programme participants may not necessarily suit others. Pawson and Tilley (2004) highlight the importance of three factors and the fit between the programme and the participants it targets. They state; "Programme building is also a matter of getting the right ingredients in place in the right setting to suit the needs of particular sets of consumers" (Pawson \& Tilley, p. 10). Therefore, right ingredients plus a right setting or context plus suiting the needs of that particular group equals a successful programme (Wadsworth, 2011). This opportunity to explore men's preferences within the reality of them having experienced the programme gave the opportunity to take into account their experiences and preferences regarding the intervention and also the context it was delivered in (McEvoy \& Richards) and the match between the ingredients of the programme and their particular needs.

Critical realism is often used in settings where the population served by the programme in question is considered underprivileged or oppressed (Wilson \& McCormack, 2006). It would have been inaccurate to consider men who have had a 
cancer diagnosis an oppressed group. It could however be argued that they were underprivileged in the sense that there were no exercise programmes designed specifically for them.

\subsubsection{Timing and type of evaluation}

Another important factor which is used to define the type of evaluation is timing. An evaluation can take place before, during or post the introduction of a programme and may be used to "assess the design, implementation, improvement or outcomes of a program" (Rossi et al., 2004, p. 18). There is no one agreed typology related to the timing and types of evaluations. Owen (2007) has four types, namely proactive, clarificative, monitoring and impact, whereas Walsh et al. (2007) list three types, namely formative, process and outcome focused. While the language for each of these writers is different, the underlying theoretical and epistemological framework of each of the typologies concerns the status of the programme and the need or purpose of the evaluation (Owen).

Formative evaluations are commonly used in early monitoring of programmes by using the information that is gathered to form, amend or improve a service (Wadsworth, 2011). The major emphasis of a process evaluation is to document and analyse the way a programme works in practice to gain an understanding not only of how it achieves what it does but also the influences at play. A process evaluation "describes how the program is operating to assess how well it performs its intended function" (Rossi et al., 2004, p. 199). In addition to being used to refine a programme, it is often used to inform others who are interested in implementing similar programmes. Given that the programme was at the implementation and development stage with the opportunity to further refine the design of the programme to better meet the men's needs, this evaluation using the Walsh et al.'s (2007) terminology, combined aspects of a formative and process evaluation and will hereafter be referred to as formative process evaluation.

\subsubsection{Theoretical lens of this evaluation}

"The aim of theory driven approaches to evaluation is to get inside the black box of a programme and identify how and why interventions work in particular circumstances" (Pawson \& Tilley, 1997 cited in McEvoy \& Richards, 2003, p. 148). The previous chapter outlined the history of the programme, what and why decisions 
were made about how to run the programme. Such decisions were made based on available resources as well as what was considered would work for men in New Zealand who had had a diagnosis of cancer. These latter decisions concern programme logic (Owen, 2007) the theory that links all parts of a programme to its outcome. It is only when the programme logic has been established that effectiveness studies or impact evaluations can be carried out to establish the benefits of the programme role.

\subsubsection{Formative process evaluation approach}

Using the open inquiry of a formative process evaluation unlike outcome evaluation which focuses on pre defined outcomes, gave the opportunity to discover or uncover unanticipated activities and outcomes. When complex interventions are implemented in clinical practice, there needs to be enough information to enable practitioners to make evidence based decisions about how best to adjust a programme in light of specific circumstances or to better meet the target groups needs (McEvoy \& Richards, 2003). The intention of this research was that the information gathered from the evaluation would make it possible to make adjustments to the programme and determine what needed to be changed, strengthened or dropped (Posavac \& Carey, 2007). To achieve these ends it was also important to find out from the participants whether the whole programme or only parts were working for the men. Questions about specific aspects of the programme such as: what would attract men to enrol, were there particular exercises that were more attractive, was a social aspect important, were there aspects of a programme that would encourage men to continue to exercise at home, was a specific venue important; were all questions that would yield important information.

Most importantly, formative process evaluation at the completion of this new programme gave the opportunity for the men and the physiotherapist to evaluate from a place of having experienced the programme and known in reality just what it was that either made the programme attractive or unattractive, acceptable or unacceptable and accessible or inaccessible, as opposed to giving a purely hypothetical perspective. 


\subsection{Method}

No one method is preferred in evaluation research and often mixed methods are utilised. Commonly a combination of survey, observation and individual or group interview are employed. However, while the ideal would have been a three phased mixed method design, in the confines and time frames of this thesis that was not possible. An ideal design would have included a needs analysis and process evaluation as separate activities by conducting a large survey of a representative sample of men who had a cancer diagnosis pre programme, observation during the programme and semi-structured interviews and outcome measurements of the participants post programme. In particular the survey pre-programme was dropped from the design to ensure timely completion of the research. Ethics approval was required for this evaluative study and waiting for approval pre programme would have caused a delay and the project would not have been able to be completed in the allocated time frame. On realising this and following much discussion and consideration, the project was simplified to consist of semi-structured interviews with participants of the programme and the physiotherapist facilitating the programme, post programme.

Though the design was refined, the original aims were met and the same research questions answered. Several questions in the post programme interviews were designed implicitly to elicit answers that would also reflect the views of the men pre programme. Qualitative methods "interpretive techniques that seek to describe, decode, translate or otherwise come to terms with the meaning, not the frequency, of naturally occurring phenomenon" (McGregor \& Murnane, 2010, p. 421) were appropriate in innovative settings such as this (Posavac \& Carey, 2007) where the purpose was to explore the experiences and perspectives of the programme user (Walsh et al., 2007). The use of qualitative methods allows a deeper probe to "look beyond surface appearances to search for the underlying processes that account for natural and social phenomena" (McEvoy \& Richards, 2003, p. 418). And, while it was recognised that the findings from this evaluation will not be generalisable, they do provide a deeper understanding of the programme and men's experience while participating, along with insights into the process of providing a programme that the men participating could help shape and evolve. They are potentially transferable and give opportunity to further enhance the programme. 


\subsubsection{Potential strengths and weaknesses of the methodology and design}

As the researcher I was not only evaluating a programme I had helped design, set up and implement, as the nurse I wore another hat with the participants. The men were either already patients or could potentially become my patients. I was very clearly "straddling the researcher / nurse role" (Baumbusch, 2010, p. 257). There are inherent dangers that accompany this dual role. Baumbusch identifies the need for those conducting what she terms "practice close research" i.e. qualitative nursing research in their area of practice, to be explicit about their preconceptions about an issue and transparent regarding their interactions with the participants.

A qualitative evaluation of this kind could draw criticism from those who view the subjective nature of this evaluation as potential for bias and thus a weakness. However, others view the inside knowledge of the evaluator who both understands the programme in depth and the reality of the context in which it stands, as a strength and essential to an accurate understanding of the findings. Wilson and McCormack (2006) state "it is important to have knowledge of a) the specifics of the programme, the history, and meaning embedded within the programme; b) the research methodology and c) the context within which the research is taking place" (p. 51). McGregor and Murnane (2010) reinforce this view and identify the place and role in qualitative research of the voices of both researcher and participants.

\subsection{Study design}

A mixed method design was used that included documentation about the programme and semi structured interviews with stakeholders - the men who participated in the programme and the physiotherapist, after the 6 week programme was finished.

\subsubsection{Sample}

Purposive sampling was employed as is appropriate in qualitative evaluation research (Posavac \& Carey, 2007). Two types of participants were invited to join the study: the 10 men who participated in the programme and the physiotherapist who led the programme. Information about the proposed evaluation at the end of the programme was shared as part of the advertising of the programme via a newspaper article and given to the men at the information morning prior to the programme commencing. 
Although it was made very clear that participation in the study was purely voluntary, and that the exercise programme and the formal evaluation were separate entities, all those participating in the programme expressed their interest in participating in the study from the outset.

\subsubsection{Data collection}

Previous studies of group exercise and therapies have used focus groups as their means of gathering data with the rationale that this mirrored the group dynamic of the intervention (Adamsen et al., 2001; Emslie, et al, 2007; Midtgaard, Rørth, Stelter, \& Adamsen, 2006) and this was initially considered for this study. However, the use of semi-structured interview was chosen over focus groups as interviews are known to provide more in depth knowledge of participant's views (Posavac \& Carey, 2007). As this was a new programme it was also not known whether participants would necessarily relate to each other. Capturing individual views was considered important and it was thought participants may not necessarily be as open with their views in a group situation. While interviews are much more time intensive, focus groups have the inherent risk of a dominant participant skewing the findings (Parahoo, 2006).

The interview schedule was pre-tested for acceptability, and internal and content validity. The first interviewee was a man who would have attended the exercise programme had his health allowed and the second a male GP. Changes to some of the wording in the questions to make them clearer and more acceptable to men were made as a result.

The semi-structured interviews with the men followed their participation in the 6 week supervised programme. The interviews with the men focussed on seven areas:

1. Participant backgrounds (age, employment status, medical history, etc.)

2. Social life (networks, male culture, etc.)

3. Attitudes to and role of exercise in their life before cancer

4. Their experiences of joining the programme

5. What components of the programme they participated in (e.g., the information session, all the exercises in the programme, exercising in between, the exercise journaling, the comradeship of the exercise).

6. The extent the programme met their needs. 
7. Suggestions for future programmes (Time of day, Advertising, Allocation of time. Resources, qualifications, gender of the professionals, etc.).

These areas were chosen because they captured information about the male participants in relation to exercise as well as specific details about their experiences with the specific programme (Appendix 4 provides more details).

The interviews enquired about how well the programme met their needs what changes they recommend be made for continuation of the programme; their preferences for particular exercises; and what they perceive to be the barriers and enablers to access exercise. The men were asked to describe their experience of the programme. Follow up questions explored and clarified the content of their responses. They were also asked about the impact of the programme and their relationship with the facilitator and others in the group. Bearing in mind the dual opportunity and threat of the interviewing process to men (Alvesson, 2011) I was careful to check that the questions were not perceived as threatening. I began each interview with a clarification of the purpose of the interview and checked again the men's comfort in continuing. I took note of Schwalbe and Wolkimor (2003) who advised that interviews with men initially asked about thoughts not feelings.

I felt a tension in the evaluation as a female interpreting the "male voice' or perspective and throughout the interviews with the men I felt a responsibility to ensure I did not ask leading questions, that I used probing questions appropriately and left opportunity for the men to say what they wanted. I regularly checked their meanings with them.

The physiotherapist was also interviewed about her experience in the facilitation of and observation of the men's experience of the programme. The interview for the physiotherapist focussed on the following areas:

1. The physiotherapist's background (as far as providing exercise for cancer patients)

2. Her experience of delivering the programme.

3. Components of the programme the physiotherapist observed the men participating in (e.g., information session, all the exercises in the programme, exercising in between, the exercise journaling, the comradeship of the exercise) 
4. The men's physical appearance and ability.

5. Challenges, motivators and obstacles to providing the programme.

6. Suggestions for future programmes (Time of day, Advertising, Allocation of time, Space/facilities/resources, qualifications, gender of the professionals, division of tasks, type of exercises etc.)

These areas were chosen to obtain the physiotherapist's observations and experiences of the programme. Details of the interview schedule are attached in Appendix 5.

Though all the interviews were scheduled to be completed in the month following the programme circumstances did not allow. The final interview was conducted with the physiotherapist (Lucy) two months after the six week programme had finished. The value of this longer interval became apparent when Lucy was able to offer insights after the second monthly follow up session that she would not have had, had she been interviewed earlier.

The interviews with the men ranged from 58 minutes to 130 minutes with an average length of 96 minutes. Three men chose to be interviewed at the Cancer Society office and seven in their own home. Wives and partners were often present during interviews in the home and though not totally involved, were drawn in by the men at times. I wonder whether the men might have answered and reflected/expanded on things differently if the wives were not there.

\subsubsection{Data analysis}

Data were analysed using an interpretive descriptive, inductive approach (Thomas, 2006, Thorne, Kirkman, \& MacDonald, 1997; Thorne, Reimer Kirkham, \& O’FlynnMagee, 2004). A detailed description of the exercise programme was developed to outline the implementation and delivery of the programme. Analysis of the interviews began at the time of data collection. Following each interview, I listened to the recording noting the intonation and pauses that added to the meaning and emphasis of the responses. Notes were made in a research journal, and additional questions added to the interview. The taped interviews were transcribed verbatim by independent transcribers and when returned I listened to the tapes again and cleaned and corrected the transcriptions. At this point transcriptions were sent to the participants who had requested them, for participant validation, so they could check for accuracy and to enable them to make additions and amendments. Interview data 
were then analysed for content and themes about the programme. I listened to the tapes several times throughout the data analysis. The aim was to look for individual perspectives as well as commonalities and differences in perspectives and experiences (Thomas).

While some methods of data analysis follow data collection and the two sit quite separately, analysis of semi-structured interviews begins at the time of data collection. During analysis I used a reflexive approach, reading through and between the lines, exploring responses and interpreting them in the context (Alvesson, 2011; Kvale \& Brinkman, 2009; Malterud, 2001; Rubin \& Rubin, 2005). It was important to first immerse myself in transcripts to gain a sense of the wider meanings of the men's words and let the themes emerge naturally and iteratively. While remaining true to the sense of the men's words and represent their voice it was important to group each set of common data into emerging themes under umbrella terms that were not limiting and prescriptive and that captured the essence of the meaning of the data (Thorne et al., 2004). The transcripts were then analysed line by line. Using a large table created on the computer specifically for this purpose, I grouped data within categories naming concepts which were found to interlink and often sit within emerging themes. These themes were modified as the analysis progressed.

The six steps in the analysis are summarised:

1. Each transcript read and a summary overview of key issues and views made

2. The transcripts were regrouped to align all answers related to each question

3. Read for particular statements of fact such as preferences about timing

4. Read for themes - themes coded

5. Content and theme data read and then grouped - moving from topics to clustering and chunking themes

6. Interviews were re read to capture that everything was included in the analysis and that themes identified were reflected in the interviews.

These are demonstrated as a in Figure 9. 


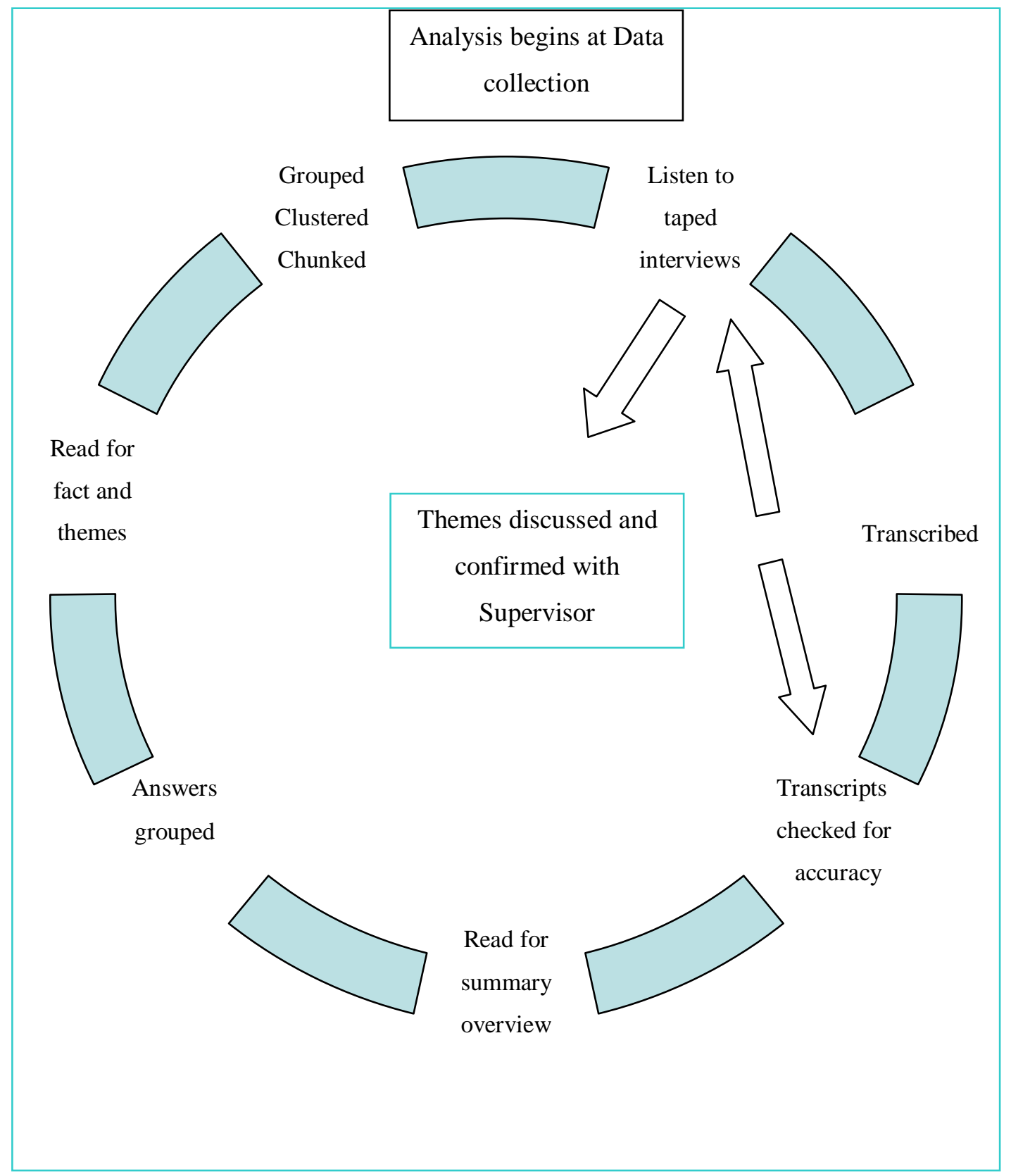

Figure 9: Data analysis cycle

As a neophyte researcher I requested feedback from my supervisor throughout this time regarding provisional themes and concepts until analysis was complete.

\section{5 Ethical considerations and approval}

Health and Disability Ethics expedited approval was obtained from Northern $Y$ regional ethics (Appendix 6). The following key issues were addressed in the application; 1) protection of participants from physical or psychological harm, 2) prevention of deception, 3) protection of privacy, and 4) informed consent. 
It was of paramount importance that none of the participants felt coerced to enter the study just because they came to the programme. They were informed at the information morning prior and in the newspaper article advertising the programme that the intention was to invite them to participate in a formal evaluation following the programme that was part of the researcher's master's thesis. The men were informed that the purpose of the study was to gain information about their preferences and experiences of the exercise programme in order to gain insight into what works and what could be improved in the delivery of such programmes. They were advised that it would add to the knowledge about how best to assist men who have had a cancer diagnosis to exercise in a way that is effective and that suits them.

Further information about the study was disseminated at the final session of the programme. A copy of the information sheets (Appendices 7,8 ) regarding the study were posted to all those who participated in the programme and an invitation made to contact the principal investigator by phone or face-to-face to have any questions answered. The men and the physiotherapist were assured that they would in no way be disadvantaged if they chose not to participate. Potential participants were given verbal details regarding what the interviews would cover prior to completing the consent process (Appendices 9, 10).

It was not anticipated that the questions in the interviews would cause distress as they were not of a sensitive nature but it was recognised that some men may become distressed when talking about how cancer had impacted on their life and ability to carry out physical activity and that their awareness of what they could no longer do could be heightened. The men were advised both verbally and in the information sheet prior to the interview of the possibility that they might become upset when sharing their experiences. At the beginning of the interview, they were advised that the interview could be stopped if that occurred and that they could choose to withdraw from the study or to reschedule the interview to another time. Follow-up counselling was made available in the event that any of the participants experienced distress as a result of any aspect of the study. As an experienced cancer nurse I was available to support people and able to advise them about the counselling services provided by the Cancer Society that they could avail themselves of. 
As a nurse I was also aware that if a man became upset during the interview this could paradoxically provide an opportunity for him to talk and share some of his distress about his cancer diagnosis. It was considered that any distress experienced in the interviews was likely to be short term in nature. This risk was offset by the opportunity the participants had in contributing to the development of exercise programmes for men with cancer generally. It was also recognised that the transcribers may have found some content of the interviews upsetting. The two transcribers were offered and declined debriefing following the completion of the transcribing.

Participants were asked to choose a pseudonym and all care was taken in the reporting of the study to ensure quotations and personal details were de-identified in the reporting of the research. However, due to the nature and location of the study it was impossible to maintain strict confidentiality; the participants knew each other and the physiotherapist was known to the participants and the community as her name had been included on the programme material. Unexpected local and national interest resulted in an article in the Nursing Review about the programme. Photographs accompanied the story. The physiotherapist and the men all gave separate consent for this. While the men are referred to their chosen pseudonyms in the findings, the physiotherapist has consented to the use of her real name.

Participant validation was sought to ensure accurate representation (Malterud, 2001). Details of the interviews were known only to the principal investigator, her supervisor and transcribers. The transcribers were required to sign a confidentiality agreement prior to commencing the transcribing (Appendix 11). In line with ethical guidelines, all efforts were made to ensure no information will be used to disadvantage the participants or the physiotherapist in any way. The data and consent forms will be stored for 10 years after the completion of the study as required by the Ethics Committee.

While no specific consideration with Maori was required for this study the principles of the Treaty of Waitangi; partnership, protection and participation, informed all aspects of this research. 


\subsubsection{Rigour/validity strategy}

A combination of evaluation criteria feasibility and qualitative evaluative research criteria (credibility, dependability, confirmability, transferability, relevance and reflexivity) were used to ensure rigorous and valid findings (Patton, 2002). Participants were assured of the value of both negative and positive findings. Honest responses and critique were actively sought. Potential bias and context of the dual role of the researcher as health professional and the impact of the researcher being involved with the implementation of the programme participation were made transparent and are noted as limitations in the published study. Interviews were taped and transcribed verbatim. Following each interview, I listened to the taped interview again, to check my style, and whether I was questioning appropriately.

Interviewer interpretation was checked by a second analyst (the supervisor) to ensure consistency and allow audit. Interviewing the physiotherapist added a further perspective and metaposition (Malterud, 2001). Using questions informed by previous validated and reliable studies conducted by renowned researchers Courneya et al. (2011) and Adamsen et al. (2001) added to the credibility of this study.

The participant's interest in assisting the research process was clear. They had given much thought and consideration to what aspects of the programme worked and what they felt could be improved. One man had a written list in preparation for the interview. The high level of trust that had developed over the time of the programme allowed men to be critically reflective of the programme. It also led to some very personal disclosure throughout the interviews. I was cautious to ensure that the men were comfortable with my reporting of what they had said and there was no confusion or overlap between the nursing and the researcher role, that is, all they had told me was, was for the purposes of the evaluation and they were comfortable with the representation and reporting of what they had shared. Additional respondent validation of findings prior to publishing would have given further opportunity to check the accuracy of analyst's interpretation and reduce the possibility of misrepresentation (Richards \& Schwartz, 2002).

I was taken by surprise by the emotion of several of the men so long after their initial diagnosis when presented with what appeared to be non sensitive questions. I offered on several occasions to halt the interview. The men were keen to continue. I ensured 
they had opportunity to discuss the reasons for their emotions both at the time and following the interview. The men were clearly all keen to participate in this research, and reported a positive experience of the interview. Only one participant indicated that he felt the interview repetitive and was keen to refer to his written responses. The interviews all took longer that the allocated hour, the men appeared in no hurry to finish. One man expressed his gratitude, stating the interview had also given him an opportunity to process.

I found interviewing the men and the physiotherapist to be a very rich and privileged experience. The findings from these interviews are presented in the next chapter. 


\section{Chapter 5: Findings}

"The Critical ingredients of success" Arthur

\subsection{Introduction}

The 10 men who enrolled in the exercise programme along with the physiotherapist all consented to participate in the evaluation of the programme. This chapter introduces these men and the physiotherapist, presents their experience of the programme, outlines what worked for them, what fitted with their natural preferences and what they felt could be improved. In an effort to weave these dual perspectives without interruption, the physiotherapist is introduced first. The findings are then presented in two parts. I first present the findings regarding the men and who they were. I provide considerable detail in this section to draw out the character and maleness of these men, to provide a sense of what they considered important; what it meant to them to be male and what participation in exercise, particularly in relation to past sport, meant to them. Secondly the findings in relation to the programme are presented. The participant's experience of the specific core components of the programme are presented first, followed by the four themes which emerged throughout the interviews: 1) the importance of a safe, inclusive, programme, 2) camaraderie, competition and humour, 3) programme and purpose, and 4) the value of the programme. The chapter concludes with the participants' recommendations for enhancing the programme.

\subsection{Introducing the physiotherapist and her skill set}

Lucy's current practice was rehabilitative based and she had an obvious passion for her earlier work in oncology. She believed that the person delivering an exercise programme of this sort must; be an exercise professional, have a health background, and have worked previously with people with cancer. Her rationale was:

If you're coming from a gym- you give people an exercise programme and they get better and better and better and you work them harder and harder and harder...to achieve the goal...but I think you've got to have the experience to know that's not how it works and you might have people who ...despite what you do are not going to get better, or they might get worse or they might have those ups and downs and I think it's dealing with that. 
She stated the need for a "wide based knowledge of lots of conditions" identifying the importance of "good musculo-skeletal knowledge" and being able to offer expert advice. Moreover she stressed the importance of being able to "communicate appropriately with people who've got cancer" stating "that's the key thing...having the right approach."

Lucy expressed her belief in the worth of exercise and physical activity in rehabilitation generally; "There's not enough focus on getting better after an illness...generally in society... you become unwell and you are an unwell person", and even more so specifically for people with cancer:

you have treatment with awful side effects and you come out the other end, run through the mill and de-conditioned and I really believe that you don't have to stay like that... whatever stage of the journey ... [you can] be given help to pick up and recondition.

\subsection{Introducing the Men and their background and who they were}

The 10 men are referred to by their chosen pseudonyms, Albert, Arthur, Bob, Dargy, Fred, Gert, Jax, Mitchell, Roland, and William. In an effort to protect the men's identifiability amongst each other, these names are not used when presenting demographic details. The men were aged between 62 and 80, with a median age of 69. Though they were relatively homogenous in terms of age, they had marked differences in physical strength and ability. Two were extremely de-conditioned, each having had a weight-loss of 30 kilograms. The significance of biological versus chronological age became very apparent when the other men in the group mistook the age of one of the participants, nearing 70, as being in his 50 s.

Moreover, while the 10 men had all had a diagnosis of cancer, their cancer experience varied greatly as did other aspects of their life history. The men came from different educational and employment backgrounds. However, they had all been in positions of responsibility and leadership in their working life and were comfortable meeting and working with groups of other men. As illustrated in Table 2 although the majority of the men had reached retirement age, a percentage of them were still self-employed, seeking employment, or very busy in voluntary-type activity. Employment status and lifestyle, did however, allow each of these men the 
flexibility to attend a programme in the morning, which may not have been possible for other men or younger men in different employment settings.

Table 2: Demographics, ethnicity and employment history

\begin{tabular}{|l|l|l|l|l|}
\hline Participant & Age & Ethnicity & $\begin{array}{l}\text { Marital } \\
\text { status }\end{array}$ & Employment \\
\hline Participant 1 & 62 & NZ Maori & Married & $\begin{array}{l}\text { Sickness beneficiary } \\
\text { Ex army Vietnam } \\
\text { Engineer. IT }\end{array}$ \\
\hline Participant 2 & 62 & $\begin{array}{l}\text { NZ European- } \\
\text { born in Kenya }\end{array}$ & Married & $\begin{array}{l}\text { Seeking part time employment } \\
\text { Currently consultancy human } \\
\text { resource and voluntary work }\end{array}$ \\
\hline Participant 3 & 65 & NZ European & Married & $\begin{array}{l}\text { Self employed health } \\
\text { professional for 32 yrs }\end{array}$ \\
\hline Participant 4 & 67 & NZ European & Married & $\begin{array}{l}\text { Retired ex bridge builder } \\
\text { supervisor }\end{array}$ \\
\hline Participant 5 & 69 & NZ European & Female & $\begin{array}{l}\text { Self employed orchardist } \\
\text { management consultancy } \\
\text { ex territorial }\end{array}$ \\
\hline Participant 6 & 69 & NZ European & Married & Retired ex hotel manager \\
\hline Participant 7 & 72 & NZ European & Married & $\begin{array}{l}\text { Retired ex Bank manager } \\
\text { last role co-ordinating } \\
\text { apprenticeship programme }\end{array}$ \\
\hline Participant 8 & 76 & NZ European & Married & $\begin{array}{l}\text { Self employed saw milling } \\
\text { business 37 years }\end{array}$ \\
\hline Participant 9 & 79 & NZ European & Married & $\begin{array}{l}\text { Retired carpenter 3 yrs prior } \\
\text { current voluntary work } \\
\text { ex territorials }\end{array}$ \\
\hline Participant 10 & 80 & NZ European & Married & $\begin{array}{l}\text { Retired ex charge position } \\
\text { railways }\end{array}$ \\
\hline
\end{tabular}

Of note all of the men were married or in a long term relationship and all were in supportive relationships. The men referred to the support of their spouse or partner especially when they were very unwell. William spoke of his reliance on his wife: "I lean on her very heavily... when I got sick, she was my angel. If it wasn't for her, I don't know what would have happened." He spoke of the frustration that accompanied his limitations and the hurtful impact on his wife: $l$ was quite nasty to her a couple of times - I think it is just because of your health, and you say things that you never mean to say."

Another man referred to specific aspects of his wife's encouragement:

She's actually probably my mouth at the moment...organising everything which I find very, very caring... I wish I had her strength... 
She doesn't actually push me to do it or nag me to do. She says go along and enjoy yourself... that's the main thing having people behind you that network...Sometimes I wonder where she gets her strength from you know. (Dargy)

Whilst the majority of the men had lived in NZ for most of their life, one had spent a large part of his adult life in Australia. Some of the men had lived in different areas of NZ. One had travelled often spending six months overseas each year. They had been raised in a variety of rural and urban settings. All but one identified as NZ European. One was born in Kenya and had his education in England. The gentleman who identified as Maori acknowledged his multiple heritages:

I've got a mixture of blood on my father's side. Got Dalmatian, Scottish and Maori. On my mother's side got Irish and Maori... I still speak my mother tongue...so English and Maori and a bit of Dalmatian I can still understand.

\subsubsection{The men's health history}

The predominance of men with a diagnosis of prostate cancer was not surprising given that this is the most common cancer for men (Table 3). Of note, four of the men had a dual diagnosis of cancer. What the table does not capture is the variation in the stage of cancer diagnoses and differing prognoses.

All men had an understanding of what it was to experience ill health to varying degrees and shared the very real and powerful common bond of having had to face their mortality. Even the most robust of the men and least affected by his cancer diagnosis had experienced a life threatening septicaemia five years prior. Another spoke of having two cardiac arrests during and post surgery and a recovery that defied medical expectations. In the interviews two men became quite emotional when recollecting the time of diagnoses, and most identified that changes for them were physical, mental and emotional post-diagnosis.

For many the physical changes such as cancer-related fatigue, change in body image and bodily functions had been major. One man had ongoing difficulties with his stoma and another had continued bowel urgency and incontinence which limited his physical and social activities. Several men reported ongoing physical effects such as 
lack of stamina, loss of muscle tone and loss of balance and co-ordination. Those who were more limited physically reported a change in social activity. Their lives had become smaller, and they had lost confidence or interest in going out. One spoke of his depression, "Sometimes I got really down in the dumps and I was really thinking of committing suicide. I was going to go for a swim out to sea and just carry on - drown" while another spoke of the "despondence and uncertainty" that accompanied his diagnosis.

Table 3: The participants' diagnoses and treatment type

\begin{tabular}{|c|c|c|c|c|}
\hline Participant & $\begin{array}{l}\text { Cancer } \\
\text { diagnosis }\end{array}$ & $\begin{array}{c}\text { Time } \\
\text { since } \\
\text { Diagnosi } \\
\mathrm{S} \\
\end{array}$ & Type of treatment & $\begin{array}{l}\text { Current } \\
\text { treatment }\end{array}$ \\
\hline Participant 1 & $\begin{array}{l}\text { Neurofibro- } \\
\text { sarcoma } \\
\text { Primary } \\
\text { Lung with } \\
\text { bone } \\
\text { metastases } \\
\end{array}$ & $\begin{array}{l}30+ \\
\text { years } \\
12 \\
\text { months }\end{array}$ & $\begin{array}{l}\text { Surg-Chemo-Rad } \\
\text { Chemo } \\
\text { Radiation }\end{array}$ & $\begin{array}{l}\text { Current } \\
\text { Palliative } \\
\text { Chemo-Rad }\end{array}$ \\
\hline Participant 2 & Prostate & 3 years & Surgery & Surveillance \\
\hline Participant 3 & Colorectal & $\begin{array}{l}18 \\
\text { months }\end{array}$ & $\begin{array}{l}\text { Surgery } \\
\text { Concurrent chemo } \\
\text { radiation }\end{array}$ & $\begin{array}{l}\text { Completed } \\
\text { treatment } 6 \\
\text { months prior }\end{array}$ \\
\hline Participant 4 & $\begin{array}{l}\text { Prostate } \\
\text { Melanoma }\end{array}$ & 5 years & $\begin{array}{l}\text { Surgery- Hormone } \\
\text { Surgery }\end{array}$ & Current ADT \\
\hline Participant 5 & Prostate & 5 years & $\begin{array}{l}\text { Brachytherapy } \\
\text { seeds }\end{array}$ & Nil \\
\hline Participant 6 & Prostate & 10 years & $\begin{array}{l}\text { Surgery } \\
\text { ADT }\end{array}$ & Surveillance \\
\hline Participant 7 & $\begin{array}{l}\text { Melanoma } \\
\text { Oesophageal }\end{array}$ & $\begin{array}{l}10 \text { years } \\
5 \text { years }\end{array}$ & $\begin{array}{l}\text { Surgery } \\
\text { Chemo - surgery }\end{array}$ & $\begin{array}{l}\text { Ongoing } \\
\text { Ongoing F/U }\end{array}$ \\
\hline Participant 8 & $\begin{array}{l}\text { Prostate } \\
\text { Colorectal }\end{array}$ & $\begin{array}{l}5 \text { years } \\
4 \text { years }\end{array}$ & $\begin{array}{l}\text { Surgery } \\
\text { Surgery } \\
\text { Concurrent Chemo- } \\
\text { Radiation }\end{array}$ & $\begin{array}{l}\text { Ongoing F/U } \\
\text { Ongoing F/U }\end{array}$ \\
\hline Participant 9 & $\begin{array}{l}\text { Melanoma } \\
\text { with lung } \\
\text { metastases }\end{array}$ & $\begin{array}{l}10 \text { years } \\
5 \text { years }\end{array}$ & Surgery & Surveillance \\
\hline Participant 10 & Prostate & $10+$ & Surgery - Radiation & Surveillance \\
\hline
\end{tabular}

Overall fatigue was a major limiting factor and even those who were less physically affected and reported that life overall had changed very little, were surprised by the 
change post diagnosis. While Arthur had been prepared for the local impact of the surgery he was unprepared for the whole body effect of surgery and anaesthesia. "It took me ages to get going again... I felt quite knocked around, and I lost a lot of my general fitness." In addition, the effects of cancer were often compounded by preexisting conditions. Several of the men had other medical problems, most commonly cardiac and degenerative bony disease. Roland pointed out that some of his limitations were also age related as well; "I run out of breath a bit -but [oncologist] said that is $50 \%$ of age and 50\% of the tumour on the lung."

\subsubsection{Men, health and support}

While not asked specific questions about men and health, the men spoke during the interviews about male attitudes to health, referring to specifics of men's fit in the public persona of cancer. They offered valuable insights. Bob spoke of his family history of prostate cancer and his personal [pro-activity] in seeking medical assistance early and the need for an "intelligent aggressiveness as far as health is concerned." Mirroring the sentiments of several other men, he made comparisons between the publicity about female and male cancers stating that the "playing field" was "tilted very strongly in favour of women." He acknowledged "the girls have been smart, and they have got themselves organised, and they are probably better team players than the blokes are." He pointed out that while he was not "bitter or radical" about it, there is "damn all pushing for men to get checked for prostate cancer."

Using strong words in a deceptively calm and measured manner Bob asked whether there is enough funding and emphasis on men's health and prevention: "how many men are either being diagnosed or dying from prostate cancers compared with women? You know, is there enough emphasis being placed on the blokes?" Bob tempered his comments, acknowledging the reluctance of many men to see a doctor, "I just think it is culturally it seems not to be a bloke thing to." Albert and William pointed out that for men to seek advice or support they first must see the need; they must be "really, really crook." Jax had a different perspective, he referred to the ignorance of men about their cancer and the lack of information he had been given prior to his surgery. He pointed out that "It would save you a lot of mental anguish if you had more information... just to speak to someone - or if it was printed in a book." He asked; "Have you ever seen - I will get down to the nitty gritty - have you 
ever seen printed anywhere how a man feels after he has had his testicles removed? Have you ever seen it?"

In terms of support, Bob reflected back on his comment during the programme that this was the first opportunity he had had to talk with others with a diagnosis: "it was the interaction really... that underscored for me... for exercise - I am motivated in a group." Fred commented, "we're macho we're not supposed to need that are we', and went on to expand: “we've got to get rid of the image that we've got [about not talking]. He explained the difficulty for him: "because of the implications that it has... you think well do people really want to hear about your change in fortune... because it's just dealing with one of the bodily functions" and his resolve to make others "aware of it" by "trying to talk... bring it out into the open a bit more... So it's not the unspeakable."

\subsubsection{The men's social life and networks}

Engagement in the wider community ranged from very socially engaged to engagement primarily with family. Many of the men belonged to community or service groups and had been or were currently in leadership positions within their chosen club, group, sports and recreation. Three spoke of their church and the significance of their faith and two belonged to an environmental group. One man had attended Alcohol Anonymous for over 40 years. Many spoke about sports teams they had been involved in and spoke of being team players.

\subsubsection{The 'Kiwi Bloke'}

The men used many metaphors and labels that reflected their male perspectives. While Albert noted the diversity of NZ men, "I know... people live and study hard and they're really good kiwi blokes and other guys that are pig hunters... and they're good kiwi blokes so I don't think there's [one type of Kiwi bloke]", other's perceptions of the stereotypical 'kiwi bloke' showed through. Though disassociating himself from that image, Bob associated maleness with alcohol: "I am not a blokey sort - I never enjoyed going to the pub with the blokes."

The importance of being strong and manly for some was evident. Albert referred to having a "big engine" and his desire for muscles and strength when he was young. "I suppose I had the energy and weight training I like being strong and I suppose that's 
the male... I like big muscles." He spoke of the desire for going farther that accompanied that 'big engine': 'I've always had big boats, launches and the same old story of always fish over the horizon... always go further than everybody else, always fish in deeper water" and the changes for him now. He likened himself to a 'neutered dog' following his treatment with hormone manipulation treatment.

Jax, who spoke about his fear of becoming effeminate post orchidectomy summed up many of the unspoken societal values of being male in NZ. He spoke of the arrival of the first male great grandchild and shared the importance of the male carrying on the family name. Several of the men alluded to aspects of the competitive, territorial, male ego. It was the 'territorial pissing' that led Albert to leave his employment to travel to the jungle in Borneo three weeks later: "Oh, like a dog... on a post you know like this is my territory... and don't come over the boundary... I used to get a bit sick of it after a while and in the end... I lifted my head up and I thought do I really want to be here?" Jax also referred several times to the male ego and the competition that engendered pointing out; "what you have got to fight is the male ego because you always want to be better than the next joker; now it is a fact." However, this territorial, competitive aspect of being male did not preclude strong male friendships.

The men spoke of male friendships in three ways; male bonding through mateship, friendships made through sports or clubs, and in relationship and contrast to friendships females have with each other. Arthur referred to the quality not quantity of friends. He viewed having a small group of good friends as being typical of a male. He referred to having acquaintances he did things with and revealed that it was his wife's friends who would support him if anything should happen to her. In contrast, Jax referred to long standing "cobbers." For Jax, a cobber was someone he could go to "and say look, I am in trouble, I want \$10,000 and he would give that to me without asking what I wanted it for... And I have been lucky - I have had a few of those." Like many of the men, he referred to the companionship of others and friendships made through sport or clubs; "running has been my main thing really where I have made friends and spent a lot of time - and of course the motorbike groups which are phenomenal because you looked after one another." 
Dargy spoke of the bonding and continued support of the men he had served with in Vietnam. Roland who had also served in the army highlighted the strength and quality of that male bonding, making comparisons with the bonding between females; "men are more bonded together than women... Women are more inclined to stab each other in the back... whereas men can form, not relationships, but friendship and encourage each other... we are more inclined to help each other than [women]." Roland's interest and concern for others was born out in this expression of his philosophy; "people nowadays say, well mind your own business - but... it is just because you mind someone else's business that when anything happens, you are there to look after them." However, he was very clear that that did not translate to emotional expressions of concern. For him "sitting around in a group crying on each other's shoulders is not a man's thing. " He expressed his impatience with those who dwell on their aches and pains.

I just shake my head and think... for heaven's sake, get over it... We all have aches and pains at our age, but to sit and dwell on it... it is really, really very difficult to be polite.

\subsubsection{Sport, exercise and being male}

For the majority of these men, physical activity had been of significance in their lives prior to their cancer diagnosis, and several had shown promise as young boys and men in their chosen sports. They were proud to talk of the competitive level they had achieved. Mitchell's "best time for the mile and [being] third to Halberg was about four and a half minutes... I could break 5 minutes for the mile, by 30 seconds." Jax, who continued to run competitively in marathons into his 70s, spoke of his "natural bent" for running and his "competitive edge... I didn't like getting beaten." Sport was also significant to the men in other ways. William spoke about the role of sport in conversations; "when I really young, there were two things in the paper that I had to read - that was sports and business - then you can talk to anybody."

Rugby had great significance for most. Bob referred to rugby's place in NZ male culture during his youth; "There were 39 rugby teams in the boarding school - and you didn't get whacked for much at school, but if you missed rugby practice, you could guarantee [you would be]- it was more than a religion... it was part of our culture in those days." Most of the men had played rugby as young men, whether competitively or as part of the requirements at school. Dargy and Albert had both 
been in the $1^{\text {st }}$ IV at school and Albert had played in an international rugby tour. He spoke of the importance of having realised his goal of being alive to see the Rugby World Cup in New Zealand in 2011.

While the men all expressed their beliefs in the benefit of exercise, their exercise histories varied from those who ran marathons and pushed themselves to the limit in their chosen sport or activity, to those who referred to physical activity as "working in the backyard" and enjoying sports which did not require strenuous activity such as "car-rallying." All viewed exercise as more than sporting activity and gym attendance and referred to its multiple benefits. Elaborating on this William reflected on the part exercise had played in his life.

Well I used to run a lot, swim a lot, I used to go to the gyms a lot-we used to bike ride a lot between the two of us... compete against each other. So that kept me going and I really miss that - because it was a release... sometimes in work you have so many problems that you try and figure which way to go, so a lot of the time I would put on my gear, go for a run or go to the gym and take it out at the gym or take it out on my run - and I would come back, have a clean brain and I know what I wanted to do.

Without exception the men spoke of the usefulness of exercise using words such as "absolutely," "incredible," "excellent," stating that to them exercise "is most important" and a "critical part of enjoying a healthy life." Most stated their enjoyment; "always loved exercise," and "I loved the physicality." Albert, who spoke openly about a difficult period in his life: "Exercise changed my life...I think it can change people's lives... If it can change mine it can change anybody's." Even those less involved in structured sport considered that everyone needs exercise.

The men gave different reasons for their belief in the benefits of exercise. Bob believed he could "function better". He enjoyed the feeling of "a good strong workout... the endorphins come back and I feel good... even when I work physically on the property, or putting in posts for a fence or something like that - I always feel better when I have been active." Others too spoke of the feeling of well-being that accompanied exercise. Albert described it as "it made me feel, you know...like 
strong, and freedom, and movement." William associated exercise with the image of youth and keeping the body in shape and working.

Arthur made a very strong link between exercise and stress management which he once taught. He shared a very personal account of his experience of exercise helping him cope with a traumatic time in his life by giving structure and measurable targets:

The love of my life was killed in a motor accident. She had introduced me to the gym and we would go together... when she died, I found the gym was really important to me... it gave me a target, I had to get up for it - at half past six I had to be there, and I had to do so much stuff which was measurable, and it gave me something during that stage to cling onto, to set some targets... getting me up, getting me going, something to do, something to achieve.

\section{Barriers and enablers to exercise}

Despite the men's overwhelming agreement that exercise was useful and enjoyable and had many benefits, there were many barriers to exercise for this group. Preexisting medical conditions, tiredness, reduced physical strength and ability were common barriers to exercise as were concerns about the safety of certain physical activities. Lack of motivation and time were also barriers, the men stating that work, visitors and phones often interrupted opportunities for regular exercise. Jax identified "mental laziness" as a barrier. Several of the men referred to the need for appropriately geared exercises.

The hope that exercise might improve his cancer related health was a major encouragement for Roland. Two of the men identified the motivation of companionship, Bob stating he would enjoy the gym more if more men attended and spousal support and encouragement from their partner to exercise and in some cases participate together was cited by several of the men as a major enabler. Arthur had bought a dog for the express purpose of giving him a reason to walk.

Many of the men referred to the structure and shape of exercise. Arthur spoke of the preference for exercise that had "a purpose." Albert's preference was for a familiar safe space. For him the routine of exercising in the morning was very important. This preference for morning exercise was shared by the majority of the men. Even those 
whose major sport had been an individual sport such as yachting or fishing, stated they enjoyed exercising with others even if on their own, within a group setting. While not strictly a preference, the social aspect of sport and exercise was referred to as something that made exercise more enjoyable.

Given this background the men had much to say about the programme.

\subsection{Findings related to the Programme}

This section is divided into two parts; the specifics of the programme and the experiences / themes that emerged during the analysis. These are summarised in Figure 10.

\subsubsection{Specific components of the programme}

The men gave detailed answers to each of the questions regarding the different aspects of the programme. These are outlined in this section in the following order: entry to the programme, information session, attendance, timing space and place, resources, circuit work relaxation, and qualifications and gender of the facilitators.

\section{Entry to the programme: Access, Criteria, Credibility and Curiosity}

There were varied reasons given for interest in and entry to the programme. All of the men without exception referred to being attracted to the specific nature of a group programme for men who had had cancer. The majority also referred to the programme's credibility and easy accessibility.

While the newspaper article had clearly attracted men to the programme who had not been previously engaged with the Cancer Society, they could not recall exactly what it was about the article that caught their interest. Bob who saw the newspaper article said: "I met the criteria that was the first thing... I'm a cancer recoverer, it was for men, it was about exercise and it was a group. It ticked all the boxes. Ping... On the phone." Jax who was also attracted by the newspaper article, referred to the programme being specifically for men with cancer and that there was "no pressure, no demands made... I just thought it'd be beneficial both physically and mentally." For Mitchell, it was the venue (the Cancer Society office) that indicated to him that he would receive "some specialist attention here and direction." 


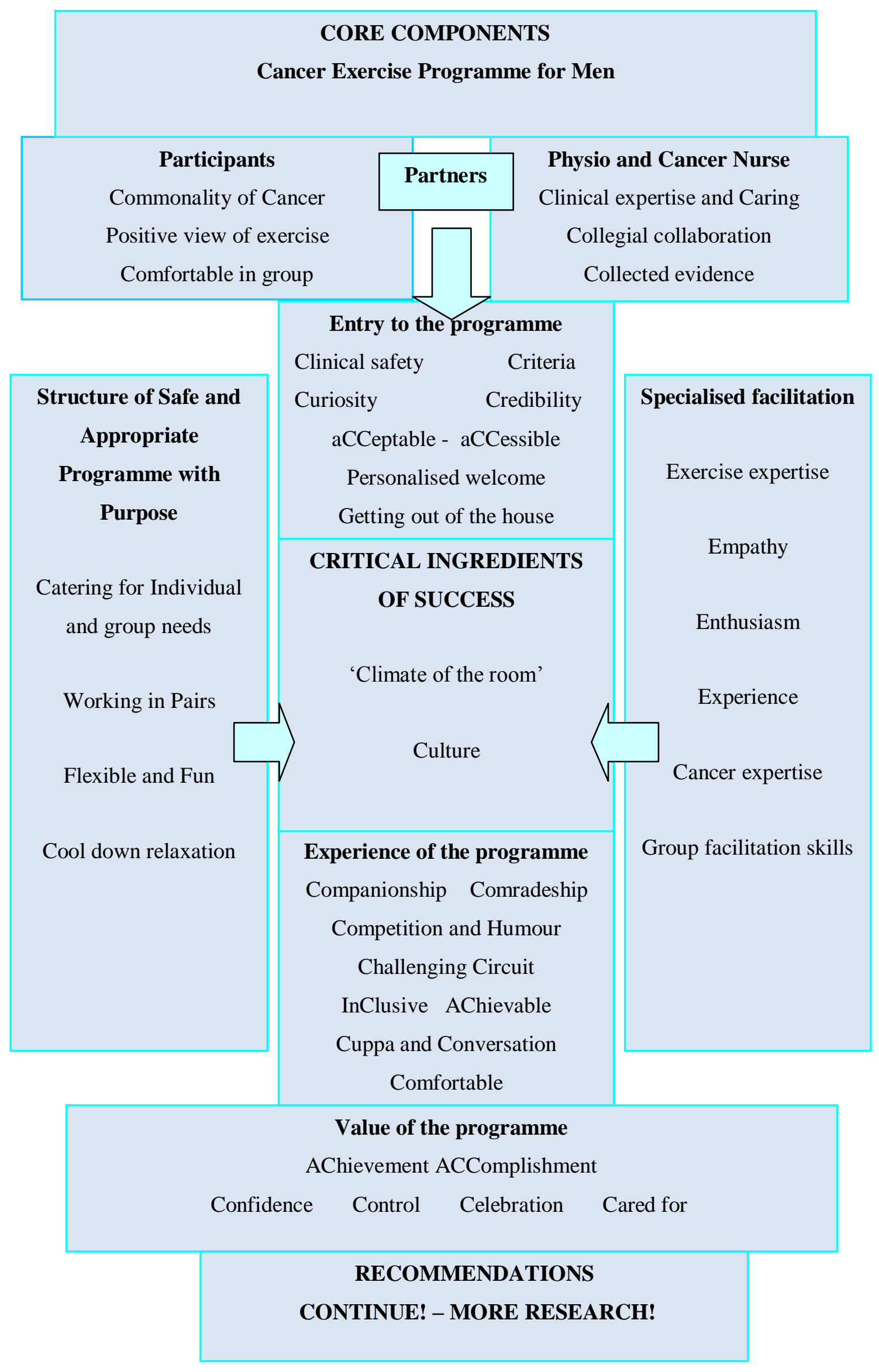

Figure 10: Core components of the Cancer Exercise Programme for Men 
For those already familiar with the Cancer Society (CS), a personal invitation to participate was a crucial factor. Arthur's response mirrored that of others: "you approaching me and offering me this was very easy to say... I am into this... If I hadn't been a member, I don't know...because I am naturally fairly reticent."

He also talked about the importance of timing and readiness:

For part of my career I was a trainer and I'm very aware that the impact of training on people is about zilch until they're ready to receive it... It is quite useful for me to look back and in some ways I could almost say I was a soft touch... the timing was great.

The novelty aspect of participating in a new programme held some attraction. Dargy was curious "to see what was there, what type of programme." Roland too, referred to the programme being "something different", to give both direction and motivation. Three of the men acknowledged their interest in aiding the research process. Arthur stated, "I strongly believed in what you were doing; the fact that you had done your reading, there was a bit of research, and I wanted to be part of that and support that." There was a sense that the men felt privileged to have the opportunity. Fred considered he "was extremely lucky to be asked... to participate to... help get me off the couch... get me out... meet some other people with a similar diagnosis."

The notion of getting out of the house, and being with other men who had had a diagnosis of cancer was a recurring theme throughout the interviews. Gert shared " $I$ knew that I had to start doing something rather than just sitting around on the computer all day." Fred too referred to "help post recovery" pointing out that, "some men might feel a wee bit bogged down...just staying around home... something like this just gets them out, involved in the community a bit more as well."

Being part of a group setting held major appeal for all. Albert pointed out, "If you said come down here and do it on your own it wouldn't have worked." Many of the men referred to being comfortable in groups and meeting and mixing with new people as enablers to joining the programme. The knowledge that the exercises would be specifically tailored for the group and individualised for each participant so that they would be safe and achievable was a powerful enabler for most. Gert referred to the fact that "the exercises were going to be designed around the types of 
guys that were there, and the cancers they had had [and] we weren't going to be doing anything that was going to be too dramatic."

The physiotherapist's observation reinforced this. For Lucy what had enabled the men was:

There's no excluding criteria, that allows a lot of people to participate that basically wouldn't be able to participate in other community groups,... we have been very encouraging and just allowed anyone to come and just do what you can... and played down the whole difficulty, that's been a big enabler.

Entry to the programme was also enabled by practical factors such as the participant's ability to be flexible with their time. While transport and travel to the programme was noted as a potential barrier, the men affected by distance and inability to drive overcame these barriers. One combined his trips to town to get things for the orchard with the exercise class. Another initially took a bus from his home to the office and a fellow participant was able to bring him to following sessions.

\section{Information session}

Nine of the men attended the information session two weeks prior to the commencement of the programme and while the express purpose of this information session for the first programme was to explain the research and recruitment process, the men recommended continuation of the information session in further programmes. They stated it gave them the opportunity to ask and have questions answered; it was "handled intelligently" (Bob). Credibility was again a critical factor. Jax spoke of the opportunity to make an assessment of the expertise of the facilitators and the importance for him of the initial personalized welcome: "you go along and see who you are dealing with, don't you? You can't be bothered wasting your time." He felt the "presentation was "critical... because you got the feeling of how it was going to go."

Furthermore some of the men spoke of the opportunity to assess not only their 'fit' with the programme and the facilitators but also with the other men. 
if we had of come in blindly, you wouldn't have known any other people... you could have felt that if I can't do this, the others are going to go "ha, ha, ha." (Roland)

The physiotherapist also noted the importance of the information morning in giving the men "reassurance that there were other people similar to them" and a "a get out clause" if they felt they needed one.

Some of the men felt that demonstration and participation in the circuit could be integrated into information sessions for future programmes, while others acknowledged the importance of a session prior to the programme for the facilitators to establish what people could do. For the physiotherapist meeting the men at the information morning was invaluable; it provided an opportunity to assess potential participants and enabled her to tailor the programme to the group's needs.

I had the circuit pretty much planned...I did change a few things because I had seen them and met some of them... I added a few more levels into some of the exercises to give people the opportunity to... really downgrade if they decided they needed to. (Lucy)

With respect to the consent process introduced at the information session which gave the nurse permission to talk to the specialist or GP about the ability of the individual concerned, Gert noted an additional advantage: "it involves them...I have since...thanked him very much for letting me partake...let him know it has been very worthwhile, to keep him thinking, [it is] a good idea." Others though not seeking consent, informed their doctors. Two men however expressed that they would have found having to gain consent from their GP or specialist, a barrier to entry to the programme. Jax stated again the importance for him of it being "laid back" and easy; "it wasn't regimented. I know we are in a situation of PC all the time now. If I had to go and get permission off my GP, I don't know whether I would have bothered." Albert used stronger words, for him having to gain permission from his GP, would have been "nanny state."

\section{Attendance}

Overall attendance was very regular (Table 4). The men who missed sessions spoke about their disappointment about not being able to attend. They felt they "had let the side down" but respected the health of their fellow participants, "I was going to go 
and [wife] said, no, you have got to be thinking of other people, no good giving them the flu." Many identified a sense of commitment and the importance of routine attendance to them. Fred, who had attended all six sessions, expressed his disappointment at not being able to attend the first follow up monthly session: "I was heartbroken...I was quite looking forward to catching up again particularly after a month of not seeing the folks.

Table 4 Attendance during the programme

\begin{tabular}{|l|c|l|}
\hline WEEK & No. attending & Reasons for not attending \\
\hline Week 1 & 10 & N/A \\
\hline Week 2 & 7 & $\begin{array}{l}2 \text { men had cold. } \\
1 \text { had prearranged engagement }\end{array}$ \\
\hline Week 3 & 10 & N/A \\
\hline Week 4 & 9 & 1 man had cold \\
\hline Week 5 & 6 & $\begin{array}{l}1 \text { man had cold } \\
1 \text { man had prearranged business trip } \\
1 \text { man had burst hot water cylinder } \\
1 \text { man had visitors }\end{array}$ \\
\hline Week 6 & & 1 man had funeral to attend \\
\hline One month f/u & 9 & 1 man prior engagement \\
\hline Two month f/u & 6 & $\begin{array}{l}2 \text { men other commitments } \\
1 \text { man unwell } \\
1 \text { man not comfortable with venue }\end{array}$ \\
& &
\end{tabular}

Lucy believed two elements contributed to the men's regular ongoing attendance: "the attitude of the whole thing, very positive and very warm ... there wasn't really a focus on fitness."

\section{Circuit work- challenging- companionship- competition- confidence}

The men referred to the circuit being well thought through with flexibility for men at different stages. It provided a whole body workout: "from the head down to your toes regardless which way you go through the circuit" (Dargy). For Albert "It was challenging, it was varied... it was increased over the sessions that we had and then there was a little change in it and we had a good relaxing session after it." Many of the men were surprised at the challenging nature of the deceptively simple looking exercises. Dargy referred to the confidence building aspect of the circuit:

The exercises were...put there to look easy and make you feel confident that you can do it and at the same time gain strength or confidence I think. That's the word, confidence. Not strength but confident in 
yourself I think... it was more difficult than it looked... I had to eat my words.

Lucy had planned exercises to work on different parts of the body, "the variety of exercise worked quite well... It wasn't too taxing on one part of the body that meant people could achieve the circuits and manage all the circuits." Lucy noted that all of the men mastered the technique and was surprised by the level of improvement for all over the six weeks.

The men agreed the circuit was individualised for different levels of ability. you didn't get sick of one exercise and there was always a lot of hilarity in between times which was really good, and if some of the chaps couldn't do that particular exercise, well it didn't really matter because all the others were doing their thing, and I know quite often me and my partner couldn't do some of the things, it didn't really matter, and everyone was busy doing their thing. (Roland)

Arthur acknowledged the challenge of meeting these differing needs and applauded Lucy's "sensitivity" in balancing a programme for both ends of the spectrum. However while the purpose of the programme for him was "to learn exercises" he pointed out that those who could "go harder" also needed to be catered for.

Even those who had already been exercising at home stated they felt a benefit from these different exercises. For Albert this included gaining "the strength in my legs [I had] had trouble getting out of the car... and then all of a sudden with this, the squats and sit ups [I could do it]."

\section{Specifics of time, timing and exercise log}

All found allocation of time for the overall session, circuit and relaxation and two minutes each station of the circuit appropriate, though some stated they couldn't keep that up at home. The men were unanimous in their choice of morning as most preferred time of day to exercise, with the majority recommending an earlier start time for the programme. Reasons cited were tiredness and fatigue as the day progressed and the need for routine. While most indicated that they would have 
appreciated the opportunity for specialised assistance with exercise earlier, they all acknowledged that there was no one time that was right for all.

Exercising between sessions varied greatly. The men reported varying usage of the exercise sheet. Some felt having a sheet to fill in during the programme increased motivation though for most this dropped off after the programme finished. Albert continued for a time even when on holiday. Roland has his sheet pinned up at home. Some of the men expressed their disappointment that the sheet was not checked by physiotherapist or the nurse while others felt it was a personal tool.

\section{Space and place}

Albert spoke of the preference for a familiar safe space and all reported their satisfaction with the venue. Many of the men commented that the size was appropriate for numbers. The small size was seen to have enhanced the overall atmosphere and promoted social interaction. Roland echoed this view, "A smaller area is more sociable - you put that group in a big hall, and you feel like a pack of twits." Lucy agreed there were advantages of the small but comfortable space with " $a$ non threatening, non medical sort of feel" and that it would "have been very different in a hospital or private gym with lots of equipment." She felt the friendly homely feel promoted "the idea that you can take the exercise... home. You don't need a flash gym [or] a clinical box ...you can do exercises anywhere." In terms of monitoring the men safely, Lucy advised no more than 10-12 in a group.

\section{Simple, inexpensive and transferable resources}

The majority of the men stated that they appreciated that the resources were simple inexpensive and transferable to their home environment. For example at home Gert used "cans of spaghetti - they are not as heavy as the dumb bells but... the resources can be minimal from that point of view." Arthur spoke of the simplicity of the resources enabling him to see the transfer of these exercises to home:

It was like it was operating in my lounge at home, with equipment that I have got at home, so... the chances of my taking it up here and doing it at home... were probably maximised... what caught my imagination was at long last here is an excellent insight into some exercises I can do at home. 
Bob pointed out that the simple equipment maximised the transferability to other venues: "most of the stuff that was there would fit in the back of [physiotherapist's] vehicle - so it means you can mount the programme pretty much anywhere."

Fred thought he might have found machines daunting while others identified the potential of exercise equipment to increase competition and highlight difference and set the competitive macho mentality up to overdo it.

The problem with machines is that you have somebody beside you working on a machine, especially if you are in a gym and you look down and see them lifting eight bars... I am going to try and lift eight bars, so you just about pull your guts out. (William)

Arthur pointed out that some of men's fascination with exercise equipment was with: pricing gym gear... and having to go home to say to the wife we need one of these. The interesting thing is I did go and buy some weights, proper weights, I couldn't handle cans of beans." He acknowledged "that a lot of men, certainly when they are retired and older...which is what a lot of your cancer patients are...don't actually have too much spare cash to spend on flash gear." The only piece of equipment the men recommended was an exercycle. From the physiotherapist's perspective the absence of machines and equipment minimised the risk of injury.

\section{Relaxation session}

Overall the men appreciated an opportunity to wind down after the strenuous exercise of two circuits. Fred spoke of the relaxation session feeling strange initially but "in a good way." He went on to express his ultimate trust in the physiotherapist expertise and judgment. "I was putty in [physiotherapist]'s hands... it's probably a good thing [for] our older bodies to wind down after the exercise." Roland concurred saying "after half an hour or three quarters of an hour doing these silly little exercises, you were completely stuffed, and so then when [physiotherapist] comes in with the relaxation, you go - thank goodness, and yeah, it was really good."

Three of the men had previous experience with meditation and relaxation techniques and two were very comfortable with the introduction of the seated relaxation. Darcy was more unsure and initially wondered if there might be some underpinning philosophy. He had seen meditation and relaxation practiced in Asia. He spoke of his 
initial wariness: "That came as a shock to be honest. I thought the first time ... What are we into? We've got to hold hands... I thought we're in one of these guru surroundings." While he recognised the purpose of the relaxation within the programme he gave a reason for his caution "I'd done different types of interrogation of the mind [in the army]." Over time he grew to appreciate the session; "The purpose of it was to, to unwind... I've got to really, really commend the course for it... it made you think at the end."

Jax who had also been sceptical initially was taken by surprise by the effect of the relaxation; "you could feel yourself relaxing and you had to stop yourself going to sleep." He went on to adopt it as a regular practice:

I was most impressed... although I haven't kept up with my exercises, I remember that relaxing... I often sit in a chair and do it - and it works... that is one thing I have carried on with.

Lucy expressed real surprise at the men's enjoyment and participation in the more advanced relaxation: "it was far more beneficial than doing the stretches... it was a real learning curve for me." Her experience of teaching relaxation techniques was based more on physiological than meditative underpinnings: "if you contract a muscle naturally it will relax naturally... that's what I have been using with some deep breathing which I've learnt from respiratory."

\section{Shaping of the programme - “cuppa”, oranges and the whistle}

The men appreciated the opportunity to help shape the programme as it progressed.

I was conscious the whole time that you and [physiotherapist] were...like little sponges. You were soaking up the feedback, it was obvious...that you were listening, you were looking for nuances... what can we do to make this better? I appreciated that. (Bob)

Roland who suggested the addition of the cup of tea or coffee following the circuit and relaxation saw it as an opportunity to "celebrate what they had achieved together. " Introduced on the third session, it quickly became an essential part of the programme. All but one of the men referred to the worth of talking together over the cup of tea or coffee at the end of the sessions: "it got people closer just being able to 
relax over a bit of a light snack and a drink."(Fred). For William "sitting around talking to people and having a cup of tea was worth a million dollars."

Peripherals such as the whistle, oranges and music added to the colour and fun of the workout and symbolised a sports team culture.

Oranges were really important - very symbolic ... for men who are brought up in a culture of half time, oranges, exercises - it is all part of that culture of sweat, exercise, something good, and there is a bonding...I was intrigued actually at the impact of the oranges, and also really nice to have something with a bit of taste - just that refreshing. (Arthur)

The men referred to the direction of and fun associated with the whistle. Lucy made the observation: "I've kind of played up the hard taskmaster bit because I think they quite like that and I have my whistle and I do it really loud...come on everyone get going and I think that's really necessary."

\section{Qualifications and gender of the professionals}

While most of the men stated they were not concerned with whether the facilitators were men or women, they identified empathy and understanding as essential qualities. There was a sense that the men may have found male facilitators a little threatening; a "smart alec" or "drill sergeant." Gert pointed out that "women tend to have more of a maternal type instinct than what men do..., more empathetic if you like." Roland felt that "the whole group responded to [physiotherapist] because she was a female, she was young... our granddaughters were the same age, so you had a paternal feeling towards her."

Many of the men highlighted the importance of both the facilitator's genuine and caring attitudes, some citing these as contributing to their continued attendance. Arthur listed personal characteristics he saw as essential for the different roles, stating that for the nurse, "I would say extroverted...you could take the piss out of us and we could take the piss out of you - which allowed the group to grow."

He viewed empathy and understanding about cancer as essential for the physiotherapist: "they have to have some knowledge, understanding of what cancer does to people." Others too referred to personal characteristics they valued: the 
physiotherapist was really bubbly and, and effervescent and you know just really passionate about the programme... She took an interest in everybody's case. (Fred). The men valued the clear directions Lucy gave: "She wasn't wishy-washy she was very direct and that was good too." (Albert)

Lucy felt that in addition to the men coming to exercise, "they've come to be... looked after as well and I think they wanted to feel that they were being cared for." She felt being "female you instantly have that ability to be that person" and that "for a man especially... with illness related issues...it's easier to call a female aside."

\subsubsection{Themes}

As the men shared their experience of the programme, it became clear that there were several themes running throughout the interviews; 1) the importance of a safe, appropriate and inclusive programme, 2) the common ground of having cancer and the camaraderie and the motivation of good humoured competition and fun within a "like minded, like diagnosed" group, 3) programme and purpose, and 4) the value of the programme.

\section{Structure + Specialised Facilitation $=$ Safe inclusive programme}

All of the men spoke of the importance of the structure that comprised of appropriately geared exercises which were challenging yet had the flexibility to cater for the varying levels of the group. One of the concerns for the men, who were less well, was how much they were able do safely. The sense of safety that the specialised facilitation brought to the group increased the men's confidence in themselves, each other and the two facilitators. The reassurance of having an exercise specialist with knowledge of the effects of cancer and treatments allowed the men to push themselves within safe boundaries knowing that the physiotherapist would gauge the appropriate level of activity and pull them back if necessary. Dargy highlighted the vulnerability of his condition and the very real concerns he had;

I was a little bit concerned about my hip my lungs. I kept thinking about any bleeding, that's what I was concerned about which never did [happen]... I think that's always been behind me... pushing to the boundary but knowing there's a safety factor too. 
The men spoke of their comfort to go at their own pace and to the level of their ability, and stop without feeling embarrassed; while at same time having the motivation of the physiotherapist's whistle. Gert pointed out that the physiotherapist's parameters and direction reduced the male macho inclination to push too hard and gave permission to stop; "the macho thing is always there... if this is designed around and sold... as being... we are not here to break records, we are here to give you some benefit and a bit more quality in your life, that is ideal." Bob recognised the need for a professional who a) could hold men at safe appropriate levels of exercise "you don't want too challenging to the stage that they are going down with cardiac problems" and b) explain the rationale: "it is pretty important whoever is running the programme, has the professionalism to be able to explain to people why."

Albert was clearly pleasantly surprised by the level of difficulty of the exercises; "I found it was quite challenging... I thought that it would be a bit fairy-ish ... a bit like fairies... like elderly guys with cancer. And it wasn't the case at all." Though Fred was "a bit apprehensive to begin with" he felt the "thought that [physiotherapist] had put into the various exercises" had met the goal of tailoring to specific and personal needs. He compared this with his previous experience of the gym, "at the gym they had me doing some exercises which I felt...why am I doing this. But those that [physiotherapist] gave us seemed... that they were tending to be beneficial."

Lucy was mindful of the potential issues for the participants and attempted to tailor the circuit in a way that catered for specific problems such as bowel or bladder incontinence, without making a focus of assessing and drawing attention to specifics: "The squats and lower limb exercises are really difficult if you have got stress incontinence... if they were leaking I didn't want it to be an issue for them." While a more specific and in depth assessment prior to the programme may have been useful, Lucy was aware of the potential embarrassment of singling men out: "it would have been awful to have pulled someone aside and say you might want to...contract your pelvic floor before you do this exercise." She instead tailored the programme in a general way that would be beneficial for the men with incontinence or bladder and bowel control, without making it obvious: 
abdominal exercises... can help people with their control... I didn't want that to be an open theme but I would hope that some of the men with those issues have found that some of the abdominal exercises possibly helped.

There were no adverse events. While the majority of the men stated that the programme had not posed any specific issues, one man felt that he "was going to black out" when lying on the floor for the relaxation and another experienced some difficulties with his stoma that precluded him carrying out one of the exercises. Another had been concerned that he may experience some difficulty with bowel urgency but was relieved to find that was not the case. Arthur had no such problems but felt the relationship with the programme staff was such that "if I... had incontinence or some impediment, it would have been easy to have approached you or [physiotherapist] and say hey listen ...I can't do this one."

While not originally intended in the initial design of the programme, space constraints meant that the men had to work in pairs. Lucy observed that working in pairs made for more inclusive group: "forcing them to pair up it... pulled those people who tend to be outsiders into the group...it worked really nicely everyone went round together." She acknowledged that trying to force the men to change partners wouldn't have worked and that they naturally found a partner they felt comfortable to work with.

While safety was the first priority and Lucy ensured she corrected incorrect technique, she was very careful not to single anyone out in an embarrassing way. She took care to ensure she gave direction to all: I got quite pernickety about exercise technique...Some of them needed a lot more help and I just decided to let them run with it as long as they were safe."

The men referred often to the importance of being comfortable; both physically and emotionally. Bob spoke about a physically "comfortable place, but it doesn't have to be flash, something where I don't sort of rip the skin off my knees on the floor." Others referred to the informal friendly atmosphere of the setting. Arthur attributed this in part to the 'the context and the atmosphere-having curtains as opposed to concrete blocks. Some noted the importance of having kitchen and toilet facilities. Bob also referred to a room where he could get changed. Albert referred to the 
comfort of familiar and neutral territory. "I feel comfortable within the garage and I feel comfortable here. I suppose its known territory... it might sound a bit flippant but I just can't be bothered going down to somebody's place that I don't know." $\mathrm{He}$ described what the word comfortable meant to him; "enjoyment and... known and peaceful."

The men referred to the belonging/kinship comfort of being with others who had cancer. Dargy commented "Everybody had the same type of illness... I felt comfortable in there [rather] than going to the gym. The gym is more to be seen I think." Lucy pointed out that: private gyms are often about wellness and being super fit and being super healthy... it would be very difficult for these people to go into that kind of environment."

All spoke in warm, positive terms about their engagement with the physiotherapist and the researcher/nurse. They spoke of the combination of clinical safety and caring the programme staff provided. They enjoyed the banter and fun and referred to the importance of a genuine and warm personalised welcome. The men also referred to the and credibility and comfort professional and specialised facilitation brought: "I think that credibility of the person running it, and the [physiotherapist] exudes credibility" (Arthur).

having [a] professional... it was because of her being there and having chosen the exercises that I was comfortable with it... she knew what she was talking about... and that gave you comfort. (Gert)

They referred to the different but complementary roles of the physiotherapist and nurse; " [ physiotherapist] is there to push us, you are there to nurture - you knowto make sure that physically it is okay" (Arthur). While several of the men acknowledged the programme could be facilitated by one person, they all stated their preference for having both a physiotherapist and a cancer nurse present and identified the reassurance that brought, particularly for those whose health was more fragile.

If it had been just in a hall somewhere, with just a physio and something had gone wrong, it could have been quite different because they wouldn't have known what was happening... it was good having 
you there. It was just that sort of reassurance, safety net if you like. (Gert)

Just as the men spoke well of the programme staff, Lucy spoke fondly of her relationship with the men in the group. She referred to the reciprocity between the men and herself and how having a group of men who "all got on well together" in turn, enabled an easy relationship and rapport between all. She attributed the more relaxed group dynamic to the specific "personalities in this group... It wasn't the usual kind of professional clean...you are the client and I am the physiotherapist kind of relationship." The group dynamics allowed her "to be a little more relaxed and a bit more cheeky."

Lucy spoke of the nurturing role of the nurse. She considered the nurse;

was really just looking after everybody and brought that softness to it...we're here to exercise but it's okay that you're not well and...that you might feel a bit emotional about this and it's okay that this might bring up... different emotional feelings...just having you there and...being female allowed that to happen a lot more.

She emphasised the importance of the nurse's experience and current clinical knowledge and the communication and facilitation aspects that the nurse was able to bring to the group.

It's essential to have someone who is there that's currently working within that area... we could have had people in here who did have complications... Being able to facilitate a group and bring people together and subtly control certain dynamics...you're very good at...if things are getting a bit out of hand time wise or people are hanging around too much or, or a conversation's going in a certain direction ....at guiding or pulling back... it's a very necessary skill. (Lucy)

She referred to the enjoyment of working as a team that worked together well; "for the men to see that we get on and work well together and we can have like little bits of banter between us you know in front of them I think has really, really helped as well." In her view the combination of physiotherapist and cancer nurse provided "the total package." 


\section{Camaraderie, Competition and Humour}

While the importance of a safe, inclusive and professionally facilitated programme with the flexibility to meet the needs of a variety of men, was referred to as vital, so too was the comradeship and companionship within a "like minded, like diagnosed" group. The common ground of having cancer connected the men despite their very real differences: "we were all from ...different commercial backgrounds, right but... we have had this jolly cancer" (Gert). The men referred to the motivation of the group. This encompassed good humoured competition in an encouraging mutually supportive group that respected and understood each other's limitations.

The men recognised and understood the real difficulties for some in carrying out some of these exercises. There also seemed to be a reassurance and comfort for the men that others too had some challenges. The men reported mutual encouragement within the group and a respect for the efforts of those who found things more difficult. William demonstrated the support and mutual understanding of the embarrassing realities of exercise and some cancers: "I mean there was one guy there who had a bag and broke wind...he got embarrassed, and I said, no good getting embarrassed mate, I said I could have it next time!"

Working in pairs gave the men the opportunity to bond and get to know each other on an individual level and the opportunity to encourage each other. Some made comparisons to sports teams and camaraderie of army life. Dargy explained the confidence building effect of the mutual encouragement within the group:

I found the group lifts your ability, your confidence and also it's fun. You're helping one another. You're not trying to push one another to the limit...you are pushing them to feel confident... that is the difference I think if you say to someone come on do it mate he's going to say oh nah but if you say to him we'll help you he's going to do it.

He spoke with respect of the strength and determination the older men exhibited in giving their 100 percent.

In the sharing of life stories men discovered commonalities unrelated to their cancer. The opportunity to talk amongst each other, though not the focus of the exercise group added to the social companionship and camaraderie of the group: "the buddy camaraderie thing before and after rather than just walk in the door, do the 
exercises, and out the door and go home - that is important." Roland also spoke of the importance of sitting and having a chat beforehand: "That is a man thing...You sit down and talk a whole lot of... politics and sport and all that sort of carry on - it is quite important."

While there was an acknowledgement that all the men attending the group had had a diagnosis, there was no expectation or pressure to discuss their cancer. However, because it was known from the start that all had cancer, there was an ease for those who did want to talk about their illness.

You can talk more freely... when you go to someone who is disgustingly healthy and you say, "Oh I have a tumour on my lung” and they go "oh yeah, that is tough luck mate" but the other participants will say "oh what is happening and how long have you had it?" and they will talk about it. [Roland]

From a social perspective, William pointed out that for him it was easier to talk in a group, I think we were talking, there was a big group, it wasn't one on one...I found it easier because we had bigger conversations to talk about." For him finding commonalities with the others helped the conversations: "I knew the people...that he knew. " For those whose lives had become smaller and dominated in many ways by their cancer, these conversations broadened their horizons.

Humour, enjoyment and positivity added to the focus on achieving. Without exception the men spoke of the fun and good humour; it always starts off with a bit of comedy of you know joke or something (Dargy) which often accompanied competition within the group; everybody would sort of help everybody... and... there was a bit of inter rivalry going, a bit of competition (Fred). Many of the men referred to the mutual good natured ribbing with others in the group. It was likened to that associated with past sport and extended to interactions with the physiotherapist:

When I was on the stepper, I said to whoever it was, we'll see how good she is...I said she talks so much I am sure she is not looking at her clock! And as soon as the two minutes came up, I yelled out two minutes and she blew the whistle - so that was a good bit of fun. (William) 
All referred to the very positive group culture; several of the men commenting on the fact that no-one complained about others. Dargy spoke of the inclusive encouragement from a group that came "from all walks of life" and "all ages: They didn't look down at you, they all encouraged you each one to do it, and the uplifting nature of the group; "everybody came in and had a good laugh so the exercise also picked you up mentally... If you were down you went in and just talking to one another... it lifted you up." He identified the benefit of "that group therapy it does help and especially... quarter of an hour with just talking to or mingling with the group before we started." Even Arthur who spoke of being self contained and reticent "really valued the social contact... having that repartee and the humour, yeah." Jax stated "Well I suppose we all feed off one another a bit."

Overall here was real sense of group cohesion with team needs of the greater group taking precedent over individual needs. While there was clearly an element of goodnatured rivalry and competition between the men, this was tempered by the awareness of others limitations and a pride in helping and encouraging each other, and an inclusiveness and respect for the attempts of others: "nobody took the Mickey out of you, you each one encouraged and I found that they were honest about it." (Dargy).

Arthur attributed much of the success of the good social process of the group to the planning and the culture or "climate of the room";

everything was right for that group; you set up the location, the facilitators and the individuals concerned, all came together, and formed a healthy functioning group that completed task but also had very good social process... we all actually got on together - and I think it is about the climate of the room and you and [physiotherapist].

Lucy emphasised the connection with and between the participants as "far, far bigger than I ever imagined... you know everyone got on well together, the chat was a really important part of it all, almost as important as the exercise." She believed this connection had helped her deliver a better programme: "because you know how much you can get away with... you know the kind of comments you can make and how you can look at bringing the group together a bit more and bringing some humour into it." 
But while the men became a cohesive group for the life of the programme there was no expectation that the social connection would continue or progress outside of the setting. When asked if he had had contact with the men following the programme Roland looked surprised and said "I think that would be taking it a bit far."

\section{Programme and Purpose}

The word purpose was used throughout the interviews in three ways; in respect to 1) the purpose of the programme, 2) a programme with purpose; and 3) as a programme that gives purpose.

\section{The purpose of the programme:}

We have all been there together to one extent or another, and we have a common objective, and that was to get ourselves a bit more fit than we were before, and feel good about it. (Bob)

It was clear that the men attending the programme had an overall wish to improve or maintain physical ability and function. While the men's realities and goals varied ranging from "getting back up to speed or back on track again" (Bob) to an improvement in balance and flexibility, overall the men held the view that there was indeed a need for a programmes for men with the express purpose of optimising physical health. Mitchell referred to the gap in follow up post treatment; "Well I thought there was a gap there that obviously... you know yourself... there was a need for follow-up."

Lucy was emphatic about the need for a physical activity programme specifically for men:

I don't think you'd get as much as openness from the men and women would probably dominate conversations and that would be detrimental to the men. I also think that with the gender differences men would feel embarrassed about having physical difficulties in front of women potentially...And I think... physicality is essential...[what] being a man is all about...it's really not accepted for men to be weaker and unable to do things I think. Again that's the key to this really isn't it? That it's just the men. 
Though not an open theme, this comment from Bill reinforced Lucy's view: "some women get upset as they don't like doing exercises in front of men - but then men get upset because they can't do the exercises that women can."

\section{Programme with a clear purpose}

"Any group process has to have a very clear purpose." (Arthur)

While acknowledging the significance of the social aspect of the exercise programme a very clear distinction was made between the primary purpose of providing an exercise opportunity and the provision of emotional support. The men appreciated the programme's stated intent, that of introducing men to exercise and its benefits. Arthur referred to is as "a no-nonsense job actually... the purpose is clear, we are here to do two circuits." He stressed the importance of purposeful facilitation; [physiotherapist] kept us fully occupied and I think that is really important-because give us enough freedom and some of us would be off skiving... but we were focussed and I think that is really important to the success.

Two of the men attended the Men's support group regularly and spoke of the benefit of being able to speak openly about their concerns.

You can say what you want. That you wouldn't say at home...the exercise thing was really good... it was just a camaraderie thing things that some of them have talked about at men's support group that they just wouldn't talk about if their wives were there - or even if they were just with buddies at the hotel-they talk about and get off their chest that they can't get off their chest at any other time. (Gert)

However, it was clear that whilst both the support group and the exercise group offered companionship and support, the format, purpose and acceptability of the groups differed vastly. For some the idea of a group where the express purpose was to talk and share specifics about their cancer felt uncomfortable. Not only was talking seen as an issue, hearing the stories of other men who were more unwell was spoken of as heavy and depressing. While the men spoke of the social aspect of the exercise programme its primary purpose was clear: 
Well the group exercise is a, (how can I put this?) is a reason for being there rather than going to talk about all your ills and aches and pains; the exercise is the reason that you are there to mix and meet these people socially... those other groups are specifically there just to talk about their aches and pains...I couldn't handle that - but we are there doing these exercises and enjoying ourselves, and we are getting fit in the process or we are helped to get fit, the social part comes in as a secondary enjoyment or pleasure (Roland)

Lucy noted the function of the programme in shifting the focus from ill-health: coming to do something... provides a wonderful distraction from ever having to mention their diagnosis or talk about anything that they've been through.

\section{Programme gives purpose}

“When you can't do anything, you lose your sense of adding value whether it is to a business you are working for, or around the house" (Gert)

Many alluded to how the programme had improved their sense of well-being, and achievement. Doing something positive gave the men a sense of satisfaction, confidence, control and pride; "Well the glow... lasts all day... you think well I have done all that exercise this morning" (Jax). For Gert;

being able to go along as a group like that and partake in the exercise programme and do the exercises, and achieve it, you have got this different attitude - I can do things - and I can carry on doing things.

\section{Value of the programme}

All of the men shared a very positive experience of the programme, "it was very good", "very helpful", "excellent actually', "it suited me personally." While for some there were specific aspects of the programme such as exercise or the individualised advice that was paramount, many of the men alluded to the combined aspects of the programme as being part of the greater whole.

The way that you combined the whole lot together was part and parcel of it, you know it is like having... a meal of... there is your meat, there is your cabbage over there and there is your potato - you take it in turns 
eating it-it wouldn't mean a thing: but when you put them all together,

you have a lovely meal, you know - a good mix. (Roland)

Although Arthur was very clear that the programme must keep its clear purpose of being an exercise as opposed to a support group, he appreciated all aspects of the programme stating: "all those components knitted together. I don't think you could take one away."

For all, the programme had some advantage towards making them feel better about their situation. For some it was the relativity of being with others "worse off". Jax stated the programme made his situation "more tenable" pointing out:

We all know that we are not going to beat it.... it is not so much the situation that you find yourself in ...it is the way you handle it which is the big thing and that exercise group certainly helps you handle cancer.

Many spoke of the 'feel good' factor when doing the exercise, and 'feeling good' about having done it and the positive nature of having done something to help the situation:

When you have quite a bit of negativity in your life, anything that is possible is really helpful and beneficial any little thing you can do is positive. (Jax)

Some even referred to a spiritual aspect, one reflecting on "healing at a soul level actually" (Arthur). The value was personal in relation to the men's individual heath and fragility. Some stated that while their strength and stamina had not increased as they may have wished, their balance and flexibility had improved. All of the men stated they had improved in some way over the six weeks. Lucy confirmed this with her observations. One man whose treatment was becoming increasingly palliative over the period of the programme stated; "I achieved all I wanted to achieve through that exercise ... physically, mentally and spiritually" (Dargy).

\subsection{Recommendations for improvements}

The recommendations that were made were primarily logistical and are covered in the order of the set up of the programme beginning with recruitment and entry, the circuit exercises, the relaxation, the refreshments, group, facilities, future programmes and cost. The men felt there was no one ideal time to offer assistance with exercise, and would depend on the individual's health status. While some of 
those who had faced and experienced aggressive chemo radiation stated they did not think they would have been able to exercise at that time most felt it would be valuable to offer at the outset:

when you get that pack of stuff after you have had your treatment... at the time when everyone's world has been turned upside down... that would be a bit like a hand rung - to grab hold of... because it brings with the suggestion that there is an upside at the end, and it is worth working for it - to me, that would be quite powerful. (Bob)

The majority stated that a referral or recommendation by a health professional or specialist would attract them and others suggested fliers and brochures added into information packs given out at diagnosis. Lucy too, identified health professional referral as the key to attracting men to further exercise programmes and suggested referral packs for consultants containing generalised advertising about the programme. In her view the ideal would be for the consultants to have the opportunity to come along and see what they were referring to.

The men recommended the information morning continue in future programmes and from Lucy's perspective this would give more opportunity to carry out individual assessments between the information morning and commencing the programme. While Lucy's preference would be for square space where she could monitor the men more easily, preferably with open doors to a deck where men could do their stepping outside on a good day her only preference for more equipment was a greater selection of weights but voiced her concern about potentially creating an unhelpful focus on "visible markers" of physical difference. She returned to the importance of not setting up a programme that highlights deficits or emphasises others strengths:

I think some of the men here would have immediately gone for those the heavier weights. And I think some of the men would not have been able to manage it and possibly felt bad about it.

The majority of the men stated they would like to begin earlier in the morning. Nine felt that the provision of morning tea and opportunities pre and post the hour long programme, for men to connect were very important but recommended a structured time limit so that they did not feel rude leaving. The man who did not stay for the social interaction stated he found that support at the men's group. However he 
enjoyed the interaction with the other men whilst exercising with them. Overall the men enjoyed the refreshments and most felt that they would be happy to contribute.

Lucy had offered to vary the circuit during the programme. The men had differing views regarding the importance of variety and change. All of the men valued the information and explanation about the exercises and some recommended even more. Gert advised numbering the order of the circuit in future while Arthur felt it would be helpful to be given more information about the purpose of each exercise: "I suspect when she introduced new exercises, we weren't sure how they related to the otherswere they substitutes?" He felt that understanding more clearly "about the purpose of each exercise, or why we are doing this exercise and that you are actually not just there just to do exercise, but to build muscle tone" could enable to transfer to home. Several of the men also recommended that the facilitators could check the exercise diaries weekly. Even those who felt the sheet was more of a personal motivator acknowledged that they would have responded to some recognition of what they had achieved throughout the week.

In terms of content Lucy warned against following fads and trends such as "yoga, pilates, boot camp, and fitness challenges... I just don't like it." In her view men were after exercises that were "real and basic nothing faddish." She emphasised the point, "I think that we have got to tailor it... the approach was good in that we had different exercises for different body parts which you can incorporate lots of different exercises. But I think they have to be real and basic exercise." In her view, men "like to really throw a lot of extra energy into an exercise" and "feel the burn": She used the same term as Albert had: "Nothing too airy fairy." Lucy reflected thoughtfully on what she might change in future programmes; "I would possibly change some of the floor work exercises... the elderly participants struggled with just getting on and off the floor."

Overall the men were happy with the seated relaxation but identified that a clearer explanation about the purpose of the relaxation session would have been helpful. Arthur pointed out that whilst with his background of meditation he was comfortable, "there were some pretty blokeish comments... the first time around." Bob recommended an explanation that focused on the physiology of muscle stiffness and recovery. Dargy suggested explanation prior so that men are not taken by surprise: 
"making people aware of it. You know not be shocked at the end like." On the other hand Gert had found Lucy's explanation of the physiology of relaxation more than adequate:

[Physiotherapist] would talk about this group of muscles, and then when you do it, you realise there is a group of muscles and if you do something different, that group of muscles on the other side of your leg come into play... the thing that really impressed me - was the mechanical aspect of the whole thing.

The men pointed out, that groups for specific cancers would exclude men with rare diagnoses and preferred the current inclusive approach. While some wondered if younger men might struggle with a widely varied age, most agreed the success of a group was more dependent on not having too widely varied levels of ability. Furthermore Roland felt quite strongly it was most important to keep the same group of men throughout the programme; "if you start dribbling people in halfway through, they don't belong'. He likened the group to a platoon of soldiers:

If they go into battle and some of them get shot and killed and they bring in replacements, those replacements are considered outsiders because they are not part of that little group - the family, the whanau! Arthur agreed that for group process it was important to keep the same group: "we became very comfortable with each other... when those guys didn't front up... there was a hole in the room... with a couple of extra people, it would have felt quite strange." While Fred felt that a fluctuating group would be acceptable and allow more men to participate, he wondered about the logistics: "it would probably be quite difficult to try and organise I suppose."

There was no charge for this programme. Though the men did not refer to that directly as an enabler, several made reference to the financial constraints that accompanied a diagnosis. Fred felt there should be financial assistance to enable men to attend programmes called for equity for men and women stating; "I would like to think that there could be a subsidy available to help support the men's exercise... But if it's for men it needs to be for women and vice versa as well."

With respect to the ideal length of the programme overall men stated they would have liked the programme to 'continue indefinitely' with "more of the same' and that 
it might be ideal in future to filter participants into an ongoing patient led walking group. All agreed they would recommend the programme to others with the proviso by one of the most enthusiastic of the participants who after thinking for a while stated that it would be dependent on that person's readiness. Perhaps the most telling feedback was the request for ongoing follow up sessions.

Overall the men too appeared to enjoy the experience of the interview; Arthur was very clear that for him the interview had been of benefit:

Today's process has certainly helped...reminded me... about how useful exercise is for me after trauma... the opportunity to reflect...actually has helped me process some stuff... I have appreciated the opportunity to review.

Fred expressed his desire to see the research make a difference for men.

\subsection{Critical ingredients of success}

In concluding his interview Arthur summed up what were for him the critical ingredients of success of this programme.

For me...the skills of you and [physiotherapist]... The physio to me has to have an understanding... about cancer and the impacts of cancer on people, and understanding of how men work, but also I think an understanding of group process - because that was what that was about largely... it is about setting up a safe space for it to happen - and safe to be who we are because I think we were all who we were.

As Lucy's interview ended she reflected on aspects of the programme that surprised her. She was clearly surprised by how accepting all the men were of each other and by the social support. She was also very surprised by how hard the men "worked and how physically able they were...some of them... who looked very de-conditioned obviously has still got the ability to really work quite hard." She noticed more improvement than she had expected to see: "by the last couple everyone was just getting on with it and they were doing really, really well."

But the major discovery and surprise for Lucy would not have been apparent had the men not requested monthly follow up sessions. We had just returned from facilitating the second month follow up when I interviewed her. Her disappointment was 
palpable as she talked about the men's drop off in exercise without the motivation of the group and the weekly sessions, and the resulting decline in ability and fitness.

Even though everyone loved the group, they loved coming to the group, they loved the exercising they loved it and it still wasn't enough to go home and think I'll walk around the block a bit more or I'll do these exercises... I've been pulled back a bit... I was probably a bit unrealistic in thinking I could inspire all 10 participants to go off and do more exercise outside of this group... I can see now that people really do need a lot more of a push than I thought...and a lot of them were self starters. A lot of them have had that background but it just goes to show that ... a prod to get them started really isn't enough... I didn't want that to be the outcome for your study either. I wanted the study to show that people will go on and exercise. But I think it just brings another interesting dynamic out.

She reflected on how these men might be able to be supported to continue with exercise with a more structured follow up group and concluded the interview with her observations: "So there's got to be I think a lot more thought around that...Probably a lot more research into what happens next!."

The significance and meanings of these findings will be discussed in the following chapter. 


\section{Chapter 6: Discussion and Conclusion}

\subsection{Introduction}

The aims of this study were to explore the experiences of stakeholders (men and physiotherapist) who participated in a newly introduced exercise programme specially designed for men who had had a diagnosis of cancer. The process evaluation was designed to investigate the men's preferences for exercise, and identify factors essential to the ongoing design and delivery of acceptable, accessible and appropriate exercise programmes for men. It was also intended that the research would contribute to knowledge about the provision of exercise programmes for men with a diagnosis of cancer generally and would assist the CSNZ in extending its health promotion and support for men. This chapter commences with an overview of the main evaluation findings. It then proceeds to discuss these findings in relation to other studies and lightly touches on men's preferences in relationship to masculinities. The third section presents my reflections on the limitations and strengths of this evaluation. The chapter concludes with implications for practice, policy and education within the NZ context, and recommendations for further research.

\subsection{Overview of findings}

The findings of this study give valuable insights into the accessibility and acceptability of the exercise programme from the unique perspective of the 10 men, and the observations of the physiotherapist providing the service. The findings are significant because to date there are no reported studies of evaluations of an exercise programme for men with any type of cancer. In recounting their experience of the programme, the men stressed the importance of the safety and inclusiveness of the structure and facilitation of the programme, and the comradeship, humour and motivation of the group. While their diagnosis of cancer was the common factor that brought these men together the focus and purpose of the programme was towards a positive improvement of their situations. The programme provided a sense of achievement, control and hope.

Overall the men reported a very positive experience and satisfaction with the programme demonstrated by their regular attendance and request for ongoing follow 
up sessions. Enablers for entry to the programme included intrinsic factors such as the men's own personal motivation to "get out of the house" and "give it a go" and extrinsic factors; the credibility and accessibility of the programme, and contextual factors; seeking specialised assistance with exercise in a safe environment, to improve their current situations. These factors helped participants to overcome some of the barriers to exercise they had identified, such as lack of companionship, motivation, fatigue and physical limitations, safety concerns and competing interests.

The men were not required to have pre-existing fitness levels. The programme was suitable for all fitness levels and ages demonstrated by the ability of even the most de-conditioned men to participate and achieve. All identified the importance of a safe inclusive programme and space. They found the exercises challenging and appropriately geared with the flexibility to cater for the varying levels of the group, allowing each man to achieve and push himself within safe boundaries. All of the men were also comfortable mixing with others and attracted to the thought of exercising in a group. They all shared a pre-existing positive attitude to exercise reporting belief in the multiple benefits of exercise and a belief that it could help. The majority of these men enjoyed physical activity.

While the design and many of the findings in this evaluation parallel and support those of the Comrades in Arms study by Adamsen et al. (2001) which looked at a combined physical activity and psycho-education programme for men, they also provide new insights in relation to features of a programme that are important and what men valued about participating in the programme. The four key findings that are discussed are; the physical and emotional safety of the programme, the belonging and inclusion of the programme which provides for group and individual needs, the acceptability of the purpose and structure of the programme and, the value of the programme.

\subsection{Safe, inclusive programme: Physical and Emotional safety}

The importance of the physical safety aspect of the programme was clearly demonstrated in this evaluation and corresponds with findings from both Adamsen et al. (2001) and Segal at al. (2009), who found the men in their studies were attracted by the security of training in a safe and specialised venue. Other studies of mixed sex exercise programmes for those with CRF (Blaney et al., 2010); colorectal patients 
recently completed treatment (Spence, Heesch, \& Brown, 2011) and patients currently undergoing chemotherapy (McGrath, Joske, \& Bouwman, 2010) also found the choice of a specialised venue provided reassurance to the participants. While the Cancer Society venue was not a medical or hospital facility it suggested specialised care to the participants in this evaluation.

\section{Safety aspects of the programme}

No adverse effects of the programme were observed by the physiotherapist or reported by any of the men. Thus the safety of the programme corresponded with previous studies which found moderate aerobic and resistance exercise monitored programmes safe even in those with advanced cancer and age (ACSM, 2010; NCCN, 2012). The majority of the men appreciated the support of their GP and Oncologist to join the programme. It was interesting to note that two of those who had written a waiver, had nevertheless gone on to discuss with their GP, not in terms of seeking permission but to inform the doctor about what they were trying to do to improve their situation. The positive reinforcement of their decision to participate in the programme appeared to give the men even greater confidence in its worth. The majority of the men felt it was critical to have the support and backing of the medical fraternity not only in terms of their participation but in referring others to the programme.

\section{Safety of specialised facilitation}

Having a professionally led, supervised programme also attracted the men and gave confidence to those who were unsure of the safety of exercise in respect to the limitations associated with their diagnosis. Concerns about safety and exercise for those with a cancer diagnosis have been identified in other studies and specialised facilitation shown to be key to the success across many exercise group studies not only those concerning men (Adamsen et al., 2001) but also in mixed sex studies (Blaney et al., 2010; Spence et al., 2011; Stevinson \& Fox, 2006) and studies investigating the uptake and benefits of exercise in those receiving palliative care (Oeschle et al., 2011; Oldervoll et al., 2005).

The men referred to safety associated with the clinical expertise of a physiotherapist who could gauge the suitability of exercises and the physical safety net of having a cancer nurse present while they were exercising. However, clinical expertise was 
only one aspect of the facilitation the men in this evaluation valued. They stressed the importance of the warm welcome and personalised interest in each individual; the balance of clinical expertise with a genuine empathic attitude and the creation of safe inclusive atmosphere. This aspect of facilitation indicates that providing for emotional safety is also important in developing the programme.

Little is known about men who have had a diagnosis of cancer preferences for female versus male facilitators of programmes and one of the questions we had when commencing the programme was whether facilitation by two females might be offputting. An important finding of this study was that female facilitation did not deter uptake of or entry and ongoing attendance to the programme. While the men did not discount male facilitation they emphasised any facilitator needed to be empathetic, understanding and someone they could feel comfortable to voice their limitations and concerns with.

This empathy and understanding was seen to deliver a deeper holistic care by the man who referred to the soul level of healing. While many referred to the mental and social benefits and a feeling of being cared for, the reference to a spiritual aspect of the programme by two of the men was unexpected. Faull and Hill (2006) who explored spirituality as a health determinant in chronic disease identify relationship, connectedness, meaning and hope as some of the essential components of spirituality. The mutual support given and received by these men is an expression of this very determinant.

One of the men linked the relaxation to his sense of spiritual care. While the relaxation was not meditative in nature perhaps the element of the time to reflect had an impact. Relaxation is not something one would expect to sit within the masculine script and the physiotherapist was careful to introduce it gradually and at an appropriate level. The acceptance of this component of the session perhaps initially had more to do with the trust in the facilitators and their strong references to its efficacy in previous research. The men's interest in and recommendation for even more information and explanation of the mechanics of both the exercises and relaxation supports the findings of Seale (2005) and Sherman et al. (2007) who highlight men's quest for information. 
The men valued the structure of a supervised group based programme with an individualised approach and found it added to the inclusiveness of the programme. Much consideration was given into how this could be achieved. While Blaney et al. (2010) identified both supervised group programmes and individualised exercises as motivators for exercise for those with CRF they acknowledged the difficulty of providing both simultaneously. The findings of this evaluation suggest that running a group exercise approach and accommodating individual need is about having a class size (approximately 10) that is small enough to provide personalised attention and advice. The types of exercises offered also minimised difference and created an inclusive atmosphere.

The focus was on each man's potential and success, their achievement and ability to do, and be there, rather than on difference or deficits which may have been highlighted at a public gym. Despite the widely diverse fitness capabilities there was not a sense amongst the group that they were different from/less than. This was due in part 1) to the participants; the nature of who they were and the common bond of having cancer that they shared, 2) the structure of the programme, and 3) the facilitation and culture of the group. The physiotherapist was mindful of anything that might highlight difference as shown in her focus on technique over repetitions. A large part of the nurse's group facilitation role was to create a safe inclusive atmosphere. Moreover the inclusive nature of the group reflected the personalities of the men who though very diverse and from different backgrounds came with a positive purpose and a common goal.

Aspects of these findings resonate with those of Adamsen et al. (2001) who found that the male only forum and safe inclusive atmosphere created by the facilitators allowed the men to be themselves and to feel normal. However, the specific aspects of a programme design that facilitates this individualisation within a group are not widely reported. Stevinson and Fox (2008) though demonstrating the inclusive nature of a circuit programme that is small in size found a low uptake of the mixed sex exercise group that was the subject of their evaluation despite referral from Oncologists. They attributed this low uptake to the poor understanding of the benefits of exercise. Blaney et al. (2010) refer to the potential embarrassment and discomfort of mixed sex groups. Perhaps the comparatively high uptake of our programme to that in Stevinson and Fox's study was in part due to it being exclusively for males. 
Furthermore while the men in my evaluation recommended referral from health professionals they also recognised the importance of timing and readiness. The men's self selection to our programme reflected their readiness to participate.

\subsection{Camaraderie: Humour- Competition- Conversation}

The dominant theme of camaraderie and companionship within this 'like minded, like diagnosed' group ran throughout all the interviews. The men were unanimous in their feedback about the value of belonging and exercising in a group with others whose goal was to do something positive about their situation. The importance of mutuality, encouragement, support and a sense of belonging was clear in this evaluation and the companionship or comradeship appeared to be almost more of a focus than the physical aspect and outcome, to some in the programme.

Humour and good-natured competition was an integral feature of the group. The competition within the group increased motivation and the fun filled atmosphere and mutual encouragement provided a positive supportive atmosphere where the men felt at ease with each other. Of significance is the impact and the "bonding' and humour that surrounded the introduction of group traditions; half time oranges, and the whistle, both symbols and reference to past sports. The introduction of the celebratory "cuppa" created an atmosphere conducive for male conversation.

There were other implicit comparisons made to sport and team; the men referring to "letting the side down" when they were unable to attend. The men were very almost unanimous about their preference for a closed versus open group with one man likening the "belonging" in the group to the bonding of a platoon of soldiers. The closed group may well have added to and enabled a stronger sense of team within the group. Emerging studies are demonstrating the impact of team and sport in motivating exercise for those with cancer (Carter et al., 2010; McGowan et al., 2012) and while a circuit programme differs in many ways to a sports team there were many aspects of sport that sat within the programme, the competition and the training together. This sense of team was reflected by the comment of the Consultant who attended our presentation about the programme at the psychosocial forum and referred to the men co-presenting as a "team of winners". 
The comparisons made to camaraderie of army life in this evaluation mirror those made by the men in Adamsen et al. (2001). Good natured humour too was found to be an essential core element by Adamsen et al. where the "The men laughed with each other as opposed to at each other" (p. 531). The significance of this good natured ribbing and the sense of belonging and participating resonates with Lashlie's (2005) observations about the importance for men of humour and belonging to something bigger.

The men emphasised the importance of being comfortable with each other, with the facilitators and comfortable and safe to be themselves. The significance of "being comfortable" underscores the need to recognise and understand what created this comfort. Several factors appeared to promote the emotional comfort; the 'togetherness' and 'belonging'.

Though not explicit in the interviews the notion of the men's acceptance of each other without judgement ran between the lines. The men came as they were; there was no pressure for them to be anything other than what they were. There were no specific entry criteria and no requirement for gym gear. The physical environment was comfortable. The non-threatening neutral space and leadership from inclusive facilitators minimised the potential for jockeying for dominance amongst the men. Working in pairs in a relatively small space though initially viewed as a constraint, was seen by several of the men to promote togetherness and connectedness. Though not wanting to interpret beyond the men's meanings, there appeared throughout the interviews in this evaluation to be a kinship that accompanied not only the shared understanding of having had a diagnosis of cancer but of living with its effects.

\subsection{Acceptability of the Programme and its Purpose}

Both the purpose and structure of this programme proved to be acceptable for the men in this study, offering both exercise and a sense of support. The acceptance of a programme with a stated purpose of increasing strength and fitness and its accompanying implicit notion of increasing control is not unexpected in the light of the findings of O'Brien et al. (2005) who identified that men were more likely to seek help for behaviours that fit the masculine script. Furthermore the exercise aspect of the programme corresponded with the action orientated preferences of men. What emerged through the evaluation was that while not the declared focus or intentional 
purpose of the activity, working around the circuit in pairs within a group in a small intimate space enhanced the opportunity for conversation, support and mutual reciprocity. It gave opportunity for the men to share with and encourage other men in the team in a natural unforced way as they worked together. Adamsen et al. (2001) refer to those dynamics within their study as "an action orientated togetherness, whereby doing something as a group is the medium, while being together is the aim" (p. 532). Likewise in this evaluation the 'togetherness' resulted from the shared activity of 'doing' the exercises.

The support and encouragement given and received with its accompanying light hearted and good natured banter appeared be more acceptable to many of the men than the support that is offered within a support group with its focus on sharing stories and intimate details of the emotional and physical impacts of cancer and treatments. These findings supports those of Adamsen et al. (2001) and Sherman et al. (2007) and the view offered by Oliffe and Thorne (2007) that men are more comfortable to demonstrate rapport and connection by humour and joking with each other, shared activity, and solving problems together. Bischoping (1993) points out the differences between men and women's conversations and the importance of these conversations. The men alluded to this several times in the interviews. They found to speak often about 'stereotypically male subjects, work, sport cars and politics. They also had the commonality of the exercises they were doing, to discuss.

The men did not push for information about the other's cancers showing a respect for the social mores and comfort of others when it came to personal disclosure. Their interest and enjoyment in meeting others and learning a little of each others' lives was evident and appeared to broaden the horizons of those whose lives had become more isolated. Exercising together provided a way of sharing without forcing disclosure. Though the cancer had brought them together it was not the focus of the group. This corresponds with findings from Mitgaard et al. (2006) where the "purposeful togetherness" of participating in the exercise programme overshadowed the focus on ill-health allowing it to "fade into the background."

While the men shared their stories it was accompanied by the doing something positive, that may sit well with the male cultural scripts of independence, control, stoicism and achievement (Cecil et al., 2008). There was a very tangible, respect and 
admiration for each others' efforts, and for those who were more unwell a pride in still being able to do something to help their current situation. The opportunity for the men who were not so well and often in the position of being helped; to support and help others, may also have been significant.

The promotion of this programme was also found to be acceptable to men. The 10 men who registered interest in this programme not previously familiar with Cancer Society services were attracted by a newspaper article titled Cancer Exercise Course Kicks Off. Although this article was unmistakably what had attracted those five men and a further five who went on the waiting list for the next program, four of the men during their interview could not identify what it was about the initial article that attracted them. While I did not have this newspaper article with me in the interviews during data collection analysis I went back to the article to see what it was that may have attracted them. We hoped to learn from this evaluation ways that attract men to the programme and make it accessible to those not already part of the service.

The language used in the article may have appealed to men. The introduction; "a new exercise programme thought to be a first in New Zealand is said to help men as they fight back at cancer" program which "kicks off'. Reference is made to the facilitators' clinical expertise and background and the evidence and research behind the programme which may have appealed to men's wish for evidence and information. The article also referred to the programme being "suitable for any fitness level, designed to allow men to push themselves when they can and ease off when they need. " This may have been a critical enabler for men unsure about what level of exercise they could safely do. Further enquiry into the language and images that will reach and recruit NZ men with a diagnosis of cancer is required.

\subsection{Value of the programme: Achievement- Control- Cared for}

The finding that the men reported an increased sense of well being, confidence and a sense of achievement is similar to those of Adamsen et al. (2001). In addition, the men in this study also shared the feel good factor following exercise and feeling good about having done the exercise. All of the men irrespective of pre existing fitness were left with a sense of achievement from the man who was already fit to the very de-conditioned, who reported improved balance and though no increased stamina the sense that they could do it "and keep on doing things." This resonated 
strongly with references in Adamsen et al. who reported increased well-being and bodily awareness, associated largely for some of the men who were more unwell, with the sense of achievement and "I can do this."

With there is little other research aside from Adamsen et al. (2001) regarding cancer exercise programmes for men it is of interest to note the many psychosocial benefits outlined in the recent Australian study by McGrath et al. (2010) who interviewed both male and female participants of the Chemo club, a gym specifically geared for cancer patients. As with our study the non judgemental support, normalisation of the cancer experience and social support offered by this programme, cultivated a positive attitude, a sense of meaning and control while providing a level of physical rehabilitation.

Our exercise programme was always about providing a service for men. While comparisons were made about the difference in funding, support and publicity about men and women's cancers and the previous gap in follow up care was noted, all of the men expressed their appreciation of a programme specifically for them. Some were visibly moved by the care they had received from the physiotherapist and nurse.

While the predominance of participants in an older age bracket might be viewed as weakness of this study, I propose it adds to its strength and utility. Greater numbers of men in this age group are diagnosed in proportion to younger men and projections indicate the numbers of men with cancer in and beyond this age group will increase (MOH, 2012). Furthermore many studies have demonstrated that older men are less likely to exercise than younger men and require more support to do so (Keogh \& Jones, 2011). While not specifically about men, a review by Courneya and Karvinen (2007) highlights that while older adults with cancer benefit from exercise, they are often underserved. This evaluation demonstrated the utility of the programme in meeting the needs of this age group. It also highlighted the significance of assessing biological over chronological age in terms of entry criteria.

Likewise this evaluation demonstrated the programme's ability to cater for men who were at differing stages including those in the palliative stage. Rehabilitation in palliative care is not a new concept. Dame Cecily Saunders expounded the need to enable the person receiving palliative care "to perform to the limit of his physical and 
mental capacity with control and independence whenever possible" (Jennings, 2012). Rosenberg and Yates (2010) elaborate on this notion highlighting the congruence in the seemingly unlikely connection between health promotion and palliative care. Lowe, Watanabe, Baracos, and Courneya, 2010 identify that palliative patients wish to participate in exercise programmes and constantly emerging studies outline the benefits (Oechsle et al, (2011) and Oldervoll et al. (2005) when exercises are tailored appropriately and programmes are monitored well.

While the programme catered for a wide range of men with differing age and stages of cancer and the structure of the programme was specifically tailored to meet both group and individual needs, potential challenges were identified. Though the men reported it was successful in achieving that goal, the tension and challenge in providing a programme that fits many diverse needs was alluded to by the physiotherapist and one of the participants. There was a sense that this group was at the limits of difference. Though the design offered differing levels of difficulty and the emphasis was on technique over the number of repetitions, the capacity to cater for extreme difference in levels of physical ability needs to be considered in future programmes.

Note was made of the transferability of the programme to home maximised by the use of simple inexpensive and transferable resources, though in reality exercise dropped off after the 6 week programme finished. This drop off in exercise, reinforces the findings of Midtgaard et al. (2006) who also found that participants in their 6-week, structured, group-based, multidimensional exercise programme for those undergoing chemotherapy also showed a significant drop in exercise level at both one and three-month follow-ups. All of the men recommended the programme run over a longer period with many stating that they would like it to go on indefinitely. This presents a challenge. The suggestion offered by Santa Mina et al. (2012) that initial supervised programmes could be followed by home based exercise programmes and routine follow ups has been shown not to work in our evaluation. Perhaps a more feasible option given the ongoing demand would be to offer block programmes and filter those who wish to continue into on ongoing programme that caters for all who have done block courses. 


\subsection{Reflections on the research}

\section{Insider / outsider}

I was both an insider and outsider in this study. I initiated the development of the programme, attended as the nurse to support the programme and was the researcher. I was aware that having multiples roles could be a limitation as the men may have been guarded in providing their 'real views' of the programme in case they offended me. However, I concur with Shaw (1999, cited in Posavac \& Carey, 2007) who considers that using qualitative methods requires: "intense long-term contact with the program, a holistic overview of the culture and context of the program, close attention to particulars, an insider's view, interpretation, little or no standardised instruments and a coherent account of the program" (p. 170).

As both nurse and researcher I became familiar with the programme and its nuances and consequently had insights into what information would be helpful. It was not until the question of whether to invite men from the waiting list to fill the gaps when participants were unwell, that I realised the significance of asking the men whether they would prefer a closed group versus an open fluctuating group over the period of the programme. Thus experiencing the programme along with the men gave me insights that led me to ask pertinent questions. Furthermore an interviewer who had not observed or understood the programme may not have appreciated the full significance of some of the responses. Had I not been involved in the facilitation of the group I would not have been privy to the informal focus type group conversations following the exercise session.

\section{Limitation and strengths of the study}

This group of men were all in the older age group. Therefore these findings are not necessarily generalisable to a younger male population. In addition, all the men already had a real belief in the usefulness of exercise and were in the words of one, 'self starters'. They were all comfortable to mix and enjoy the group/team aspect and enjoyed meeting new people. Clearly these findings are also not generalisable to men even within the same age group who do not share the view of the worth of exercise, or feel the same comfort in socialising with others. Furthermore one cannot underestimate the effect of the research process. These men were all interested in the research and may have responded differently had the evaluation not been part of a formal study. The impact of the Hawthorne effect where participants as a result of 
the extra attention they receive as the researched, is well documented (Shuttleworth, 2009). It is also important to acknowledge that purposive sampling of men registering for a group programme recruits a self selected group for whom such a programme would naturally be more attractive.

The main strength of this evaluation is that it is the first of its kind that we know of that has been carried out. The critical realism framework was a good fit in the attempt to find what worked for whom and in what circumstances. The rigor of this research is demonstrated by the credibility, feasibility and utility of the findings. Using this framework also provided an opportunity to know more about men's response to cancer, as this information was gathered as part of establishing the context for the men.

\subsection{Implications}

The findings from this evaluation highlight the physical and psychosocial benefits of this innovative exercise programme. It was not only found to offer another way of providing support for the needs of men, providing an alternative vehicle to the standard support groups currently offered with limited success, but also to facilitate men's entry into other supportive services. Many of men who would not otherwise have had contact with CSNZ who were attracted by this programme have gone on to attend the Living Well programme and access ongoing support. Furthermore the regular attendance of the exercise programme and the two further follow up sessions, demonstrate not only the men's satisfaction with the exercise programme but also its potential to grow.

The feasibility and uptake of this low cost exercise programme which provides assistance for the individual exercise needs of men with very varied physical ability and gives opportunity for men to encourage and be with each other in a positive way, has major implications for the CSNZ considering their goal for equal access and reducing inequities for men with a diagnosis. Without the need for expensive equipment or venues this programme could be set up on a limited budget with the cost of the physiotherapist's time the only ongoing expense. Furthermore the beauty of this programme lays in its ability to be tailored and adjusted for the population it attracts. This has many benefits in terms of utility and versatility. 
However if this programme is to be adopted and enlarged and researched to find innovative ways of tailoring it to attract a wider range of men, the findings must first be disseminated and shared. Funding is required to further both the education and implementation of the programmes in other areas. This prototype could be expanded upon and with an appropriate framework and education set up around it, could be packaged and implemented in other centres and divisions of the CSNZ to provide another type of support for men. There are implications for practice, policy and education.

\subsubsection{Implications for practice}

The evaluation demonstrated the need for a multidisciplinary team of a physiotherapist and nurse facilitating the programme to ensure safety monitoring of potentially fragile population with varied and changing needs. Optimally this would be a qualified physiotherapist with oncology and rehabilitation background and a registered nurse with oncology experience and familiar with facilitating CSNZ programmes and groups. They each need experience in working with people with cancer along with personal attributes that promote engagement trust and rapport and a sense of fun. Support from medical professionals is also important in aiding recruitment and ensuring safety for the participants.

Two practical issues are raised for discussion. The first is around the availability of skilled and interested physiotherapists. The second is in regard to enlisting the support of health professionals who have the credibility to encourage men to exercise and confirm the safety of carrying this out in a monitored supervised context. There is a need to get health professionals on board not only in terms of referral but also from the consent and safety perspective and the opportunity to work as part of the wider team.

The implications of involving the medical fraternity are wide reaching. During her interview the physiotherapist offered the suggestion of inviting doctors to an open day. In all reality positive feedback and outcomes from participants to their GP and specialist may be one of the most effective ways to enlist their support. In our experience of this first programme, links and communication with influential stakeholders including the local Medical Director of Oncology and the two Haematologists were invaluable. The opportunity to talk to a wide range of health 
and allied staff about the programme in turn opened up a further invitation from one of the medical consultants to talk to a group of senior house officers at one of their CME meetings. It would be important for others wishing to initiate similar programmes to form these relationships and communication.

\subsubsection{Policy and organisational implications}

This prototype may well be a model for a collaborative Cancer Society Support Services and Health Promotion programme that I envisage would be delivered with national consistency and supporting resources in Divisions and Centres throughout New Zealand. The programme would sit well within the suite of Men's Health initiatives that are currently funded by Movember, as it works to support men with a cancer diagnosis, including prostate cancer, have an improved quality of life.

\subsubsection{Implications for education}

Dependant on the availability of physiotherapists with the appropriate background, skills and personal characteristics, education and training may be required. The newly developed American College of Sports Medicine (ACSM) certification programme for exercise specialists specialising in care of cancer patients may provide a model. If this programme were to be adopted it would be important to explore the cost and feasibility of training programmes and recruit passionate enthusiastic facilitators with group facilitation skills.

\subsubsection{Implications for research}

In terms of research several questions arise. Given that only men of a certain age group attended the programme, we need a better understanding of what would attract young men The number of men attracted to the programme indicates that there certainly is a gap for men of an older age group. Would that translate to a younger population? Was the absence of men under 60, due purely the logistics of time of day? It is important to know whether this exercise programme might also appeal to younger men, and if not what might appeal. Might some collaboration with Canteen or other organisation attract younger men of working age? While there are smaller numbers of young men with a cancer diagnosis their need is as great.

And what of men with no previous interest in exercise; what would engage them? The men in this group identified themselves as self-starters. All of them had a preexisting attitude that exercise was helpful. Many had previously been involved in 
sports teams and many of them excelled. But even with this group of self starters, the motivation and practice of regular exercise declined once the programme had discontinued.

Future research should also focus on attempting to identify the ideal length of time of programme in order to support the transfer or translate it into exercise at home for these men. Midtgaard et al. (2006) identify the need for research which will "establish the optimal programme length and content for sustained exercise adherence in cancer patients" (p. 13). The question has been posed, should a programme run indefinitely? And if so what would that do to the life and dynamic of the group process that the men in this programme valued? Bearing in mind the strong views regarding closed vs. open groups would that take away something that was quite vital to the success of this group?

Research is required into what comes next for these men. Would an advanced programme for those men who have shown marked physical improvement to filter into prove effective? Given the preference for exercise with purpose would a training group with the express purpose for a fundraising walk or publicity for men's cancer be a motivating factor. The exercise programme outlined in this study follows a traditional sports model of exercise. It would be important to find whether there is another way of assisting men who are not attracted by the sports model with physical activity and search for other formats of support for men who don't fall into this category.

\subsection{Conclusion}

In conclusion this study brings valuable insights into what men value in support, and demonstrates men's appreciation and acceptance of services and support designed and offered specifically for them. Several things stand out as a result of this evaluation. Firstly the importance of a relaxed easily accessible entry that allowed at the same time, a safe assessment. Secondly, the importance of a safe, inclusive tailored programme that had the flexibility to cater for men with diverse needs and the benefit of using simple, inexpensive and transferable resources. The third was the opportunity for the men to achieve realistic goals and the hope that was associated with that; the focus on and sense of improving, achieving, doing something positive 
and purposeful and gaining control. Pervading all of this was the importance of humour, lightness and fun and a positive yet real atmosphere that allowed the men to be themselves.

In closing, the findings from this study indicate that not only is this exercise programme a way of encouraging men to carry out physical activity it is also a new way of supporting men who have had a diagnosis of cancer. It brings men together to support each other. 


\section{Appendices}

\section{Appendix 1: Circuit sheet}

\section{$\sqrt{2}$}

CIRCUIT SHEET

\begin{tabular}{|c|c|c|c|c|c|c|c|c|c|c|c|c|c|c|c|}
\hline Station & & & & 2 & & 3 & & & & & 5 & & & \multicolumn{2}{|c|}{6} \\
\hline & \multicolumn{3}{|c|}{ SQUAT LUNGE } & \multirow[t]{2}{*}{$\begin{array}{l}\text { STEP } \\
\text { UP'S }\end{array}$} & \multicolumn{3}{|c|}{ PLANK } & \multicolumn{2}{|c|}{$\begin{array}{l}\text { CALF } \\
\text { RAISE }\end{array}$} & \multirow[t]{2}{*}{$\begin{array}{l}\text { BICEPS } \\
\text { CURLS } \\
\end{array}$} & \multirow[t]{2}{*}{$\begin{array}{l}\text { Dumbell } \\
\text { running }\end{array}$} & \multicolumn{2}{|c|}{$\begin{array}{l}\text { SWISS } \\
\text { BALL }\end{array}$} & \multicolumn{2}{|c|}{$\mathrm{BACK}$} \\
\hline LEVEL & 1 & 2 & & & 1 & 2 & 3 & 1 & 2 & & & 1 & 2 & 1 & 2 \\
\hline Week 1 & & & & & & & & & & & & & & & \\
\hline Week 2 & & & & & & & & & & & & & & & \\
\hline Week 3 & & & & & & & & & & & & & & & \\
\hline Week 4 & & & & & & & & & & & & & & & \\
\hline Week 5 & & & & & & & & & & & & & & & \\
\hline Week 6 & & & & & & & & & & & & & & & \\
\hline
\end{tabular}




\section{Appendix 2: Exercise Diary}

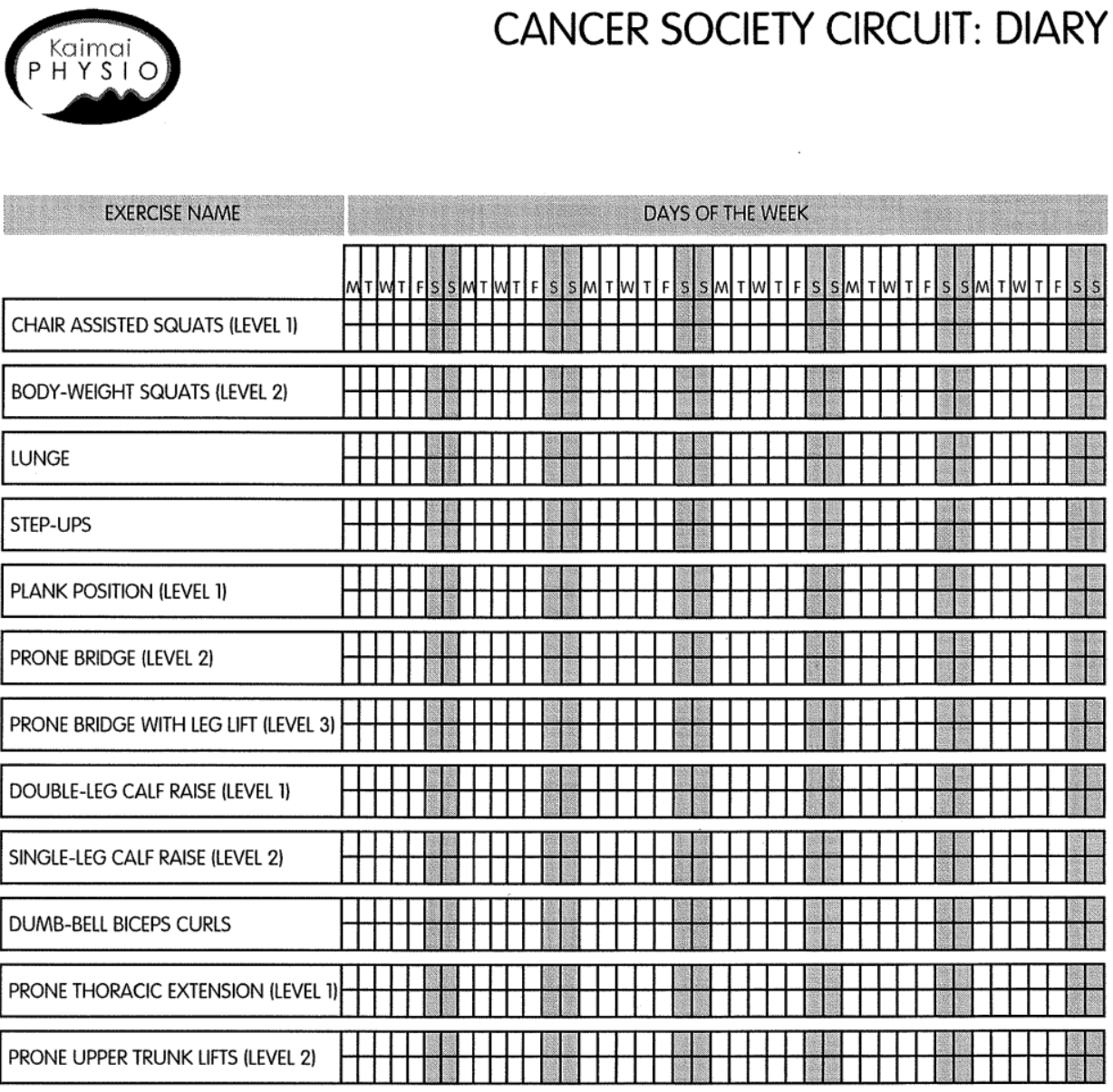

- 2009 The Rehab Lab Limiled. Used under license. No reproduction permitted without permission. unw. therehablab.com 


\section{Appendix 3: Nursing Review Article}

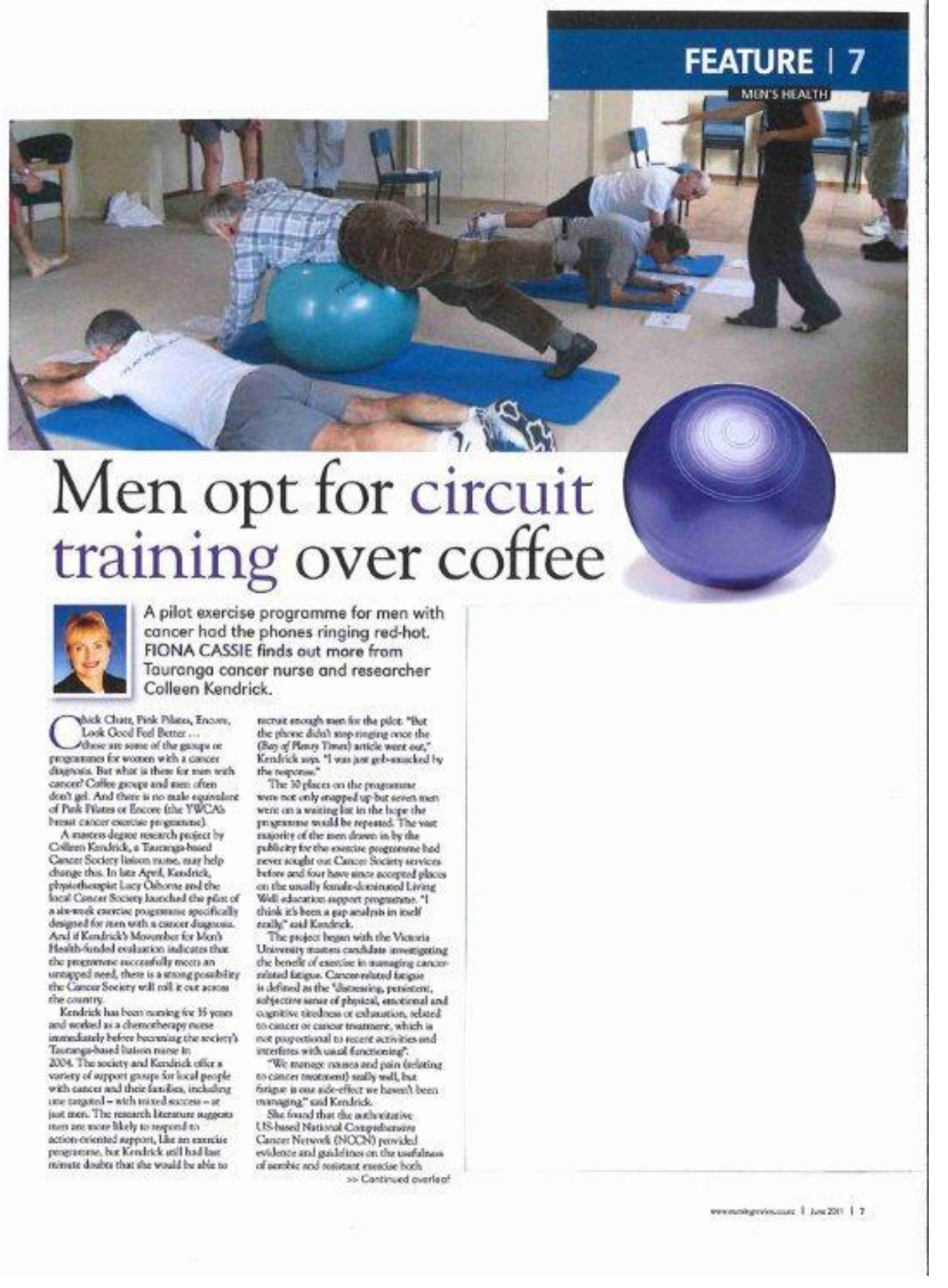




\section{I FEATURE}

> Continued from page 7 during and after treatment fix meducing fatigue. She was further inspired by ensing acress the 2011 Danich 'Boxhers in Arms' sudy thar showed the positive impact on men with cancer - both physically and psschologically - of group programme invol To date, New Zealand exercise rovgrammes for people with cancer have laryely been targered ar wumen. particularly women with hresst cancer. There have heen unisex walking pongramneses but these have had a very ow upeake by men. The lad of execise

improving survivors' quality of life, moes. penplér phossical activis trearment. Alsn while poorle exporsed inserested in exercise programunes, the intematinaal evidence showed low rumbers actually toak them ure when the were affered "ls hizhtlighered the noed for more research to look at specific need and to tailor programeres that really astracted people"

Kendrick's masters research airns to Wsciner the exercise prefferences of men with cancer and identify the factors moxted to create an exercis pr.

Each weekly circuit session is supervised and monitored by Osborne and Kendrick and offers 45 minutes of aerobic and resistance exercise, followed by 15 minutes of relaxation. The men leave with an individual programme so they can carry on exercising between the weekly sessions. prozramues carcering fox men was also
identified in a recent survey of Canoer Soxiery scaift.

Mearrohile, a recenk titeraruse review for the Cancer Sockery, by Szwymile- Cow Richards and Eean into phnjical activity among cancer aicrivors, fround thet while the evifenoe hadked exeecising as

har artracts a wile variety of men. Kendrick designed the Tauranga exercise peceramme in rastorishio with wo expert phisiotherapiss, including tucy Othome, who has a backgrivend in cancer rehabilization and who deliwers the programme. They drew in buth the $\triangle \mathrm{CCN}$ and the American College of
Sparts Melicine exercise guildelives for concer survinos, to create the circuist tused exercise progeramme. Kendrick said one of the challenges was to rawide a group pergramme thar could be

tailoced to mees each ind widust"s needs The circait pooxnamne allows this by powiding different degrees of difficults allowisgy the ment to step up or ense bock depending on their level of fiuness on the day.

Each weekly circuit session is surervised and nxunitored ty Oshome and Kendrick and offers 45 minutes of zerobic and resistance exercias, followed by 15 mirutes of telaration. The taen lerve wich an irudividual progratame so they can carry an axcrising betwoen the weekly sessions. The majuciey of the men on the prosnamine are in their $60 \mathrm{~s}$ of $7 \mathrm{ls}$, with one in his $80 \mathrm{~s}$. Somse are atill undenswing cancer treatment. Kendrick sad it has soly been recently that rescarch has shoren that exescise during treatment can he useful and safe. Though there is still that inclinativen $f_{0}$ atvice people to rest, and for sione peogie ging through trescmenic they ciatt ever think ahout exercive:" The particular antraction of this prognumine is thas the sercise is offered in a sefe and surpurted environment, with boch a perysotherapis

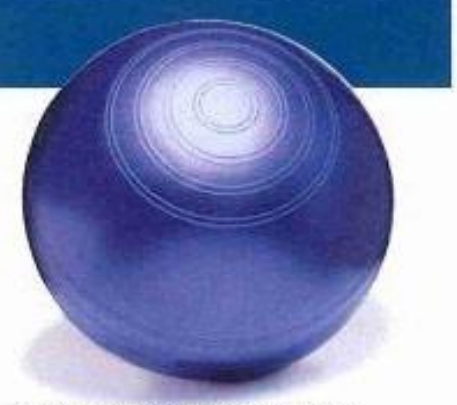

and nurse on hand. While the peograme may also offer soene of the benefies of a support enowip, Kendrick is keen not to overplay this. Thave been very cateful to sure pit tos much of a stappost goves; spin on (the programene):

Anvitier ungromoned spin-off may te a. more positive body image as wixh the prel of the Lionk Good Feel Better prograsume foe menen - men can strugule with the has of plysical strength and muscle tone resulcivg frum cancet and ins treatment

What the men gain from the puogramme (finishing in June) is a major focus of Kendtick's tescarch. Ther will be interviewed abost the progrannme huring her evaluntion. And if the evidence stacks up it could be that in time Kiwi men with cancer will have an exenciose programine targeted jast fix them .... and not a pink ribbon in sight. +
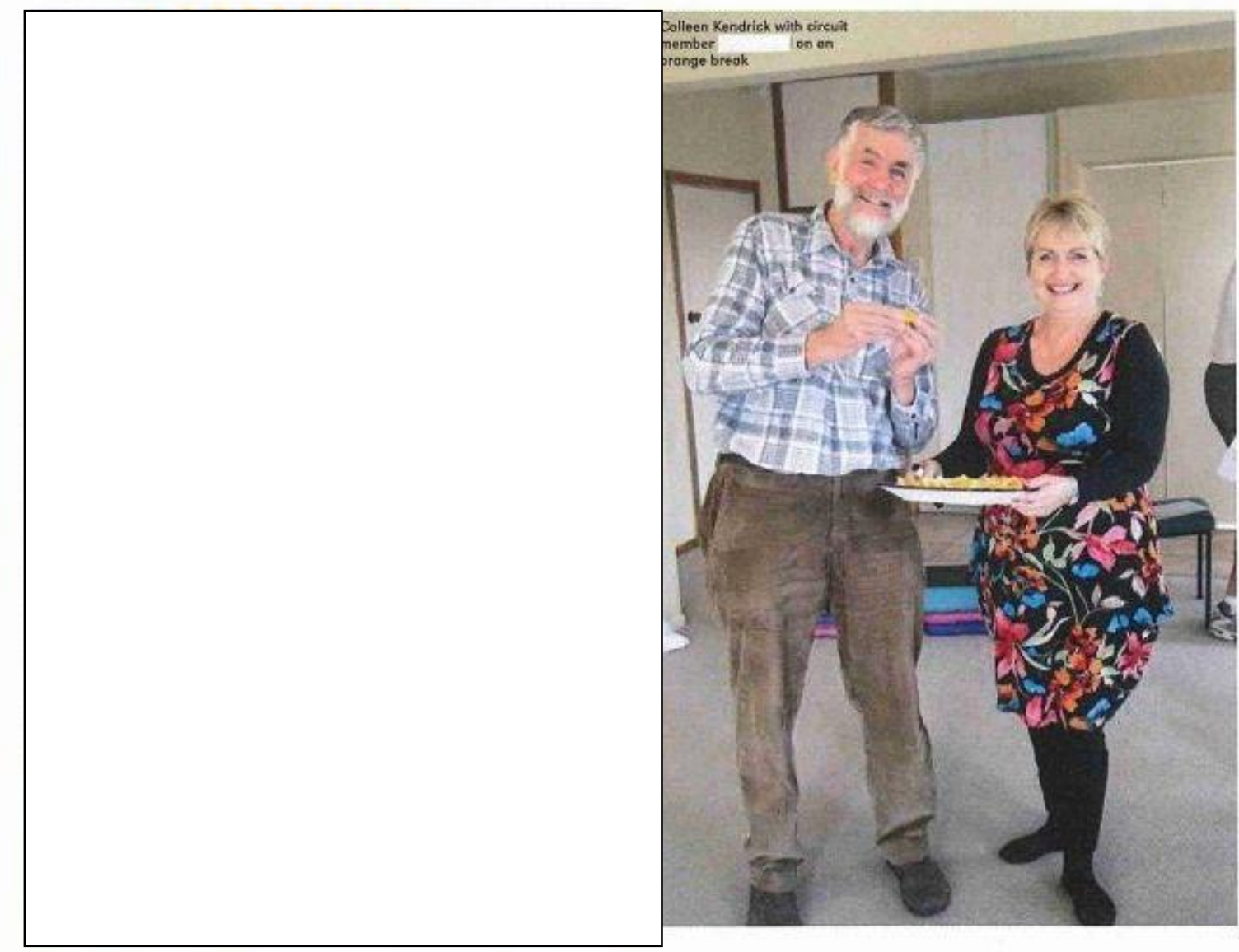

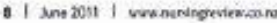




\section{Appendix 4: Interview schedule for men}

\section{BACKGROUND INFORMATION}

Tell me a little about yourself

- age, employment status,

- social

- Health history including cancer, etc.

2. SOCIAL LIFE (NETWORKS, MALE CULTURE, Perspectives etc.)

Tell me about your social life and networks e.g., church, clubs, organisations, sports teams, work history

Have these changed following your cancer diagnosis? And if so how?

\section{ROLE OF EXERCISE (HISTORY AND ATTITUDES TO )}

Tell me a little about your exercise/ physical activity before your diagnosis

What do you think about the usefulness of exercise?

What might be the barriers to exercise for you at present?

What would encourage you to exercise?

Have you any preference around physical activity in terms of types, settings or times for activity? Group or solo exercise?

\section{REFERRAL/ ENTRY TO THE PROGRAMME}

Tell me about why you initially decided to come to this exercise programme

What enabled and (or) what were the barriers to attending this programme?

What is your view of the need for physical activity programmes and resources specifically for men with cancer?

Can you please tell me about that?

Would have you liked to have heard about an opportunity to have assistance with exercise earlier in your cancer journey

\section{EXPERIENCE OF THE PROGRAMME}

Please tell me about your experience of the exercise programme?

How often did you go?

Now I would like to ask about specific aspects of the programme:

The information morning

Circuit work

Relaxation session

Exercise log

Exercising between sessions

Allocation of time

Time of day

Venue

Resources

Qualifications and gender of the professionals

One of the things I have wondered about as we consider how to structure future programmes. How important is it to have one group of men throughout the programme? 
How do you think you would have felt if other men joined the programme part way through?

Tell me what you felt when you missed a session?

Tell me what if was like when you came back to the group?

Did you manage to keep up the exercise between sessions?

Did you find the programme posed any specific issues because of your therapy or complications or affects of cancer (e.g. incontinence)? Why is this?

What engagement did you have with the other men in the group, both during the exercise programme and before or after?

What engagement did you have with the physiotherapist and the researcher both during the exercise programme and before or after?

\section{VALUE OF THE PROGRAMME}

What did you find valuable/helpful? Exercise, relaxation, social networking, physiotherapist?

Why was this?

What did you find the least valuable/ helpful for you?

Why was this?

Tell me about any impact on your quality of life, fatigue and general physical and mental health participating in this programme may have had

\section{SUGGESTIONS FOR IMPROVEMENT}

Can you please tell me about any suggestions you may have for improvements that would have enhanced this programme?

What other types of exercise would you consider could be added to this programme? How might we tailor the exercise more generally for men?

What other therapy, programme, or supportive service do you consider that the Cancer Society could consider offering specifically for men?

To what extent should future exercise programmes target men with specific cancers or specific age groups?

What do you consider would be essential in an exercise programme in order to cater specifically for men?

Having experienced this programme what would attract or deter you to come to another exercise programme? In terms of advertising, invitation, referral by health professional

Having experienced this programme would you recommend it to others?

What would be your reservations to recommending it to others?

What would be your main reasons for recommending it to others?

FINALLY:

Were there any discoveries you made during the course of the programme that surprised you? If so can you tell me what they were?

Do you have any other comments, suggestions, questions, thoughts or comments you would like to share?

Thank you for participating in this interview. 


\section{Appendix 5: Interview Schedule for Physiotherapist}

\section{BACKGROUND INFORMATION}

Could you tell me a little about your background in delivering exercise to people with cancer?

What are your thoughts on the importance of having such a background in delivering such programmes?

\section{EXPERIENCE OF THE PROGRAMME}

Tell me about your experience of delivering the exercise programme?

Now I would like to ask about your views of what went well with specific aspects of the programme:

Information morning

Circuit work

Relaxation session

Exercise log and exercising between sessions

Allocation of time

Time of day

Venue

Resources

Number of men in the group

To what extent did the programme pose specific issues for individuals because of participants' complications or affects of cancer (e.g. incontinence)?

Tell me about your relationship with the men in the group?

Tell me about your relationship with the liaison nurse and her role in the programme?

\section{OBSERVATIONS OF PARTICIPATION IN VARIOUS ASPECTS OF THE} PROGRAMME

What components of the programme did you observe the men participating in (e.g., the information session, all the exercises in the programme, exercising in between, the exercise journaling, the comradeship of the exercise)

What did you observe them to find valuable/helpful?

\section{PHYSICAL CONSIDERATIONS}

Can you tell me a little of what you observed over the six weeks of the men's appearance and physical form, their uptake of the exercises and their ability to carry these out?

\section{CHALLENGES, MOTIVATORS AND OBSTACLES}

What is your view of the need for physical activity programmes and resources specifically for men with cancer? Can you please tell me about that?

What barriers did you encounter facilitating this programme?

What enablers did you encounter to facilitate the programme?

Tell me about what you observed to be enablers and or barriers for the men attending this programme

\section{SUGGESTIONS FOR IMPROVEMENT}

What suggestions do you have for improving the programme? E.g., what other types of exercise would you consider could be added to this programme?

How might we tailor the exercise more generally for men?

What other therapy, programme, or supportive service do you consider that the Cancer Society could consider offering specifically for men?

To what extent should future exercise programmes target men with specific cancers or specific age groups? 
What do you consider would be essential in an exercise programme in order to cater specifically for men?

Having facilitated this programme do you have any suggestions about what would attract or deter men to come to another exercise programme? In terms of advertising, invitation, referral by health professional

\section{FINALLY:}

Were there any discoveries you made during the course of the programme that surprised you? If so can you tell me what they were?

Do you have any other comments, suggestions, questions, thoughts or comments you would like to share?

Thank you for participating in this interview. 


\title{
Appendix 6: Ethics Amendments and Consent
}

$22^{\text {nd }}$ June 2011

\section{In regards to: Ethics ref: NTY/11/EXP/034 \\ Study title: Exercise for Men: Exploring the exercise preferences and experiences of men who have had a diagnosis of cancer. Investigators: Ms Colleen Kendrick}

\author{
Amrita Kuruvilla \\ Administrator - Northern Y Regional Ethics Committee \\ Ethics Committee \\ 3rd floor, BNZ building \\ 354 Victoria St \\ PO Box 1031 \\ Hamilton
}

Dear Amrita,

Thank you for your email 21.6.11 confirming approval for the study subject to the following conditions: that the data will be stored for 10 years and the voluntary participation statement is moved on the first page of the PIS.

The following changes have been made

1. The application has changed to reflect that data will be stored for 10 years (see attached amended ethics form)

2. The voluntary participation statement has been moved up near the top of the information sheet (see attached).

I would also like to report two things that have happened thus far and how I intend to address these in the research. Firstly, there has been unexpected local and national interest in the exercise programme - resulting in an article in the local paper $\left(28^{\text {th }}\right.$ April, 2011) and in Nursing Review (June 2011). The article in the Bay of Plenty Times included a photograph of the physiotherapist facilitating the programme and in the Nursing Review article, photographs with some of the men on the programme have been included (see attached). The men needed to separately consent for this. This means that the physiotherapist and some of the men's identity will be known in the local region. If any of these photos are used in the research dissemination additional permission will be obtained from the men about the use of this.

I have therefore further amended the consent forms to ask if the participants give consent to the publication of the photos from these articles in the published study. As stated in the proposal, during the consent process men will be asked to provide a pseudonym to protect their individual identity.

Secondly, as part of organising the exercise programme I was present at the weekly sessions along with the physiotherapist. After each session I made notes of my observations such as the numbers attending, how the programme was delivered, and my observations of what was 
working well and not so well - all important considerations when running a new programme and in a process evaluation such as this. I also observed how the men engaged during and after the programme, and was involved in several discussions with the men. I would like to make reference to some of these observations and discussions in the thesis but consider I need approval to do this. My proposal is that in the latter part of each interview I raise the key observations (partnering with one person versus doing exercise alone, the impact of missing a session for the person and for the group) and discussion topics raised (role of exercise for men, being macho, being able to talk) and seek their comments on this. The observations and discussions will thus be used to inform the interviews as opposed to data in their own right. I have amended the interview schedule to reflect this.

Thank you. I am really looking forward to approaching the physiotherapist and the men for interview.

Yours sincerely,

Colleen Kendrick

CC Dr Katherine Nelson 
From: northerny ethicscommittee@moh.govt.nz

Sent: Thursday, June 30, 2011 1:01 PM

Subject: copy of ethics cty approval letter posted on 29/6/11

29 June 2011

\section{Ms Colleen Kendrick \\ TAURANGA}

Dear Colleen

\section{Ethics ref: NTY/11/EXP/034 (please quote in all correspondence) \\ Study title: Exercise for Men: Exploring the exercise preferences and Investigators: Ms Colleen Kendrick experiences of men who have had a diagnosis of cancer.}

This study was given ethical approval by the Northern Y Regional Ethics Committee .

\section{Approved Documents}

- Information sheet and Consent form for participants version 1

- Information sheet and Consent form for physiotherapists version 1

This approval is valid until 29 June 2012, provided that Annual Progress Reports are submitted (see below).

Amendments and Protocol Deviations

All significant amendments to this proposal must receive prior approval from the Committee.

Significant amendments include (but are not limited to) changes to:

the researcher responsible for the conduct of the study at a study site

- the addition of an extra study site

- the design or duration of the study

- the method of recruitment

- information sheets and informed consent procedures.

Significant deviations from the approved protocol must be reported to the Committee as soon as possible.

\section{Annual Progress Reports and Final Reports}

The first Annual Progress Report for this study is due to the Committee by 29 June 2012.

The Annual Report Form that should be used is available at

www.ethicscommittees. health.govt.nz. Please note that if you do not provide a progress report by this date, ethical approval may be withdrawn.

A Final Report is also required at the conclusion of the study. The Final Report Form is also available at www.ethicscommittees.health.govt.nz.

\section{Statement of compliance}

The committee is constituted in accordance with its Terms of Reference. It complies with the Operational Standard for Ethics Committees and the principles of international good clinical practice.

The committee is approved by the Health Research Council's Ethics Committee for the purposes of section 25(1)(c) of the Health Research Council Act 1990.

We wish you all the best with your study.

Yours sincerely

Amrita Kuruvilla

Administrator

Northern Y Regional Ethics Committee

Email: amrita_kuruvilla@moh.govt.nz 


\section{Appendix 7: Information Form for Men}

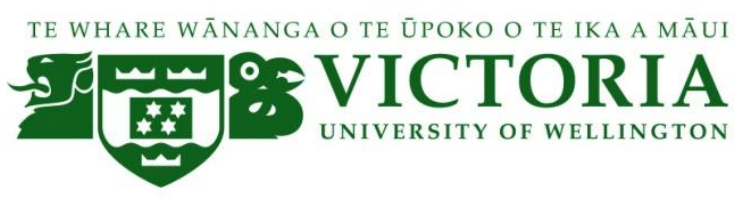

\section{A study exploring the exercise preferences and experiences of men who have had a diagnosis of cancer}

\section{Information Sheet for potential research participants}

Hello. My name is Colleen Kendrick. I work as a Liaison Nurse for the Waikato Bay of Plenty Cancer Society of New Zealand. I am a student researcher and I would like to invite you to participate in a study that I am conducting for my Master of Arts (Applied) in Nursing through the Victoria University of Wellington. Participation in this study is entirely voluntary and will require informed consent.

\section{Who can participate in the research?}

Men who participated in the Men's exercise programme in Tauranga that ran between April and June 2011.

\section{What is the purpose of the study?}

The aim of this study is to explore men's experience of the exercise programme, investigate their preferences for exercise and identify factors that will assist the design and delivery of acceptable and accessible exercise programmes for men who have had a cancer diagnosis.

In particular the study will look at what influenced, hindered or facilitated the men's participation in the programme, how well the participants felt it met their specific needs, what they liked about different aspects of the programme and the suggestions they would make for improvement.

The information gained from this study will help those providing cancer support services understand men's experience and preferences for exercise and assist them to provide programmes that meet the needs of men who have had a diagnosis of cancer.

\section{What will participation in the study involve?}

If you decide to accept this invitation it will involve giving up approximately an hour of your time for an interview, one to two weeks following the exercise programme. The interview will be at a time that suits you and can be at your home or at the Cancer Society office. The interview will be audio-taped and will ask questions about exercise generally, your experience of the exercise programme, and what you found helpful and what you think could be improved. Participants can decline to answer any of the questions and have the tape recorder turned off at any time.

Following the interviews the tape-recordings will be transcribed and if you choose a copy of your transcription will be sent to you for your checking. The transcript will then be read by myself and my Supervisor. 
You may withdraw from the study up to two weeks after the interviews prior to data analysis. If you choose to withdraw from the study, all data from your interview will be destroyed. Quotations from your interview may be used in the writing up of the research.

\section{Benefits and Risks of this study}

Possible benefits of this study are the opportunity to share your experiences and preferences and contribute to an improved way of supporting and providing exercise opportunities for men who have had a cancer diagnosis, in a way that caters specifically for males.

It is not envisaged that any of the questions will be of a sensitive nature. However, there is a possibility that the interview might bring up matters of concern for you. If you become distressed while you are talking about your experience, the interview will be stopped and you can choose to withdraw from the study, reschedule to another suitable time or take a short break before resuming the interview.

\section{Confidentiality and storage of data}

Men who participate in the exercise programme will be known to each other, and therefore within the group confidentiality is not possible. However, in the reporting of the research findings all efforts will be made to minimise identification of any of the participants. All names used in the interview will be removed and some details may be changed to protect the identity of participants. You will be asked to select a pseudonym (false name) which will be used when referring to you.

All raw data will be kept confidential between my Supervisor, the transcriber (who will sign a confidentially agreement) and myself. A digital copy of the interviews will be stored on a password protected computer at the Cancer Society and erased at the end of the study. Your consent form and transcripts will be stored in a locked filing cabinet at the Cancer Society for ten years in accordance with ethics requirements. Following this they will be destroyed.

\section{The results of the study}

The findings from this study will be published in a thesis which will be lodged at the Victoria University of Wellington. This thesis will be accessible electronically. An article regarding this research will be submitted for publication in a scholarly journal and presentations offered at Seminars and Conferences. A summary of the study findings or the full thesis will be sent to you once the study is completed.

In addition the findings of the study will be disseminated to the Cancer Society of New Zealand and other health professionals throughout the Oncology Health Setting in order to inform implementation of similar programmes.

\section{What will happen next?}

If you choose to enter the study, please let me know by either contacting me on 07 5712035 or by completing and returning the enclosed consent form. I will then contact you and arrange for the interview. If you choose not to participate, your ongoing care will not be compromised in any way.

Thank you for your consideration of participating in this study. If you have any questions or would like further information please contact me or my supervisor $\mathrm{Dr}$ Katherine Nelson.

Colleen Kendrick (Principal Investigator)

Colleen Kendrick 
C/- Waikato Bay of Plenty Cancer Society of New Zealand

P.O Box 1081

Tauranga

colleenkendrick@cancersociety.org.nz 0274541338

Dr Katherine Nelson (Research Supervisor)

Senior Lecturer

Graduate School of Nursing, Midwifery and Health

Victoria University of Wellington

Wellington

kathy.nelson@vuw.ac.nz 044636138

\section{Rights of research participants}

In New Zealand all research involving human participants must have ethics approval. This research has been approved by the Northern $Y$ Health and Disability Ethics Committee (NTY/11/EXP/034. 29/6/2011). You may contact the Health and Disability Ethics committee if you have any concerns about this study. This is a free service and you can contact them on 0800555050.

If you would like advice as to your rights as a participant in health related research you can also approach a Health \& Disability Consumer Advocate by phoning

0800205555 (Upper North Island)

0800423638 (Mid/lower North Island) 


\section{Appendix 8: Consent Form for Men}

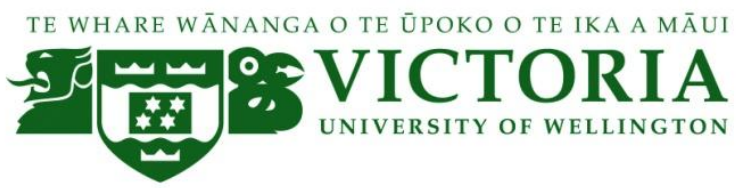

\section{CONSENT FORM}

\section{Exercise for Men: Exploring the exercise preferences and experiences of men who have had a diagnosis of cancer. \\ Principal Investigator: Colleen Kendrick}

If you are willing to take part in this study by being interviewed about your preferences and experiences of the supervised men's exercise programme please read the statements below. If you agree with these please sign this form and return to the researcher.

- This study has been explained to me by Colleen Kendrick. I have read and I understand the information sheet dated 29/6/2011 for volunteers outlining the details of this study.

- I have had the opportunity to discuss this study. Any questions that I have had have been answered to my satisfaction. I am aware that I can ask further questions about this study at any time.

- I understand that my participation in this study is voluntary and that I can withdraw from this study at any time without my care being compromised in any way.

- I understand that my participation in this study may be known to other men who participated in the exercise programme.

- I give permission for the photos used in the publicity about the exercise programme to be used but understand that no additional details that can identify me or my family will be used in the reporting of the research findings.

- I am aware that my interview will be audio taped to ensure an accurate record of my responses.

- I am aware that I can receive a summary of my interview so that I can confirm or change my responses before my information is analysed.

I have had time to consider whether to take part. I (full name) hereby consent to take part in this study Date: 
Project explained by:

Researcher's Signature: Date:

Would you like to receive a copy of your transcript for checking? Yes / No

Would you like your audiotapes erased or returned to you? Yes / No

Would you like a copy of the results of this study? Yes / No

Address for transcripts or summary:

Thank you for agreeing to take part in this study. If you have any questions please contact me or my research supervisor Dr Katherine Nelson.

Colleen Kendrick

\section{Principal Investigator}

Colleen Kendrick

Master of Arts in Nursing (Applied) student

Victoria University of Wellington

C/- Waikato Bay of Plenty Cancer Society of New Zealand

P.O. Box 1081

Tauranga

colleenkendrick@cancersociety.org.nz 0274541338

\section{Rights of research participants}

In New Zealand all research involving human participants must have ethics approval. This study has received ethical approval from the Northern $Y$ Regional Ethics Committee. You may contact the Health and Disability Ethics committee if you have any concerns about this study. This is a free service and you can contact them on 0800555050 . 


\title{
Appendix 9: Information Form for Physiotherapist
}

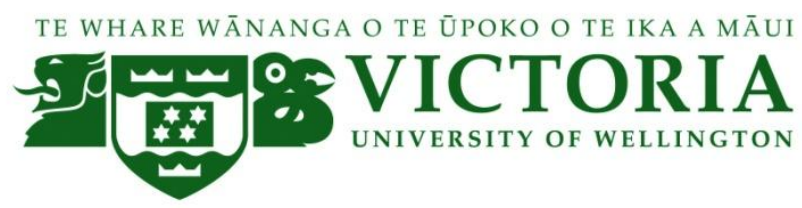

\section{A study exploring the exercise preferences and experiences of men who have had a diagnosis of cancer}

\author{
Information sheet for Physiotherapist
}

\section{Information Sheet for potential research participants}

Hello. My name is Colleen Kendrick. I work as a Liaison Nurse for the Waikato Bay of Plenty Cancer Society of New Zealand. I am a student researcher and I would like to invite you to participate in a study that I am conducting for my Master of Arts (Applied) in Nursing through the Victoria University of Wellington. Participation is entirely voluntary and will require informed consent.

\section{Who can participate in the research?}

Men who participated in the Men's exercise programme in Tauranga that ran between April and June 2011 and the physiotherapist who facilitated the programme.

\section{What is the purpose of the study?}

The aim of this study is to explore men's experience of the exercise programme, investigate their preferences for exercise and identify factors that will assist the design and delivery of acceptable and accessible exercise programmes for men who have had a cancer diagnosis.

In particular the study will look at what influenced, hindered or facilitated the men's participation in the programme, how well the participants felt it met their specific needs, what they liked about different aspects of the programme and the suggestions they would make for improvement.

The information gained from this study will help those providing cancer support services understand men's experience and preferences for exercise and assist them to provide programmes that meet the needs of men who have had a diagnosis of cancer.

\section{What will participation in the study involve?}

If you decide to accept this invitation it will involve giving up approximately an hour of your time for an interview, one to two weeks following the exercise programme. The interview will be at a time that suits you and can be at your home or at the 
Cancer Society office. The interview will be audio-taped and will ask questions about your experience of designing and delivering the exercise programme and what you found helpful and what you think could be improved. You can decline to answer any of the questions and have the tape recorder turned off at any time.

Following the interviews the tape-recordings will be transcribed and if you choose a copy of your transcription will be sent to you for your checking. The transcript will then be read by myself and my Supervisor. Quotations from your interview may be used in the writing up of the research.

You may withdraw from the study up to two weeks after the interview prior to data analysis. If you choose to withdraw from the study, all data from your interview will be destroyed.

\section{Benefits and Risks of this study}

Benefits of this study is the opportunity to have documented what is important in designing and delivering structured exercise programmes specifically designed for men who have had a cancer diagnosis.

It is not envisaged that that there will be any risks for you and no questions will be of a sensitive nature. However, if the interview brings up matters of concern for you, or if you become distressed while you are talking about your experience, the interview will be stopped and you can choose to withdraw from the study, reschedule to another suitable time or take a short break before resuming the interview.

\section{Confidentiality and storage of data}

You will be known to the men who participate in the exercise programme and to those in the local branch of the Cancer Society therefore confidentiality is not possible. However, in the reporting of the findings all names used in the interview will be removed and some details may be changed to protect the identity of participants. You will be asked to select a pseudonym (false name) which will be used when referring to you.

All raw data will be kept confidential between my Supervisor, the transcriber (who will sign a confidentially agreement) and myself. A digital copy of the interviews will be stored on a password protected computer at the Cancer Society and erased at the end of the study. Your consent form and transcripts will be stored in a locked filing cabinet at the Cancer Society for ten years in accordance with ethics requirements. Following this they will be destroyed.

\section{The results of the study}

The findings from this study will be published in a thesis which will be lodged at the Victoria University of Wellington. This thesis will be accessible electronically. An article regarding this research will be submitted for publication in a scholarly journal and presentations offered at Seminars and Conferences. A summary of the study findings or the full thesis will be sent to you once the study is completed.

In addition the findings of the study will be disseminated to the Cancer Society of New Zealand and other health professionals throughout the Oncology Health Setting in order to inform implementation of similar programmes.

\section{What will happen next?}

If you choose to enter the study, please let me know by either contacting me on 07 5712035 or by completing and returning the enclosed consent form. I will then 
contact you and arrange for the interview. If you choose not to participate, your ongoing care will not be compromised in any way.

Thank you for your consideration of participating in this study. If you have any questions or would like further information please contact me or my supervisor $\mathrm{Dr}$ Katherine Nelson.

Colleen Kendrick (Principal Investigator)

Colleen Kendrick

C/- Waikato Bay of Plenty Cancer Society of New Zealand

P.O Box 1081

Tauranga

colleenkendrick@cancersociety.org.nz 0274541338

Dr Katherine Nelson (Research Supervisor)

Senior Lecturer

Graduate School of Nursing, Midwifery and Health

Victoria University of Wellington

Wellington

kathy.nelson@vuw.ac.nz 044636138

\section{Rights of research participants}

In New Zealand all research involving human participants must have ethics approval. This research has been approved by the Northern $\mathrm{Y}$ Health and Disability Ethics Committee (NTY/11/EXP/034. 29/6/2011). You may contact the Health and Disability Ethics committee if you have any concerns about this study. This is a free service and you can contact them on 0800555050 .

If you would like advice as to your rights as a participant in health related research you can also approach a Health \& Disability Consumer Advocate by phoning

0800205555 (Upper North Island)

0800423638 (Mid/lower North Island) 


\title{
Appendix 10: Consent Form for Physiotherapist
}

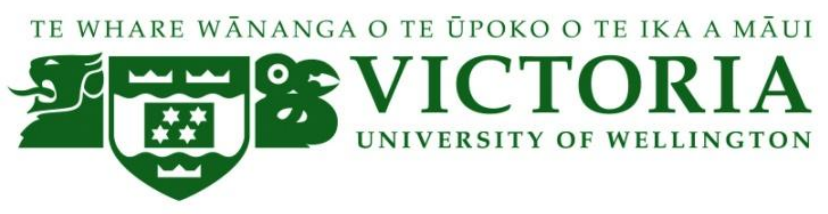

\section{CONSENT FORM}

\author{
for the Physiotherapist
}

\section{Exercise for Men: Exploring the exercise preferences and experiences of men who have had a diagnosis of cancer.}

\section{Principal Investigator: Colleen Kendrick}

If you are willing to take part in this study by being interviewed about your facilitation of the supervised men's exercise programme please read the statements below. If you agree with these please sign this form and return to the researcher.

- This study has been explained to me by Colleen Kendrick. I have read and I understand the information sheet dated 29/6/2011 for volunteers outlining the details of this study.

- I have had the opportunity to discuss this study. Any questions that I have had have been answered to my satisfaction. I am aware that I can ask further questions about this study at any time.

- I understand that my participation in this study is voluntary and that I can withdraw from this study at any time without being compromised in any way.

- I understand that my participation in this study will be known to the men who participated in the exercise programme and to others in the local branch of the Cancer Society.

- I give permission for photographs used to publicise the exercise programme to be included in the published study, but understand that no further details that can identify me or my family will be used in the reporting of the research findings.

- I am aware that my interview will be audio taped to ensure an accurate record of my responses.

- I am aware that I can receive a summary of my interview so that I can confirm or change my responses before my information is analysed.

I have had time to consider whether to take part. 
Project explained by:

Researcher's Signature:

Date:

Would you like to receive a copy of your transcript for checking? Yes / No

Would you like your audiotapes erased or returned to you? Yes / No

Would you like a copy of the results of this study? Yes / No

Address for transcripts or summary:

Thank you for agreeing to take part in this study. If you have any questions please contact me or my research supervisor Dr Katherine Nelson.

Colleen Kendrick

\section{Principal Investigator}

Colleen Kendrick

Master of Arts in Nursing (Applied) student

Victoria University of Wellington

C/- Waikato Bay of Plenty Cancer Society of New Zealand

P.O. Box 1081

Tauranga

colleenkendrick@cancersociety.org.nz 0274541338

\section{Rights of research participants}

In New Zealand all research involving human participants must have ethics approval. This study has received ethical approval from the Northern $Y$ Regional Ethics Committee. You may contact the Health and Disability Ethics committee if you have any concerns about this study. This is a free service and you can contact them on 0800555050 . 


\section{Appendix 11: Confidentiality Agreement for Transcribers}

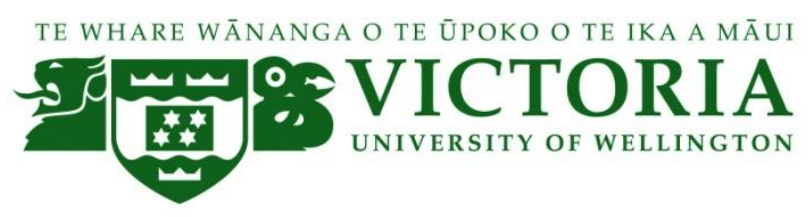

\section{Confidentiality Agreement for Transcriber of a Research study, titled:}

Exercise for Men: Exploring the exercise preferences and experiences of men who have had a diagnosis of cancer.

\section{Researcher: Colleen Kendrick}

I have read the information sheet outlining this study. I have discussed with the researcher the nature of the research and have had any questions that I have had answered to my satisfaction. My role as the research transcriber has been outlined to me by the researcher.

At all times the research information (tapes and transcripts) will be inaccessible to other persons. The researcher has assured me that she will debrief me following transcribing to address any issues that transcribing bring up for me.

Most importantly, I understand and agree to keep the information I hear and type in the course of transcribing confidential to the researcher and myself.

Full Name:

Signature:

Date:

Researcher's Signature:

Date: 


\section{References}

Adamsen, L., Rasmussen, J.M., \& Pedersen, L.S. (2001). 'Brothers in arms': How men with cancer experience a sense of comradeship through group intervention which combines physical activity with information relay. Journal of Clinical Nursing, 10(4), 528-537.

Adamsen, L., Andersen, C., Midtgaard, J., Moller, T., Quist, M., \& Rørth, M. (2009). Struggling with cancer and treatment: Young athletes recapture body control and identity through exercise: Qualitative findings from a supervised group exercise program in cancer patients of mixed gender undergoing Chemotherapy. Scand J Sports Med Sci, 19 (1), 55-66.

Adamsen, L., Quist, M. Andersen, C., Moller, T., Herrstedt. J., Kronborg, D., Baadsgaard, M.T.,...\& Rorth, M. (2009). Effect of a multimodal high intensity exercise intervention in cancer patients undergoing chemotherapy: Randomised controlled trial. British Medical Journal, 339: b3410.

Alberga, A., Segal, R., Reid, R., Scott, C., Sigal, R., Khandwala. F., Jaffey. J., ... \& Kenny., G. (2012). Age and androgen-deprivation therapy on exercise outcomes in men with prostate cancer. Supportive Care in Cancer, 20(5),971-981.

Alvesson, M. (2011). Interpreting interviews. London, Sage.

Baumbusch, J. (2010). Semi-structured interviewing in practice-close research. Pediatric Nursing, 15(3), 255-258.

Bélanger, L.J., Plotnikoff, R. C., Clark, A., \& Courneya, K.S. (2012). A survey of physical activity programming and counseling preferences in youngadult cancer survivors. Cancer Nursing, 35(1), 48-54.

Bischoping, K. (1993). Gender differences in conversation topics, 1922-1990. Sex Roles, 28, 1-18.

Blaney, J., Lowe-Strong, A., Rankin, J., Campbell, A., Allen, J., \& Gracey, J. (2010). The cancer rehabilitation journey: Barriers to and facilitators of exercise among patients with cancer-related fatigue. Physical Therapy, 90(8), 1135-1147.

Burns, S.M., \& Mahalik, J.R. (2007). Understanding how masculine gender scripts may contribute to men's adjustment following treatment for prostate cancer. American Journal of Men's Health, 1(4), 250-261. 
Cancer Society of New Zealand. (2011). Cancer-related fatigue. Retrieved on June 11, 2011 from http://www.cancernz.org.nz/assets/files/docs/info/IS_Fatigue07.pdf Carter, C.L, Onicescu, G., Cartmell, K.B., Sterba, K.R., Tomsic, J., Fox, T., \& Alberg, A.J. (2010). Factors associated with cancer survivor's selection between two group physical activity programs. Journal of Cancer Survivorship, 4(4), 388-98.

Cecil, R., McCaughan, E. \& Parahoo, K. (2010). 'It's hard to take because I am a man's man': An ethnographic exploration of cancer and masculinity. European Journal of Cancer Care, 19(4), 501-509.

Clark, A. (2001). Evaluation research in nursing and health care. Nurse Researcher, 8(3), 4-14.

Connell, R.W. (1996). Teaching the boys: New research on masculinity, and gender strategies for schools. Teachers College Record, 98(2), 206-235.

Connell, R.W. (2005). Masculinities. Los Angeles. University of California Press.

Courneya, K.S. (2003). Exercise in cancer survivors: An overview of research. Medicine and Science in Sports and Exercise, 35(11), 1846-1852.

Courneya, K.S., \& Karvinen, K.H. (2007). Exercise, aging and cancer. Applied Physiology, Nutrition, and Metabolism, 32(6), 1001-1007.

Courtenay, W.H. (2000). Constructions of masculinity and their influence on men's well-being: A theory of gender and health. Social Science and Medicine, 50(10), 1385-1401.

Cramp, F., \& Daniel, J. (2009). Exercise for the management of cancer-related fatigue in adults. Cochrane Database of Systematic Reviews, Issue 2. Art. No.: CD006145. DOI: 10.1002/14651858.CD006145.pub2.

Culos-Reed, S.N., Robinson, J.L., Lau, H., O'Connor, K. \& Keats, M.R. (2007). Benefits of a physical activity intervention for men with prostate cancer. Journal of Sport \& Exercise Psychology, 29(1), 188-127.

Culos-Reed, S.N., Robinson, J.L., Lau, H, Stephenson, L., Keats, M., Norris, S., ...Faris, P. (2010). Physical activity for men receiving androgen deprivation therapy for prostate cancer: Benefits from a 16 week intervention. Supportive Care in Cancer, 18(5), 591-599.

Durie, M.H. (1998). Whaiora: Maori health development. ( $2^{\text {nd }}$ Ed). Auckland: Oxford University Press. 
Emslie, C., Whyte, F., Campbell, A., Mutrie, N., Lee, L., Ritchie, D. \& Kearney, N. (2007). 'I wouldn't have been interested in just sitting round a table talking about cancer'; Exploring the experiences of women with breast cancer in a group exercise trial. Health Education Research, 22(6),827-838.

Fairey, A.S., Courneya, K. S., Field, C.J., \& Mackey, J.R. (2002). Physical exercise and immune system function in cancer survivors: A comprehensive view and future directions. Cancer, 94(2), 539-551.

Faull, K. \& Hill, M.D. (2006). The role of the spiritual dimension of the self as the prime determinant of health. Disability and Rehabilitation, 28(11), 729-740.

Ferrer, R.A., Huedo-Medina, T.B., Johnson, B.T., Ryan, S., \& Pescatello, L.S. (2011). Exercise interventions for cancer survivors: A meta-analysis of quality of life outcomes. Annals of Behavioral Medicine, 41(1), 32-47.

Galvão, D.A., Taaffe, D.R., Spry, N., Joseph, D. \& Newton, R.U. (2012). Combined resistance and aerobic exercise program reverses muscle loss in men undergoing androgen suppression therapy for prostate cancer without bone metastases: A randomized controlled trial. Journal of Clinical Oncology, 28(2), 340-347.

Gerschick, T.J., \& Miller, A.S. (1995). Coming to terms. Masculinity and physical disability. In D. Sabo \& D.F. Gordon (Eds.), Men's health and illness. Gender, power, and the body, (pp. 183-204). Thousand Oaks, CA: Sage.

Gibbs, L., \& Reidpath, D. (2005). What about the men? Gender differences in utilisation of chronic illness self management services. Australian Journal of Primary Health, 11(1), 63-71.

Gibbs, L. (2005). Applications of masculinity theories in a chronic illness context. International Journal of Men's Health, 4(3), 287-300.

Gibbs, L. (2007). Identifying work as a barrier to men's access to chronic illness (arthritis) self-management programs. International Journal of Mens Health, 6(2), 143-155.

Gift, A. G., Stommel, M., Jablonski, A., \& Given, W. (2003). A cluster of symptoms over time in patients with lung cancer. Nursing Research, 52(6), 393-400.

Gjerset, G.M., Fosså, S.D., Courneya, K.S., Skovlund, E., Jacobsen, A.B., \& Thorsen, L. (2011). Interest and preferences for exercise counselling and 
programming among Norwegian cancer survivors. European Journal of Cancer Care, 20(1), 96-105.

Gjerset, G.M., Fosså, S.D., Dahl, A.A, Loge, J.H., \& Ensby, T., \& Thorsen, L. (2011). Effects of a 1-week inpatient course including information, physical activity, and group sessions for prostate cancer patients. Journal of Cancer Education, 26(4), 754-760.

Globocan. (2008). Cancer incidence and mortality worldwide in 2008.

Downloaded 21.5.12 from

http://globocan.iarc.fr/pie_pop.asp?selection=139554\&title=New+Zealand

Gordon, D.F. (1995). Testicular cancer and masculinity. In D. Sabo \& D.F. Gordon (Eds.) Men's health and illness: Gender, power and the body. (pp. 246-265). Thousand Oaks, CA: Sage.

Hagen, B., Grant-Kalischuk, R., \& Sanders, J. (2007). Disappearing floors and second chances: Men's journeys of prostate cancer. International Journal of Men's Health, 6(3), 201-223.

Hayes, S.C., Spence, R.R., Galvao, D.A., \& Newton, R.U. (2009). Australian association for exercise and sport science position stand: Optimising cancer outcomes through exercise. Journal of Science and Medicine in Sport; 12(4), 428-434.

Hofman, M., Ryan, J.L., Figueroa-Moseley, C.D., Jean-Pierre, P., \& Morrow, G.R. (2007). Cancer-related fatigue: The scale of the problem. The Oncologist, 12(1), 4-10, doi:10.1634/theoncologist.12-S1-4 AlphaMed Press.

Jacobsen, P., Donovan, A., Vadaparampil, S., \& Small, B. (2008). Systematic review and meta-analysis of psychological and activity based interventions for cancer-related fatigue. Health Psychology, 26(6), 660-667.

Jackson, L., Ervin, K., Gardner, P. and Schmitt, N. (2001) Gender and the internet: Women communicating and men searching, Sex Roles: A Journal of Research, 44(5), 363-379.

Jemal, A., Bray, F., Center, M.M., Ferlay, J., Ward, E. \& Forman, D. (2011). Global cancer statistics. CA: A Cancer Journal for Clinicians, 61(2), 6990. doi: $10.3322 /$ caac. 20107

Jennings, R. (2012) A rehabilitative approach to palliative care. www.hospice.org.nz/cms_show_download.php?id=254 
Jones, L.W., \& Courneya, K.S. (2002). Exercise counselling and programming preferences of cancer survivors. Cancer Practice, 10(4), 208- 215.

Kangas, M., Bovbjerg, D.H., \& Montgomery, G.H. (2009). Cancer-related fatigue: A systematic and meta-analytic review of non-pharmacological therapies for cancer patients. Psychological Bulletin, 134(5), 700-741.

Kapur, G., Windsor, P.M., \& McCowan., C. (2010). The effect of aerobic exercise on treatment-related acute toxicity in men receiving radical external beam radiotherapy for localised prostate cancer. European Journal of Cancer Care, 19(5), 643-647.

Karvinen, K.H., Courneya, K.S., Venner, P., \& North, S. (2007). Exercise programming and counselling preferences in bladder cancer survivors: A population-based study. Journal of Cancer Survivorship, 1(1), 27-34.

Keogh, J.W., \& Jones, L. (2011). The importance of promoting physical activity for cancer survivorship. New Zealand Medical Journal, 124 (1337), 1-4.

Keogh, J.W., \& MacLeod, R. (2012). Body composition, physical fitness, functional performance, quality of life and fatigue benefits of exercise for prostate cancer patients: A systematic review. Journal of Pain and Symptom Management, 43(1), 96-110.

Keogh, J., Shepherd, D., Krageloh, C., Masters, J., Shepherd, G., \& MacLeod, R. (2010). Predictors of physical activity and quality of life in New Zealand prostate cancer survivors undergoing androgen-deprivation therapy. The New Zealand Medical Journal, 123 (1325), 20-29.

Klemm, P., Hurst, M., Dearholt, S.L. \& Trone, S.R. (1999). Cyber solace gender differences on internet cancer support groups, Computers in Nursing, 17(2), 65-72.

Kuchinski, A., Reading, M., \& Lash, A. (2009). Treatment - related fatigue and exercise in patients with cancer: A systematic review. MEDSURG Nursing, 18(3), 174-180.

Kushi, L.H., Doyle, C., McCullough, M., Rock, C.L., Demark-Wahnefried, W., Bandera, E.V.,...Gansler, T. (2012). American Cancer Society Guidelines on nutrition and physical activity for cancer prevention: reducing the risk of cancer with healthy food choices and physical activity. CA: A Cancer Journal for Clinicians, 62(1), 30-67. DOI: 10.3322/caac.20140

Kvale. S., \& Brinkman, S. (2009). InterViews: Learning the craft of qualitative research interviewing, (2nd Ed). California, Sage. 
Lashlie, C. (2005). He'll be ok: Growing gorgeous boys into good men. Auckland, Harper Collins.

Law, R., Campbell, H., \& Dolan, J. (1999). Masculinities in Aotearoa/New Zealand. Palmerston North, NZ: Dunmore Press.

Lincoln, Y, \& Guba, E. (1985). Naturalistic inquiry. Beverly Hills, California. Sage.

Lowe, S.S., Watanabe, S.M., Baracos, V.E., \& Courneya, K.S. (2010). Physical activity interests and preferences in palliative care patients. Supportive Care in Cancer, 18(11), 1469-1475.

Lowe, S.S., Watanabe, S.M., Baracos, V.E., \& Courneya, K.S. (2012). Determinants of physical activity in palliative cancer patients: An application of the theory of Planned Behavior. Journal of Supportive Oncology, 10(1), 30-36.

Macdonald, J. (2006). Shifting paradigms: A social-determinants approach to solving problems in men's health policy and practice. Medical Journal of Australia, 185(8), 456-458.

Malterud, K. (2001). Qualitative research: Standards, challenges, and guidelines. The Lancet. 358(9280), 483-488.

McEvoy, P., \& Richards, D. (2003). Critical realism: A way forward for evaluation research in nursing? Journal of Advanced Nursing, 43(4), 411420.

McGowan, E., Speed-Andrews, A.E., Rhodes, R.E., Blanchard, C.M., CulosReed, S.N., Friedenreich, C.M., \& Courneya, K.S. (2012). Sport participation in colorectal cancer survivors: An unexplored approach to promoting physical activity. Supportive Care in Cancer, [Epub ahead of print]PMID:2263913

McGregor, S., \& Murnane, J. (2010). Paradigm, methodology and method; Intellectual integrity in consumer scholarship. International Journal of Consumer Studies, 34(4), 419-427.

McGrath, P. \& Holewa, H. (2012). What does the term 'survivor' mean to individuals diagnosed with a haematological malignancy? Findings from Australia. Supportive Care in Cancer, DOI: 10.1007/s00520-012-1453-4

McGrath, P., Joske, D., \& Bouwman, M. (2010). Benefits from participation in the chemo club: Psychosocial insights on an exercise program for cancer patients. Journal of Psychosocial Oncology, 29 (1), 103-119. 
Midtgaard, J. (2006). The body, cancer and psychological well-being: The psychosocial impact of a multidimensional exercise programme offered as a complementary intervention to cancer patients undergoing chemotherapy. $\mathrm{PhD}$ thesis. University of Copenhagen. Retrieved on 30.3.2011 at www.ucsf.dk/body.cancer.psychological.well-being

Midtgaard, J., Tveterås, A., Rørth, M., Stelter, R., \& Adamsen, L. (2006). The impact of supervised exercise intervention on short-term postprogram physical activity behavior in cancer patients undergoing chemotherapy: One- and three-month follow-up on the Body and Cancer project. Palliative \& Supportive Care, 4(1), 25-35.

Midtgaard, J., Rørth, M., Stelter, R. \&, Adamsen, L. (2006). The group matters: An explorative study of group cohesion and quality of life in cancer patients participating in physical exercise intervention during treatment. European Cancer Care 15(1), 25-33.

Ministry of Health, (2012). Cancer: New Registrations and Deaths 2012: Revised Edition. Retrieved on 21.4.12 from http:// www.moh.govt.nz/dataandstatistics

Moore, S.E.H. (2008). Gender and the 'New Paradigm' of health. Sociology Compass, 2(1), 268-280.

Morton, Jamie. "Cancer exercise course kicks off”. Bay of Plenty Times, 14 April 2011, p. 3.

Murnane, A., Geary, B., \& Milne, D., (2012). The exercise programming preferences and activity levels of cancer patients undergoing radiotherapy treatment. Supportive Care in Cancer, 20(5), 957-962.

National Comprehensive Cancer Network (NCCN). (2012). NCCN clinical practice guidelines in oncology: Cancer-related fatigue. V.1. 2012 Retrieved 6.6.2012. From http://www.nccn.org/professionals/physician_gls/PDF/fatigue.pdf

O'Brien, R., Hunt, K., \& Hart, G. (2005). 'It's caveman stuff, but that is to a certain extent how guys still operate': Men's accounts of masculinity and help seeking. Social Science and Medicine, 61(3), 503-516.

O'Brien, R., Hart, G., \& Hunt, K. (2007). "Standing out from the herd": Men renegotiating masculinity in relation to their experience of illness. International Journal of Men's Health, 6(3), 178-200 
Oechsle, K., Jensen, W., Schmidt, T., Reer, R., Braumann, K., de Wit, M., \& Bokemeyer, C. (2011). Physical activity, quality of life, and the interest in physical exercise programs in patients undergoing palliative chemotherapy. Supportive Care in Cancer, 19 (5), 613-619.

Oldervoll, L., Loge, J., Paltiel, H., M. Vidvei, U., Hjermstad, M., \& Kaasa, S. (2005). Are palliative cancer patients willing and able to participate in a physical exercise program? Palliative \& Supportive Care, 3(4), 281-287.

Oliffe, J. (2005). Constructions of masculinity following prostatectomy-induced impotence. Social Science and Medicine, 60(10), 2249-2259.

Oliffe, J. (2006). Embodied masculinity and androgen deprivation therapy. Sociology of Health and Illness, 28(4), 410-432.

Oliffe, J, 1., Ogrodniczuk, J., Bottorff, J. L., Gregory, T. G., \& Halpin, M. (2009). Connecting humor, health, and masculinities at prostate cancer support groups. Psycho-oncology, 18(9), 916-926.

Oliffe, J., \& Thorne, S. (2007). Men, masculinities, and prostate cancer: Australian and Canadian patient perspectives of communication with male physicians. Qualitative Health Research, 17(2), 149-161.

Ottoson, J., \& Patterson, I. (2000). Contextual influences on learning application in practice: An extended role for process evaluation. Evaluation and the Health Professions, 23(2), 194-211.

Owen, J. (2007). Program evaluation: Forms and approaches. $\left(3^{\text {rd }}\right.$ Ed). New York. The Guildford Press.

Parahoo, K. (2006). Nursing research; Principles, process and issues. ( $\left.2^{\text {nd }} \mathrm{Ed}\right)$. New York. Palgrave, Macmillan.

Patton, M. (2002). Qualitative research and evaluation methods (3rd Ed.). London, Sage.

Pawson, R., \& Tilley, N. (2004). Realist evaluation. www.communitymatters.com.au/RE_chapter.pdf

Phillips, J. (1996). Man's country? The image of the Pakeha male, a history. Auckland. Penguin.

Posavac, E., \& Carey, R. (2007). Program evaluation: Methods and case studies. New Jersey, Pearson Prentice Hall.

Richards, H., \& Schwartz, L. (2002). Ethics of qualitative research: Are there special issues for health services research. Family Practice, 19(2), 135139. 
Robertson, L., Richards, R., Egan, R., \& Swymlek-Gay, E. (2012). Promotion and support of physical activity among cancer survivors: A service provider perspective. Psycho-Oncology, Published online in Wiley Online Library (wileyonlinelibrary.com). DOI: 10.1002/pon.3032

Rogers, L.Q., Malone, J., Rao, K., Courneya, K. S., Fogleman, A., Tippey, A.,... Robbins, K.T. (2009). Exercise preferences among patients with head and neck cancer: Prevalence and associations with quality of life, symptom severity, depression, and rural residence. Head and Neck, 31(8), 994-1005.

Rossi, P.H., Lipsey, M.W., \& Freeman, H.E. (2004). Evaluation: A systematic approach. $\left(7^{\text {th }}\right.$ Ed.) Thousand Oaks, California, Sage.

Rosenberg, J., \& Yates, P. (2010). Health promotion in palliative care: The case for conceptual congruence. Critical Public Health, 20(2), 201-210.

Rubin, H. \& Rubin, I. (2005). Qualitative interviewing: The art of hearing data. $\left(2^{\text {nd }}\right.$ Ed). California, Sage.

Rycroft-Malone, J. (2004). The PARIHS framework - a framework for guiding the implementation of evidence-based practice. Journal of Nursing Care Quality, 19 (4), 297-304.

Sabo, D. and Gordon, D. (1995). Men's health and illness: Gender, power and the body. Thousand Oaks, California, Sage.

Santa Mina, D.S., Ritvo, P., Matthew, A.G., Rampersad, A., Stein, H., Cheung, A.M.,... \& Alibhai, S.M. (2012) Group exercise versus personal training for prostate cancer patients: A pilot randomized trial. Journal of Cancer Therapy, 3, 146-156 doi:10.4236/jct.2012.32020 Published Online April 2012 (http://www.SciRP.org/journal/jct)

Schag, C.A.C., Ganz, P. A., Wing, D. S, Sim, M. S, Lee, J. J. (1994). Quality of life in adult survivors of lung, colon, and prostate cancer. Quality of Life Research. 3, 127-141.

Schmitz, K.H., Courneya, K.S., Matthews, C., Demark-Wahnefried, W., Galvao, D.A., Pinto, B.M.,... Schwartz, A.L. (2010). American college of sports medicine roundtable on exercise guidelines for cancer survivors. Medicine \& Science in Sports \& Exercise, 42 (7), 1409-1426.

Schwalbe, M., \& Wolkomir, M. (2003). 'Interviewing men' in J. Holstein \& J. Gubrium. (Eds.). Inside interviewing. (pp. 55-70). Thousand Oaks CA: Sage. 
Seale, C. (2002). Cancer heroics: A study of news reports with particular reference to gender, Sociology, (36)1, 107-126.

Seale, C. (2005). New directions for critical internet health studies: Representing cancer experience on the web. Sociology of Health \& Illness, 27(4), 515540.

Seale, C., Ziebland, S., \& Charteris, B. (2006). Gender, cancer experience and internet use: A comparative keyboard analysis of interviews and online cancer support groups. Social Science and Medicine, 62 (10), 2577-2590.

Segal, R. J., Reid, R. D., Courneya, K. S., Malone, S. C., Parliament, M. B., Scott, C. G.,...Wells, G .A. (2003). Resistance exercise in men receiving androgen deprivation therapy for prostate cancer. Journal of Clinical Oncology, 21(9), 1653-1659.

Segal, R.J., Reid, R.D., Courneya, K.S., Sigal, R.J., Kenny, G.P., Prud'Homme, D.G.,...D'Angelo, M.E. (2009). Randomized controlled trial of resistance or aerobic exercise in men receiving radiation therapy for prostate cancer. Journal of Clinical Oncology, 27(3), 344-351. DOI: 10.1200/JCO.2007.15.4963

Seymour-Smith, S. (2008). 'Blokes don't like that sort of thing': Men's negotiation of a 'troubled' self-help group identity, Journal of Health Psychology, 13(6), 785-797.

Sherman, A.C., Pennington, J., Latif, U., Farley, H., Arent, L., \& Simonton, S. (2007). Patient preferences regarding cancer group psychotherapy interventions: A view from the inside. Psychosomatics, 48(5), 426-432.

Shuttleworth, M. (2009). Hawthorne effect. Retrieved 22.6.2012 from Experiment Resources: http://www.experiment resources.com/hawthorneeffect.html.

Singleton, A. (2008). "It's because of the invincibility thing": Young men, masculinity, and testicular cancer. International Journal of Men's Health, 7(1), 40-58.

Spence, R., Heesch, K., \& Brown, W. (2011). Colorectal cancer survivors' exercise experiences and preferences: Qualitative findings from an exercise rehabilitation programme immediately after chemotherapy. European Journal of Cancer Care, 20(2), 257-266. 
Stevinson, C., \& Fox, K.R. (2006), Feasibility of an exercise rehabilitation programme for cancer patients. European Journal of Cancer Care, 15: 386-396. doi: 10.1111/j.1365-2354.2006.00677.x

Szymlek-Gay, E., Richards, R., Egan, R. (2011). Physical activity among cancer survivors: A literature review. New Zealand Medical Journal, 124 (1337), 77-89.

Thomas, D.R. (2006). A general inductive approach for analysing qualitative data. American Journal of Evaluation, 27(2), 237-246.

Thorne, S., Kirkman, S.R., MacDonald, J. (1997). Interpretive description; A noncategorical qualitative alternative for developing nursing knowledge. Research in Nursing and Health, 2 169-17.

Thorne, S., Reimer Kirkham, S., \& O’Flynn-Magee, K. (2004). The analytic challenge in interpretive description. International Journal of Qualitative Methods, 3(1). Article 1. Retrieved [18.6.2012] from http://www.ualberta.ca/ iiqm/backissues/3_1/pdf/thorneetal.pdf

Thorsen, L., Courneya, K.S., Stevinson, C. \& Fosså, S.D. (2008). A systematic review of physical activity in prostate cancer survivors: Outcomes, prevalence, and determinants. Supportive Care in Cancer, 16(9), 987-997.

Trinh, L., Plotnikoff, R.C., Rhodes, R.E., North, S. \& Courneya, K.S. (2011). Physical activity preferences in a population-based sample of kidney cancer survivors. Supportive Care in Cancer, DOI 10.1007/s00520-0111264-z.

Vallance, J., Courneya, K., Jones. L., \& Reiman, T. (2006). Exercise preferences among a population-based sample of non-Hodgkin's lymphoma survivors. European Journal of Cancer Care, 15(1), 34-43.

Wadsworth, Y. (2011). Do it yourself social research. ( $\left.3^{\text {rd }} \mathrm{Ed}\right)$, California, Left Coast Press.

Wadsworth, Y. (2011). Everyday evaluation on the run. ( $3^{\text {rd }}$ Ed), California, Left Coast Press.

Walsh, K., Duke, J., Foureur, M., \& MacDonald, L. (2007). Designing an effective evaluation plan: A tool for understanding and planning evaluations for complex nursing contexts. Contemporary Nurse, 25(1), 136-145. 
Wenger, L. (2011). Beyond ballistics: Expanding our conceptualization of men's health-related help seeking. American Journal of Men's Health, 5(6), 488499.

World Health Organization. (2012). International classification of functioning, disability and health: ICF. Geneva: Author.

Wilson, V., \& McCormack, B. (2006). Critical realism as emancipatory action: The case for realistic evaluation in practice development. Nursing Philosophy, 7(1), 45-57. 